\title{
A rapid and effective reaction of 2-methylpyridin- $N$-oxides with triphosgene via a [3,3]-Sigmatropic rearrangement: Mechanism and applications
}

\author{
Hao Li, ${ }^{\dagger}$ Hong-Cheng Xia, ${ }^{\dagger}, \ddagger$ Fang-Yuan Nie and Qin-Hua Song ${ }^{*}$ \\ Department of Chemistry, University of Science and Technology of China, Hefei 230026, P. R.
}

China

E-mail: qhsong@ustc.edu.cn

\section{Table of Contents}

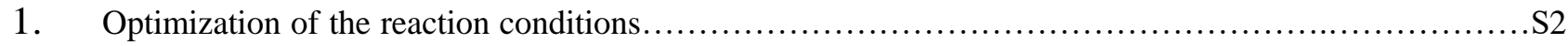

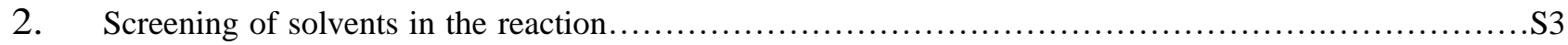

3. Spectral response of $\mathbf{2 g}$ toward phosgene and its substitutes..................................S3-4

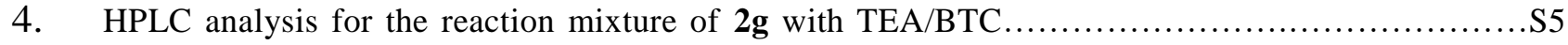

5. HRMS for the reaction mixture of $\mathbf{2 g}$ with phosgene, TCF or BTC as well as TEA/BTC................S5-6

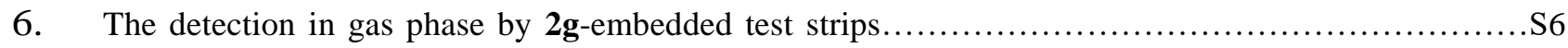

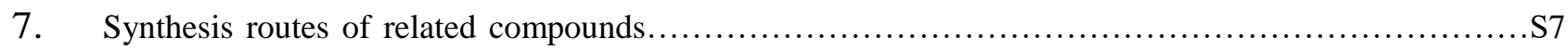

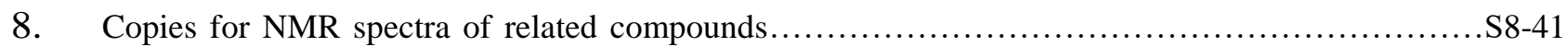

\footnotetext{
$\uparrow$ These authors contributed equally.

Present Address: Xinxiang Medical University, Xinxiang 453003, P. R. China.
} 


\section{Table S1. Optimization of the reaction conditions}

\begin{tabular}{|c|c|c|c|c|}
\hline Entry & BTC (equiv) & TEA (equiv) & Solvent & Yield $(\%)^{a}$ \\
\hline 1 & 0.5 & 3.0 & DCE & 12 \\
\hline 2 & 0.5 & 3.0 & DCM & 57 \\
\hline 3 & 0.5 & 3.0 & DEE & 7 \\
\hline 4 & 0.5 & 3.0 & dioxane & trace \\
\hline 5 & 0.5 & 3.0 & $\mathrm{THF}$ & 2 \\
\hline 6 & 0.5 & 3.0 & acetone & 15 \\
\hline 7 & 0.5 & 3.0 & $\mathrm{CH}_{3} \mathrm{CN}$ & 47 \\
\hline 8 & 0.33 & 3.0 & DCM & 24 \\
\hline 9 & 1.0 & 3.0 & DCM & 4 \\
\hline 10 & 0.5 & 0 & DCM & 3 \\
\hline 11 & 0.5 & 1.0 & $\mathrm{DCM}$ & 4 \\
\hline 12 & 0.5 & 2.0 & DCM & 46 \\
\hline 13 & 0.5 & 4.0 & $\mathrm{DCM}$ & 65 \\
\hline 14 & 0.5 & 5.0 & DCM & 68 \\
\hline 15 & 0.5 & 6.0 & DCM & 66 \\
\hline 16 & 0.5 & 7.0 & DCM & 64 \\
\hline
\end{tabular}

${ }^{a}$ Isolated yields. 


\section{Screening of solvents in the reaction}
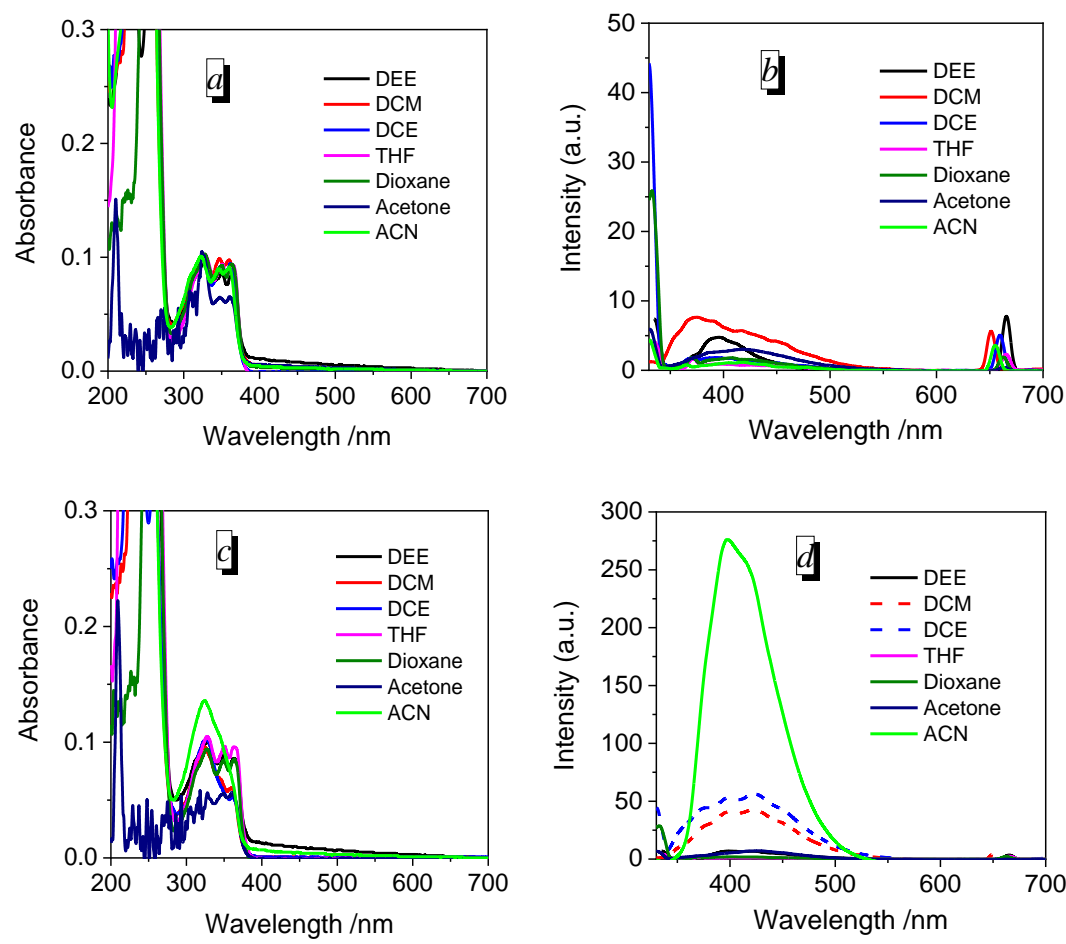

Figure S1. Absorbance and Fluorescence spectra of $2 \mathbf{g}(20 \mu \mathrm{M})$ solution with TEA (5 equiv) before (a, b) or after additions of 0.5 equiv triphosgene for $5 \mathrm{~min}$ (c, d, excitation at $325 \mathrm{~nm}$ ), in different solvents: DEE, diethyl ether; DCM, dichloromethane; DCE, 1,2-dichloroethane; THF, tetrahydrofuran; dioxane; acetone; ACN, acetonitrile.

\section{Spectral response of $2 \mathrm{~g}$ toward phosgene and its substitutes}
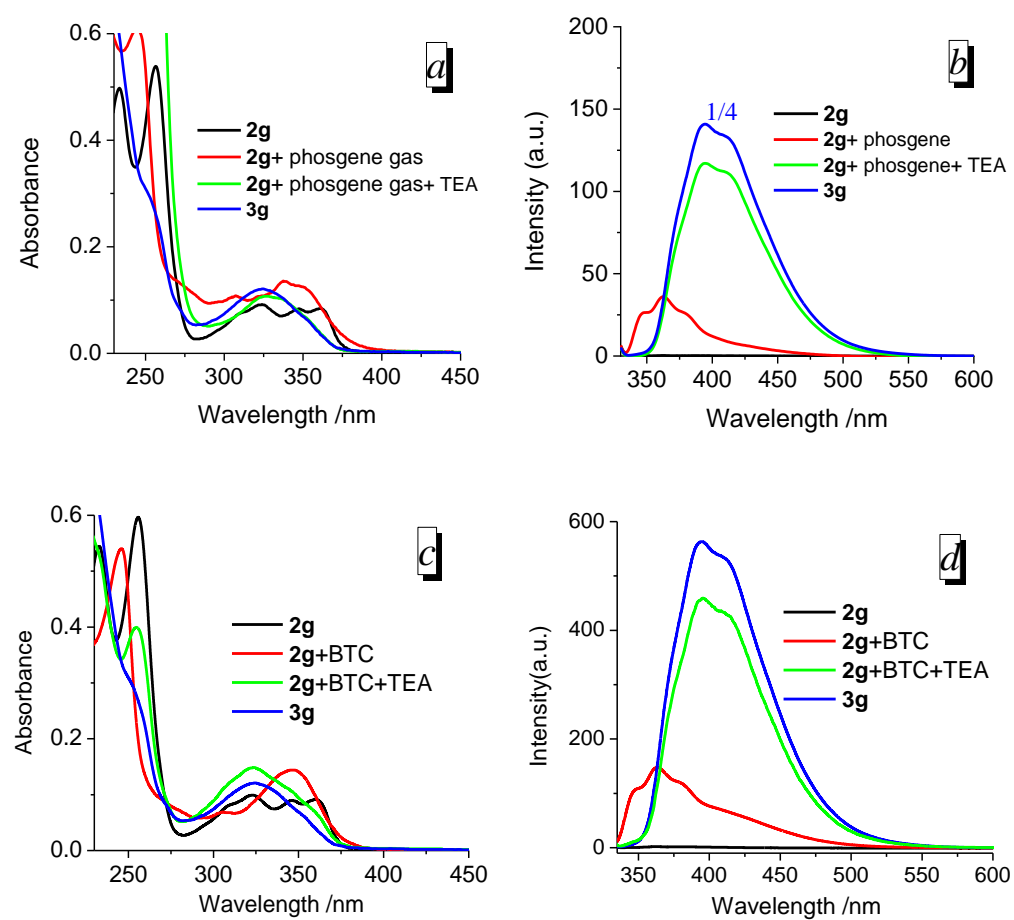

Figure S2. (a, c) UV/Vis absorption and (b, d) fluorescence spectra of $20 \mu \mathrm{M} 2 \mathrm{~g}$ solution upon bubbled with phosgene gas or addition of $20 \mu \mathrm{M}$ triphosgene (BTC) solution, and then addition of TEA, excited at $325 \mathrm{~nm}$ 

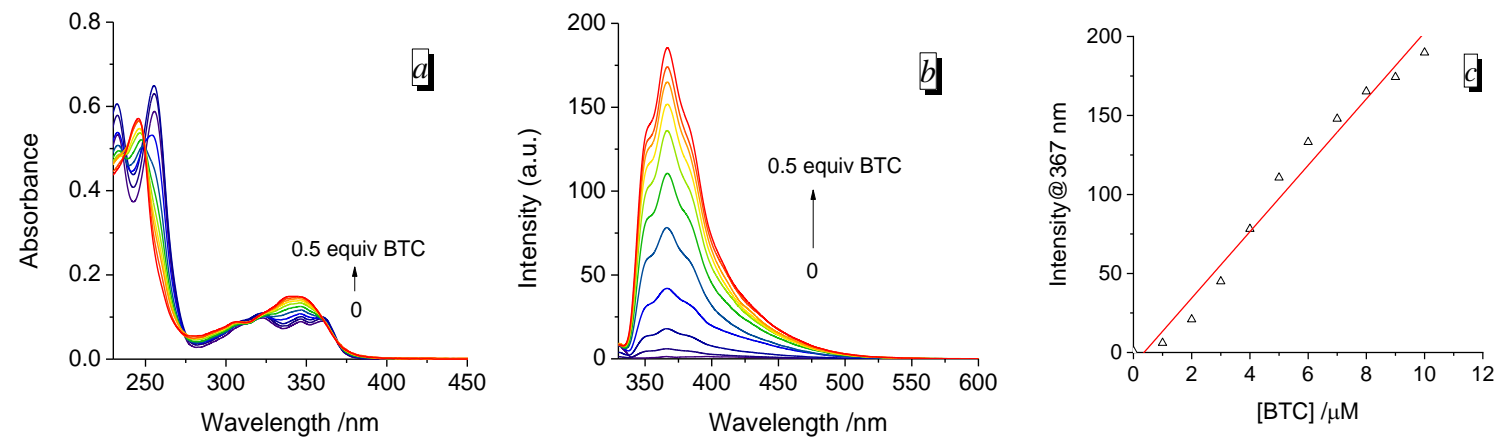

Figure S3a. (a) UV/Vis absorption and (b) fluorescence spectra of $2 \mathbf{g}(20 \mu \mathrm{M})$ solution upon additions of different amounts of triphosgene $(0-10 \mu \mathrm{M})$, excitation at $325 \mathrm{~nm}$. (c) the plot of intensity vs [BTC] of above solutions without TEA.
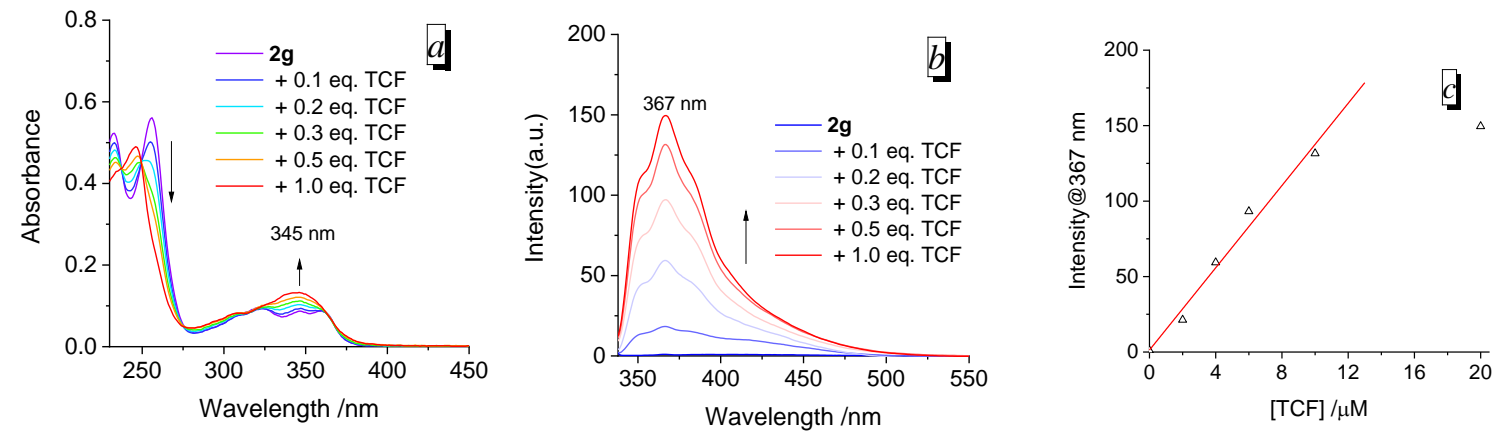

Figure S3b. UV/Vis absorption and fluorescence spectra of $20 \mu \mathrm{M} \mathbf{2 g}$ solution upon additions of different amount of diphosgene (TCF) (0-1.0 equiv) in $\mathrm{CH}_{3} \mathrm{CN}$, excitation at $325 \mathrm{~nm}$. (c) the plot of intensity vs [TCF] of above solutions without TEA.
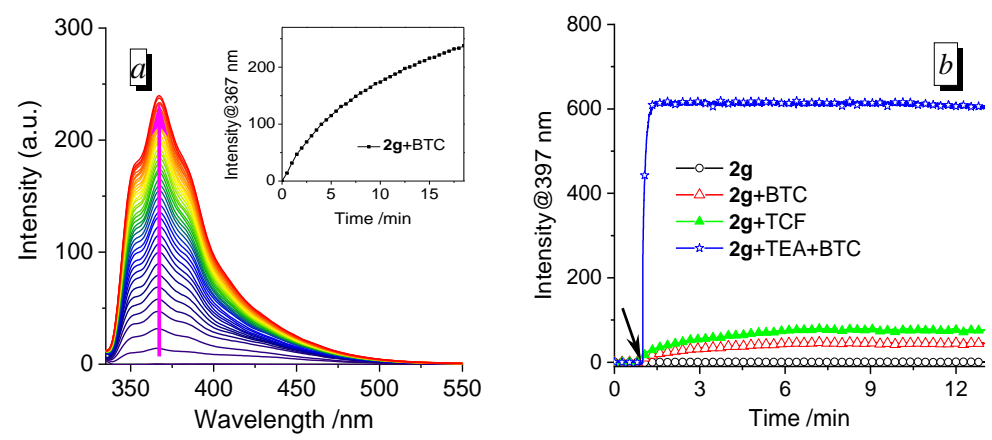

Figure S4. (a) Time-dependent fluorescence spectra of $20 \mu \mathrm{M} \mathbf{2 g}$ upon the addition of $20 \mu \mathrm{M}$ BTC, and (b) fluorescence intensity at $397 \mathrm{~nm}$ of $\mathbf{2 g}$ solutions or the addition of $20 \mu \mathrm{M}$ BTC, $20 \mu \mathrm{M} \mathrm{TCF}$ or $10 \mu \mathrm{M}$ BTC with $100 \mu \mathrm{M}$ TEA in $\mathrm{CH}_{3} \mathrm{CN}$, excited at $325 \mathrm{~nm}$. 


\section{HPLC analysis for the reaction mixture of $2 \mathrm{~g}$ with TEA/BTC}

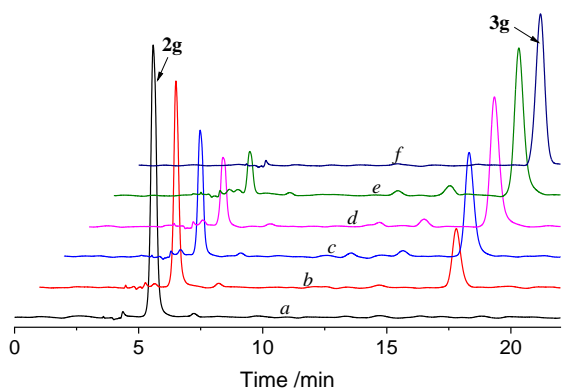

Figure S5. HPLC profiles of $20 \mu \mathrm{M} 2 \mathrm{~g}$ with 5 equiv TEA solution before (a) and after additions of different amounts of BTC (b-e, 0.5-1.0 equiv) in $\mathrm{CH}_{3} \mathrm{CN}$, and neat product $3 \mathrm{~g}$ (f), methanol/water $(25: 75, \mathrm{v} / \mathrm{v})$ as eluent, monitored at $339 \mathrm{~nm}$.

5. HRMS for the reaction mixture of $2 \mathrm{~g}$ with phosgene, TCF or BTC as well as TEA/BTC
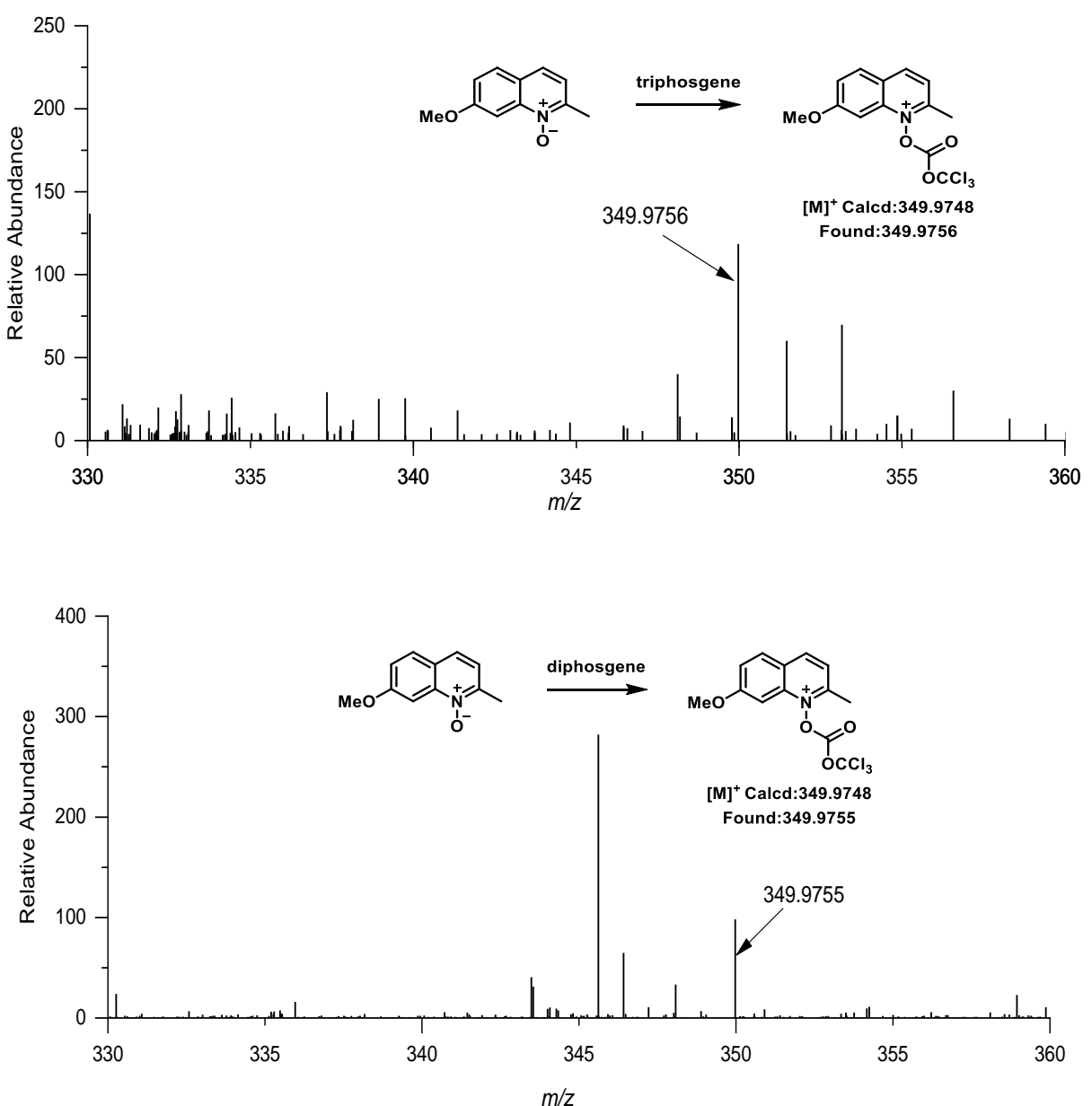

Figure S6a. HMRS for the mixture of $\mathbf{2 g}$ with BTC (up) or TCF (down) in the $\mathrm{CH}_{3} \mathrm{CN}$ solution. 


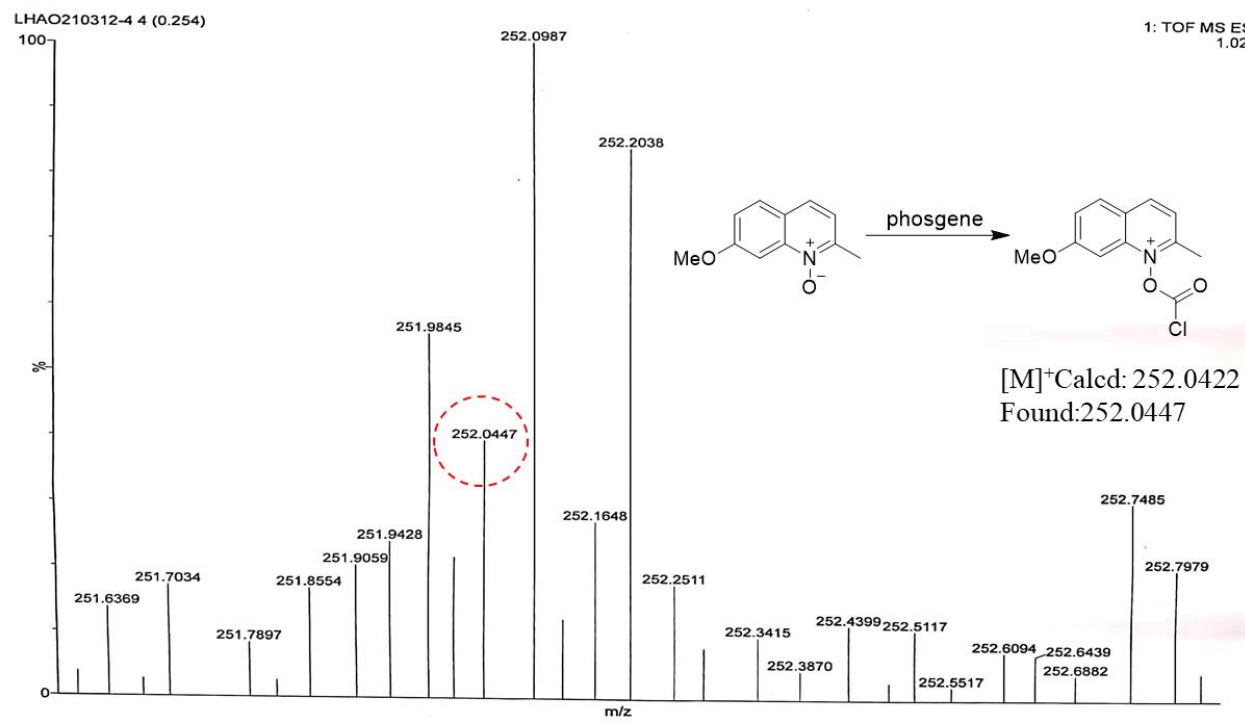

Figure S6b. HMRS for the mixture of $\mathbf{2 g}$ solution bubbled with phosgene gas in the $\mathrm{CH}_{3} \mathrm{CN}$ solution.

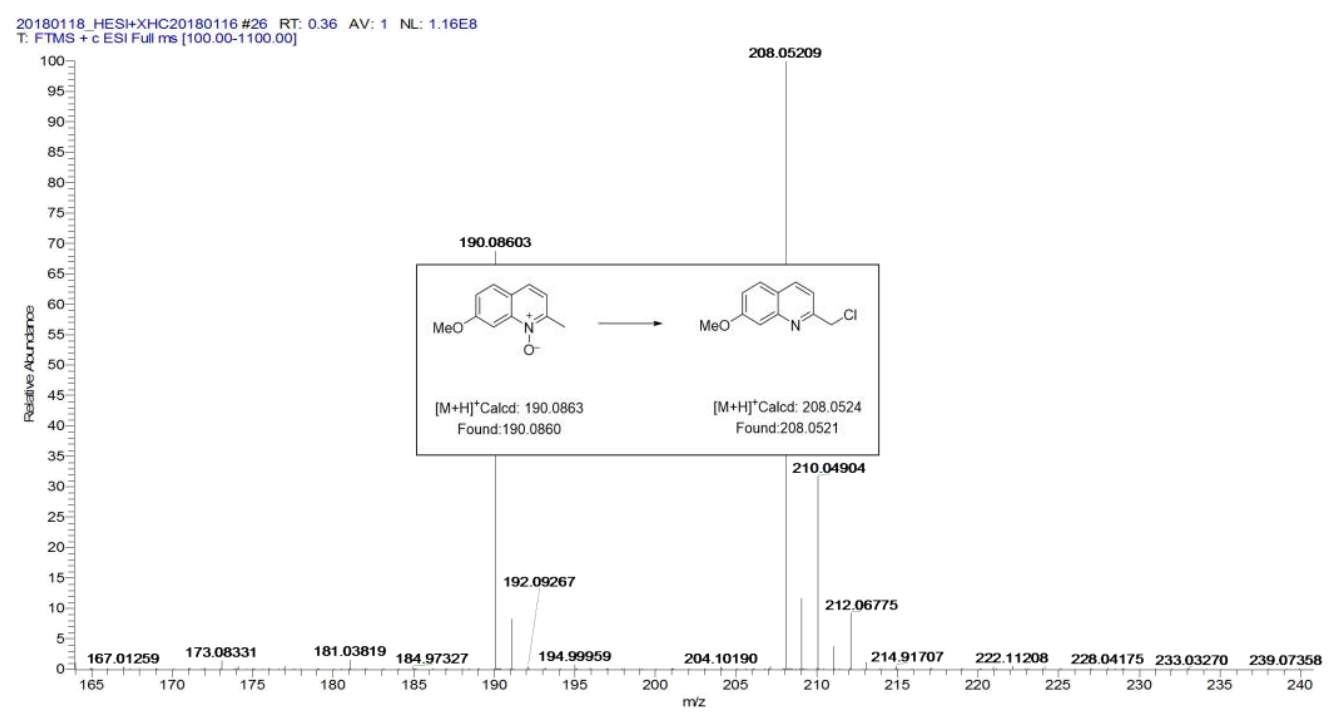

Figure S7. High-resolution mass spectrogram for mixture of $\mathbf{2 g}$ with BTC in the presence of 5 equiv TEA in the $\mathrm{CH}_{3} \mathrm{CN}$ solution.

\section{The detection in gas phase by $2 \mathrm{~g}$-embedded test strips}

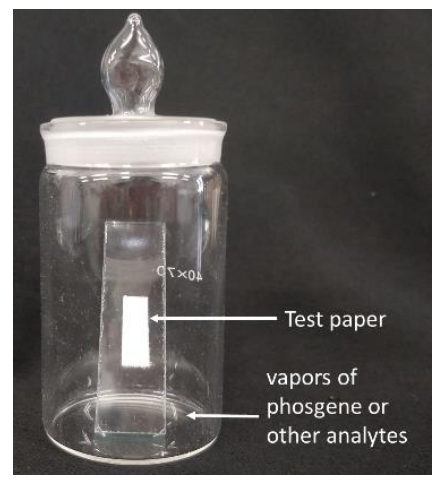

Figure S8. Legend of the detection device of phosgene and vapor of other analytes. 
7. Synthesis routes of related compounds
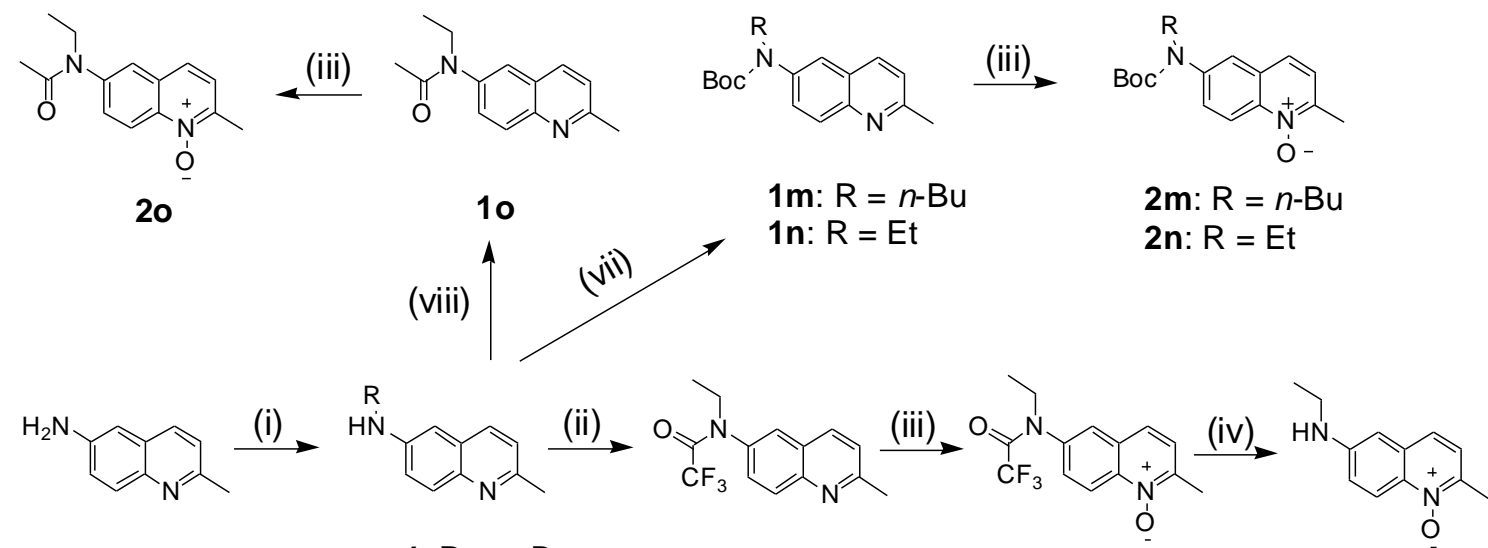

$\mathbf{4}: \mathrm{R}=n-\mathrm{B}$
$\mathbf{5}: \mathrm{R}=\mathrm{Et}$

$2 p$

2k

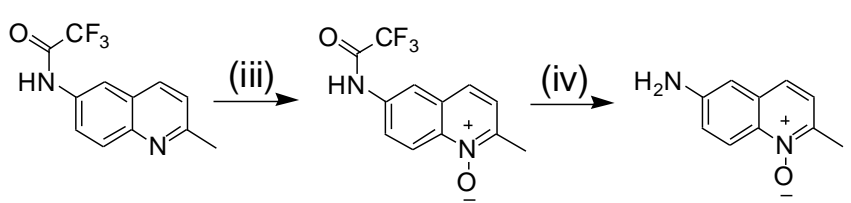

$1 q$

$2 q$

2I

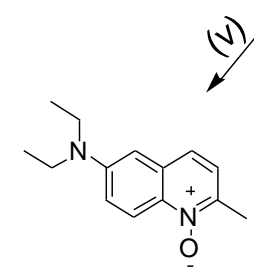

$2 \mathbf{i}$

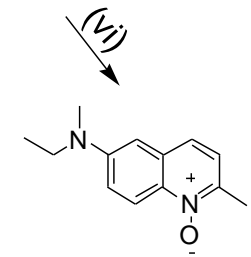

2j

Scheme S1. Synthetic route for the related compound: (i) iodoethane, $\mathrm{K}_{2} \mathrm{CO}_{3}, \mathrm{DMF}, 80^{\circ} \mathrm{C}$. (ii) TEA, TFAA, DCM, $0^{\circ} \mathrm{C}, 0.5$ h, r.t. (iii) $m$-CPBA, $\mathrm{DCM}, 0^{\circ} \mathrm{C}, 0.5$ h, r.t., 12 h, $\mathrm{K}_{2} \mathrm{CO}_{3}, 0.5$ h. (iv) $\mathrm{NaOEt}$, EtOH, $54^{\circ} \mathrm{C}, 20$ h. (v) acetaldehyde, THF, $3 \mathrm{M} \mathrm{H}_{2} \mathrm{SO}_{4}, 0^{\circ} \mathrm{C}, \mathrm{NaBH}_{4}$, r.t., 5 h. (vi) formaldehyde, THF, $3 \mathrm{M} \mathrm{H}_{2} \mathrm{SO}_{4}$, $0^{\circ} \mathrm{C}, \mathrm{NaBH}_{4}$, r.t., $5 \mathrm{~h}$. (vii) tert-butyldicarbonate, dioxane, $80^{\circ} \mathrm{C}, 12 \mathrm{~h}$. (viii) $\mathrm{Ac}_{2} \mathrm{O}$, pyridine, $25^{\circ} \mathrm{C}, 1 \mathrm{~h}$. 
8. Copies for NMR spectra of related compounds
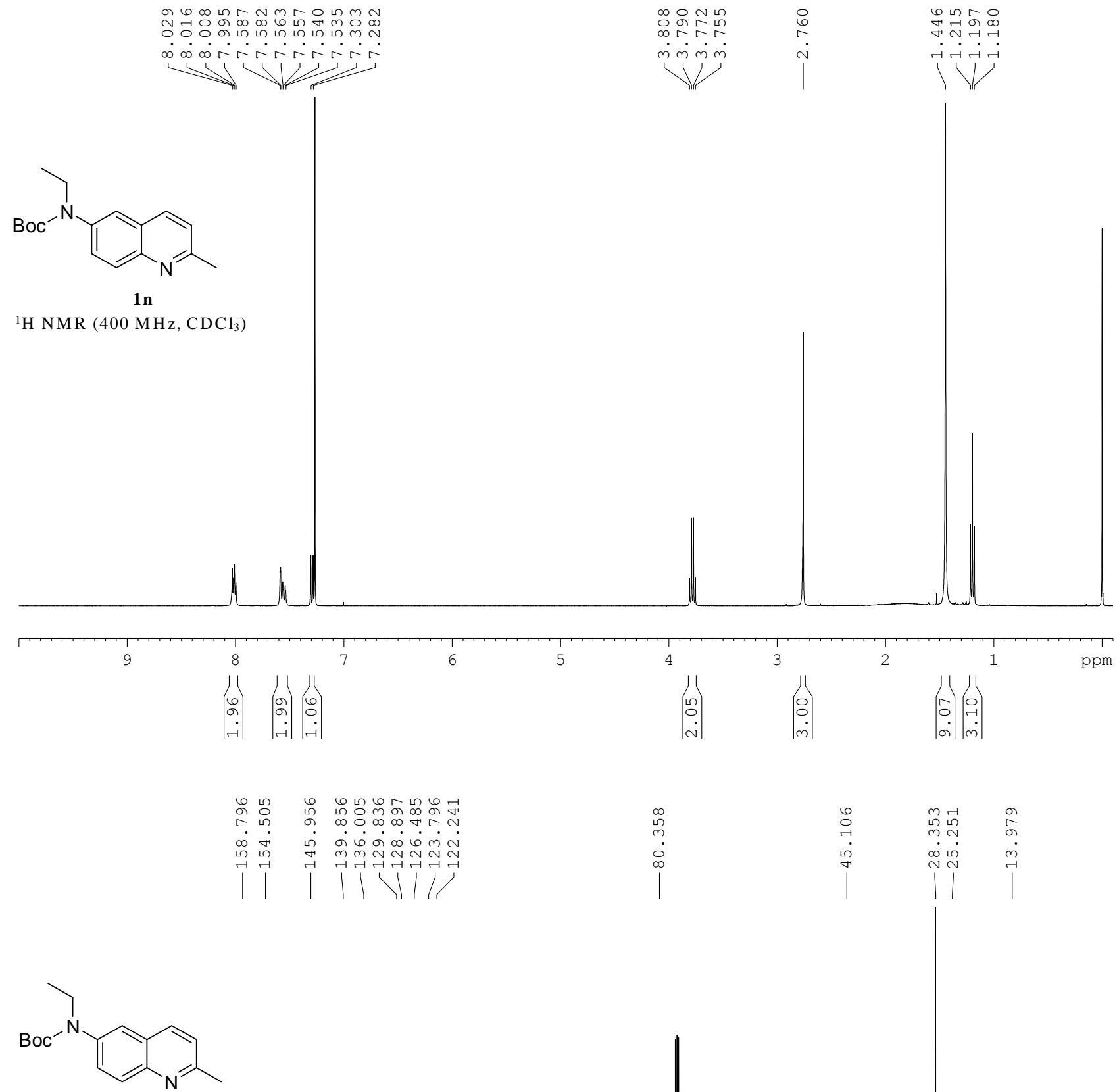

$1 \mathrm{n}$

${ }^{13} \mathrm{C}\left\{{ }^{1} \mathrm{H}\right\}$ NMR $\left(100 \mathrm{MHz}, \mathrm{CDCl}_{3}\right)$

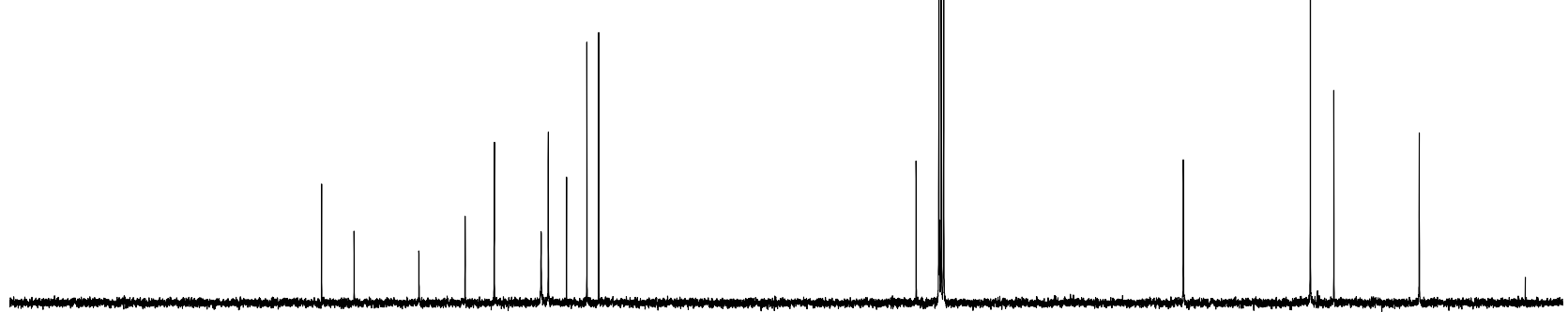

$\begin{array}{lllllllllllllllllll}190 & 180 & 170 & 160 & 150 & 140 & 130 & 120 & 110 & 100 & 90 & 80 & 70 & 60 & 50 & 40 & 30 & 20 & 10\end{array}$ 

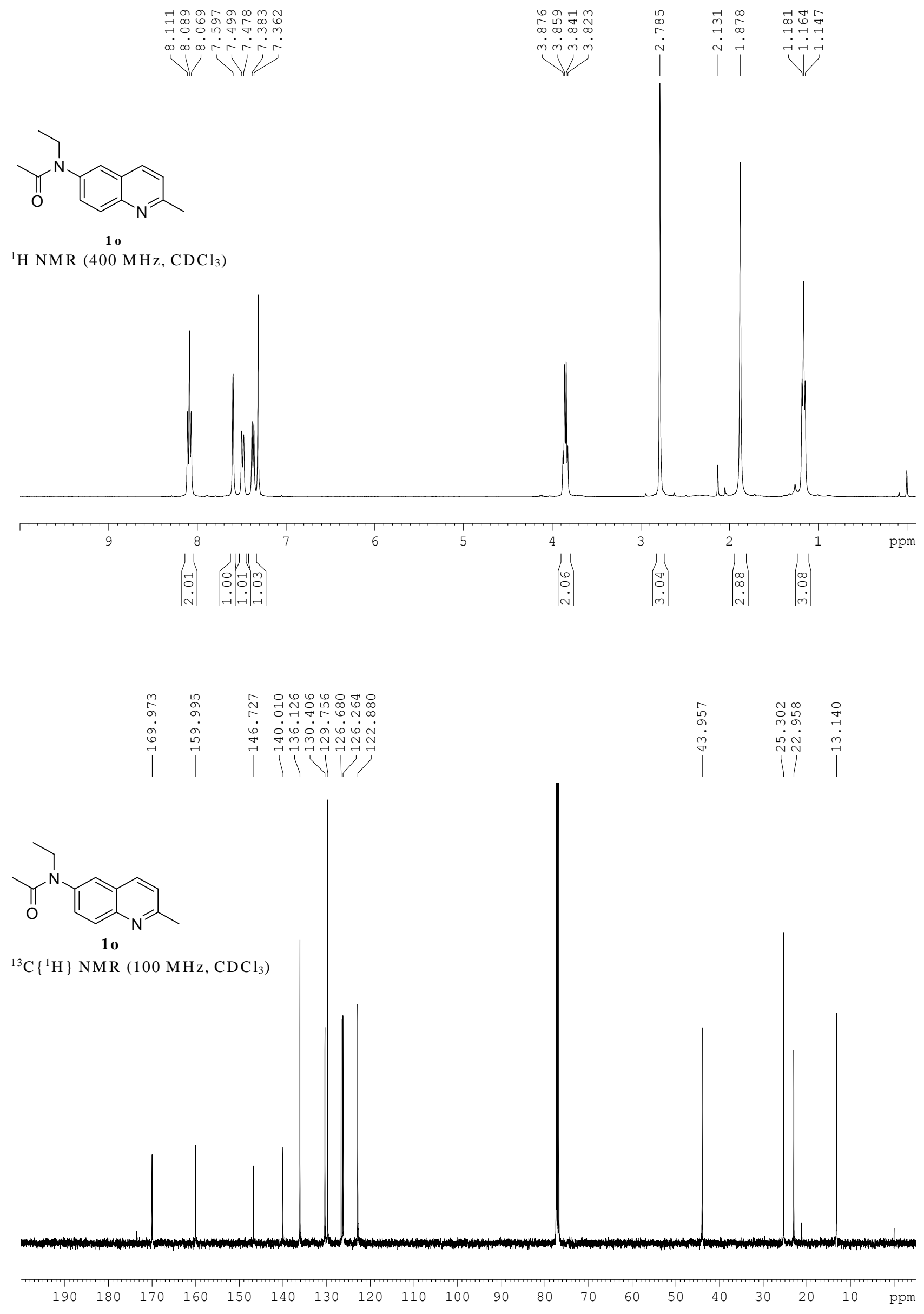

S9 


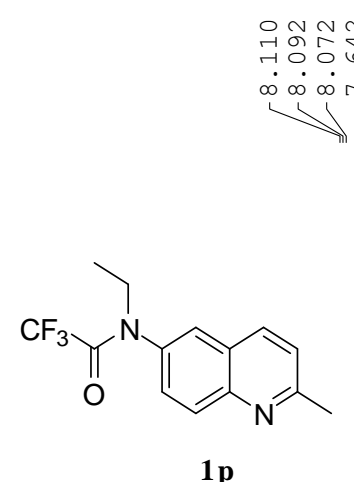

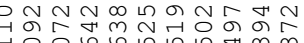

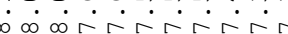

$\rightarrow 1$

${ }^{1} \mathrm{H}$ NMR $\left(400 \mathrm{MHz}, \mathrm{CDCl}_{3}\right)$
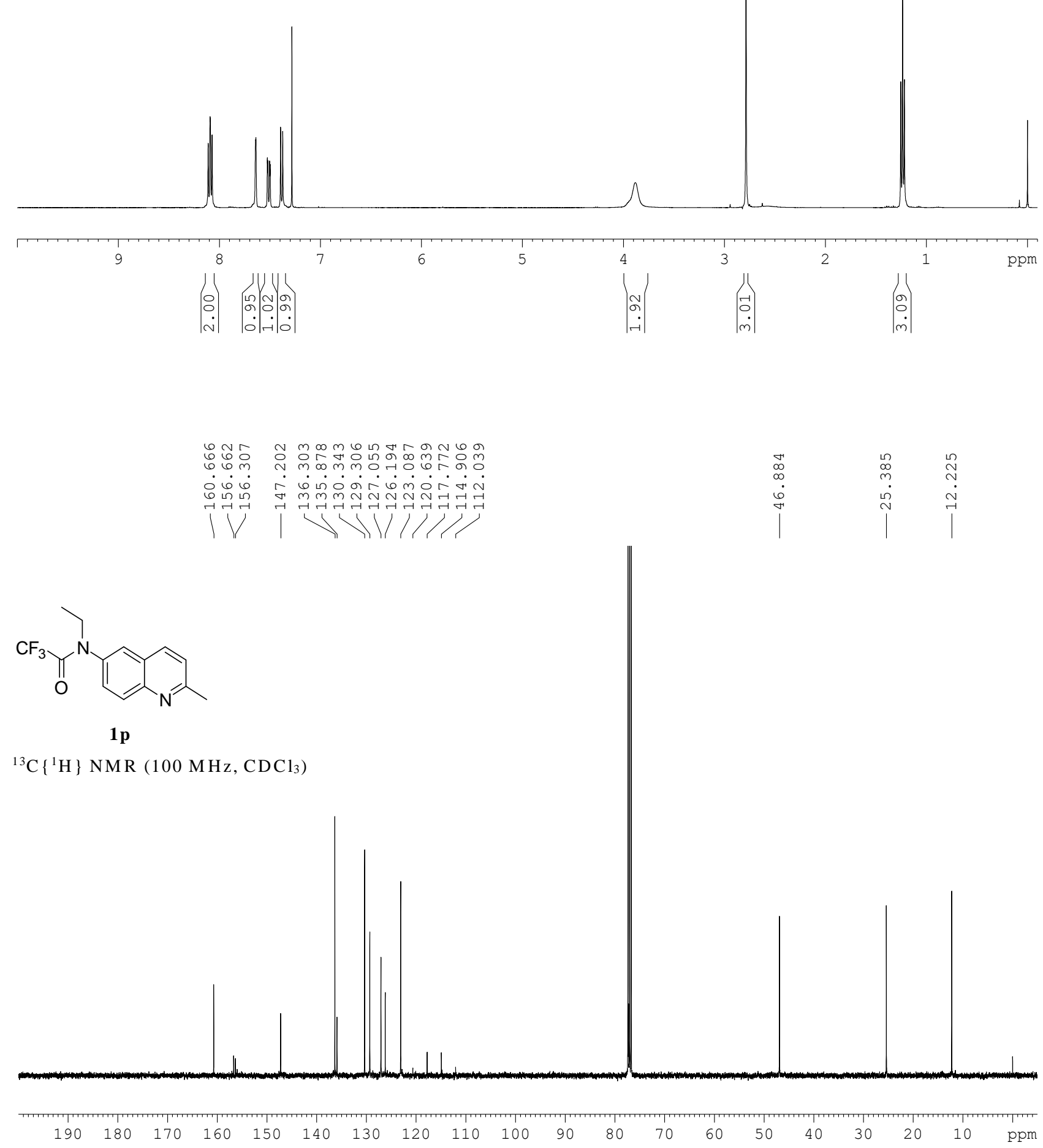

$1 \mathrm{p}$

${ }^{13} \mathrm{C}\left\{{ }^{1} \mathrm{H}\right\}$ NMR $\left(100 \mathrm{MHz}, \mathrm{CDCl}_{3}\right)$

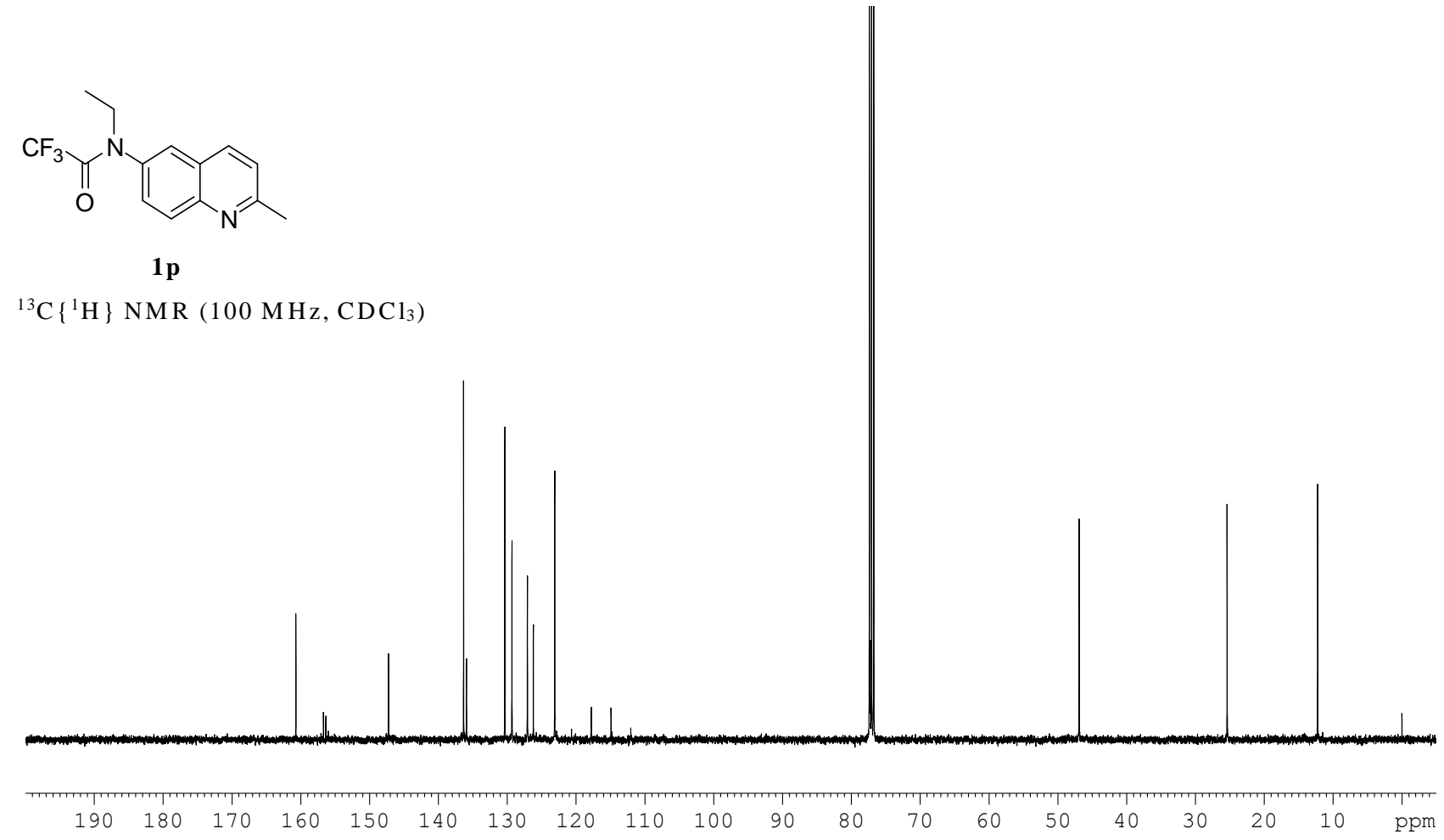

$\begin{array}{llllllllllll}190 & 180 & 170 & 160 & 150 & 140 & 130 & 120 & 110 & 100 & 90 & 80\end{array}$

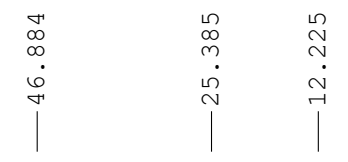



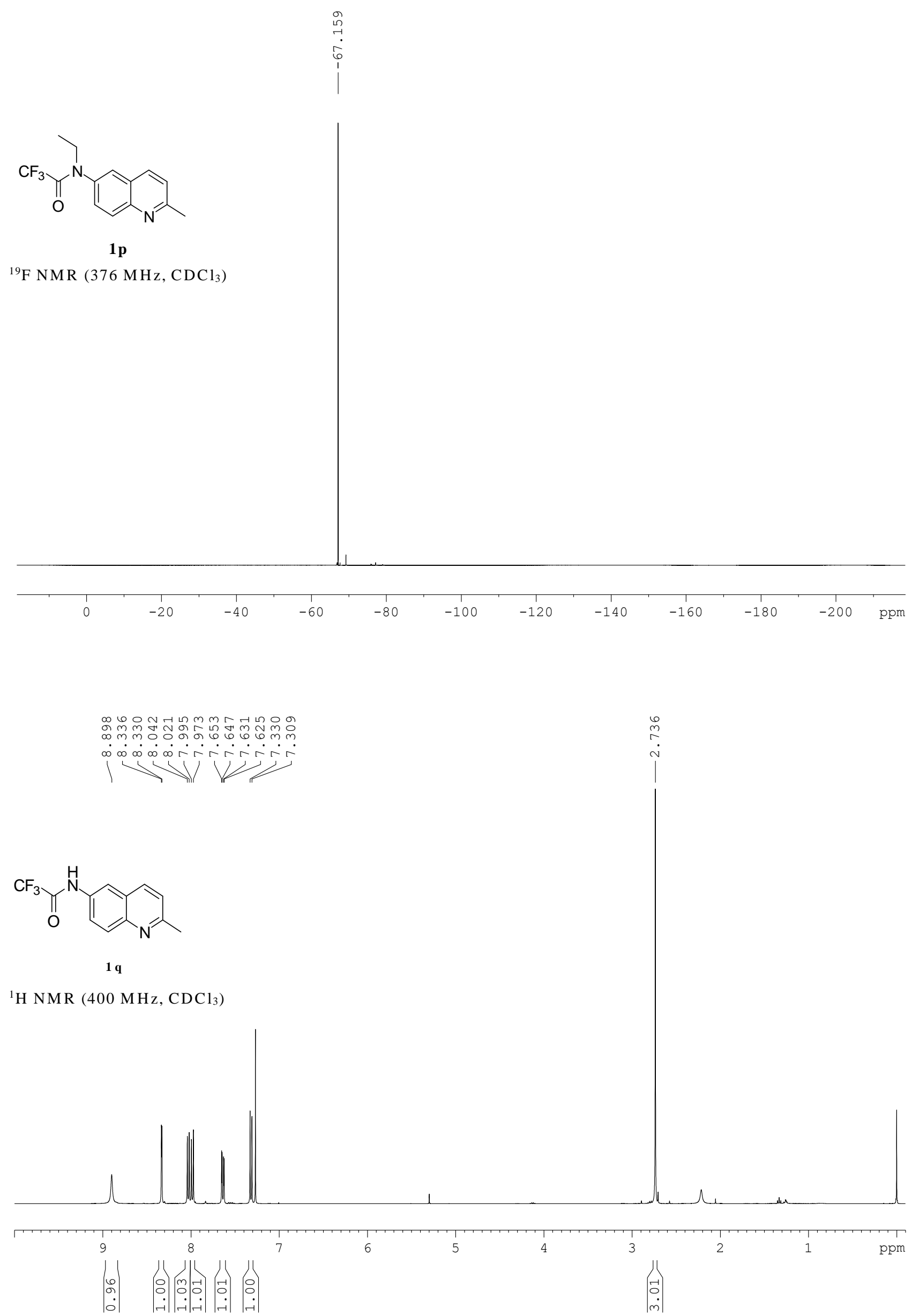


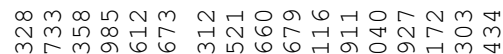

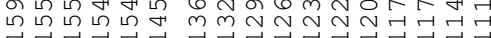

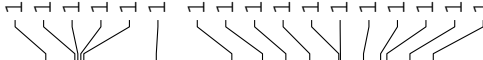
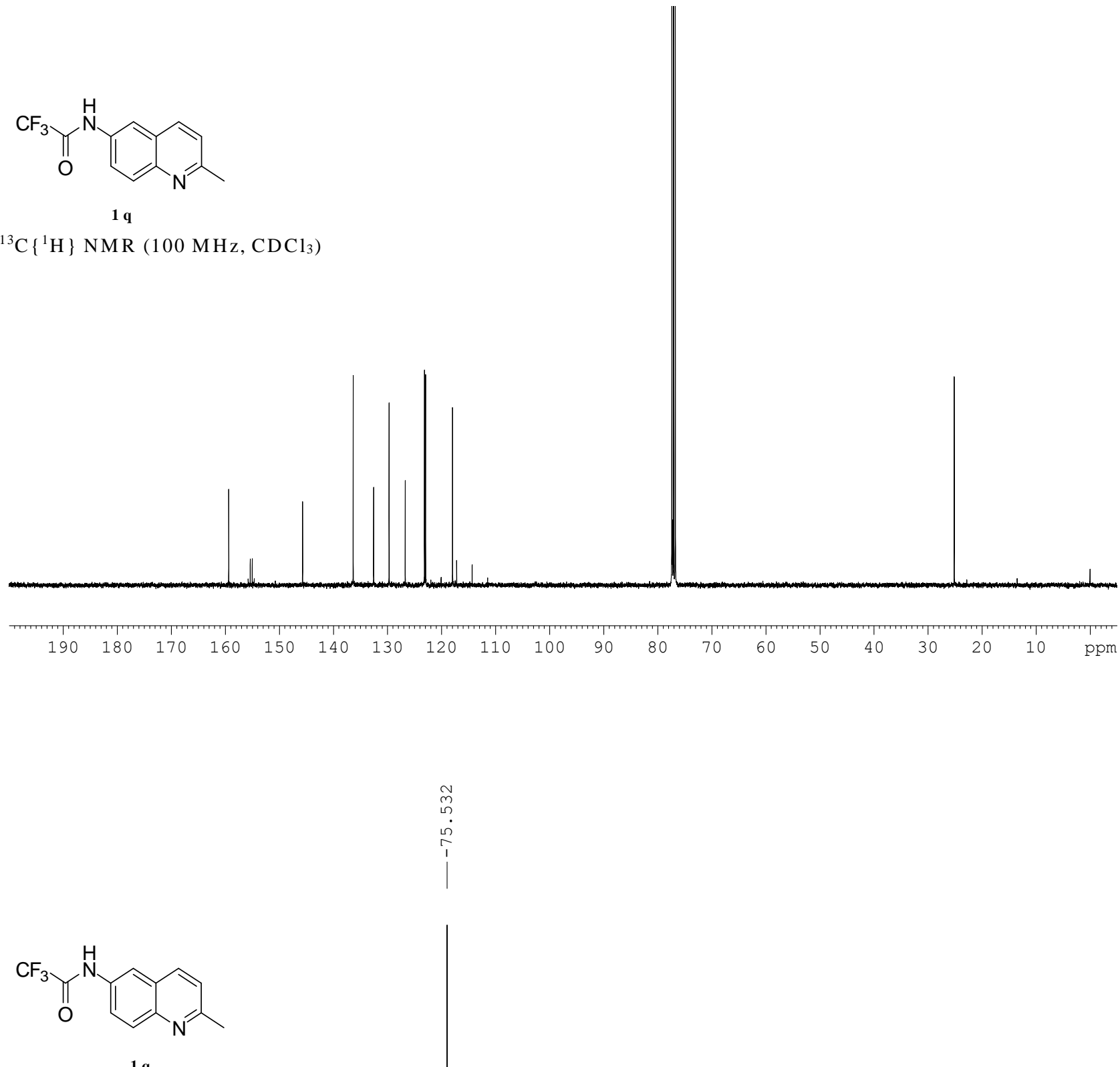

${ }^{19} \mathrm{~F}$ NMR $\left(376 \mathrm{MHz}, \mathrm{CDCl}_{3}\right)$

F NMR (376 $\left.\mathrm{MH}_{2}, \mathrm{CDCl}_{3}\right)$

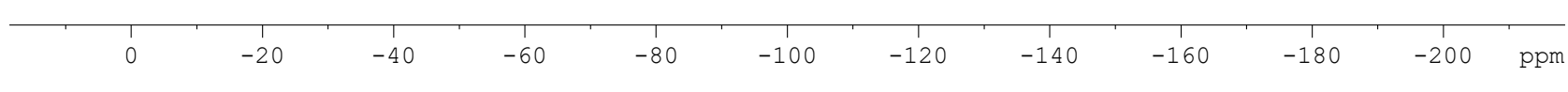




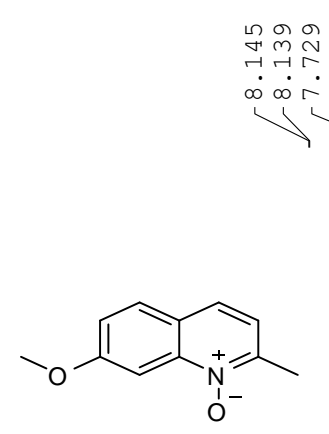

$2 \mathrm{~g}$

${ }^{1} \mathrm{H}$ NMR $\left(400 \mathrm{MHz}, \mathrm{CDCl}_{3}\right)$
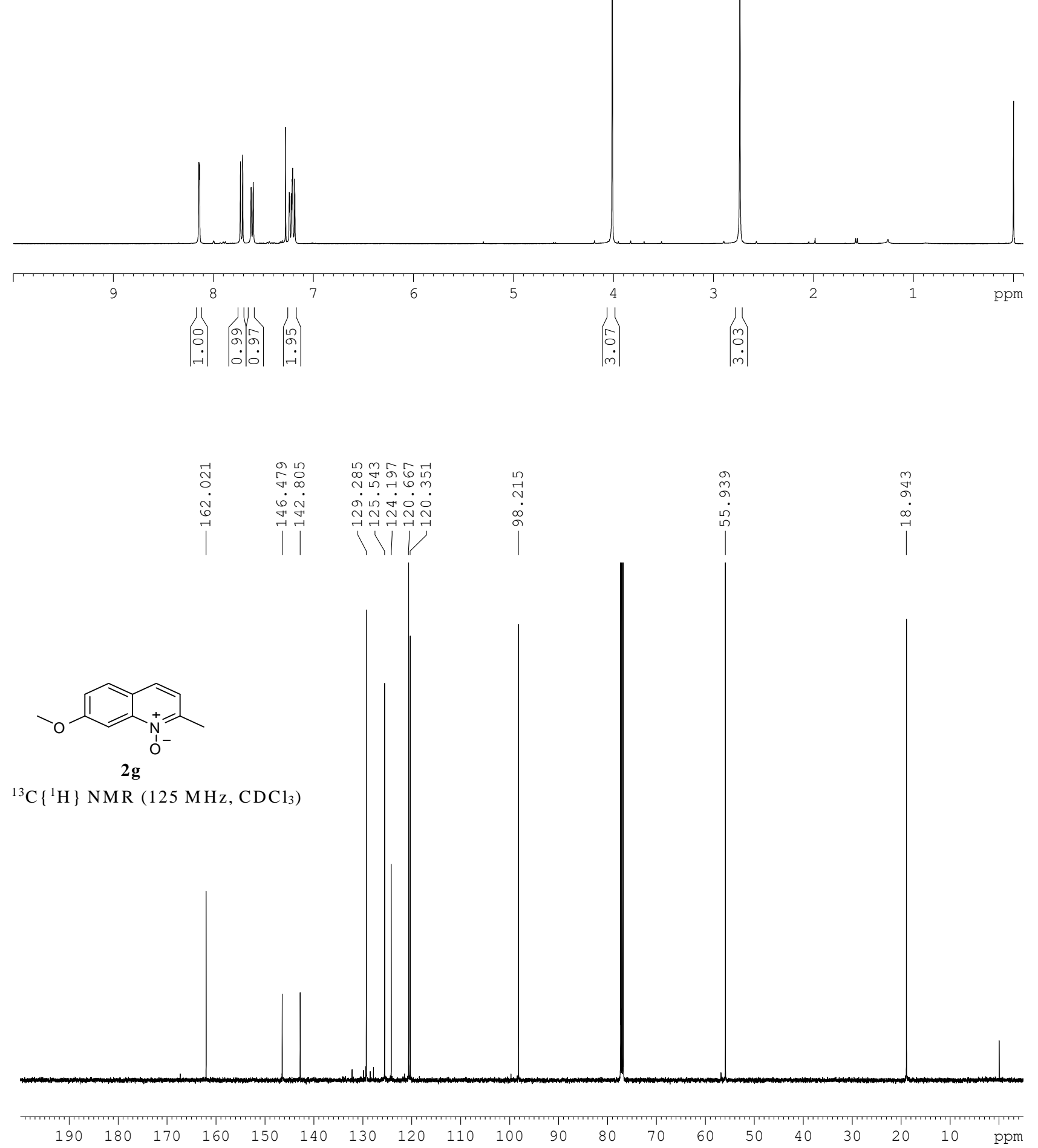

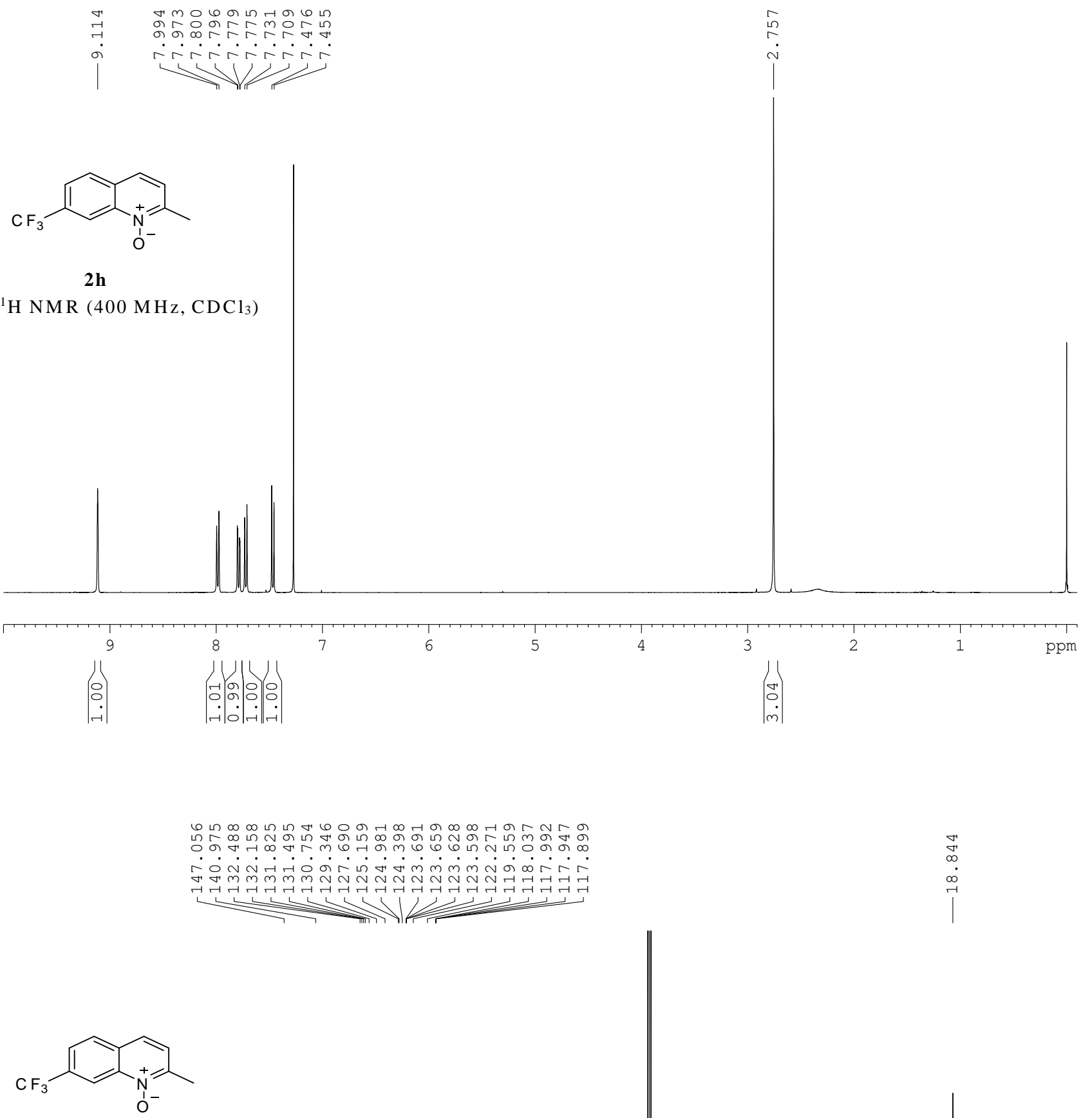

$2 h$

${ }^{13} \mathrm{C}\left\{{ }^{1} \mathrm{H}\right\} \mathrm{NMR}\left(100 \mathrm{MHz}, \mathrm{CDCl}_{3}\right)$ 


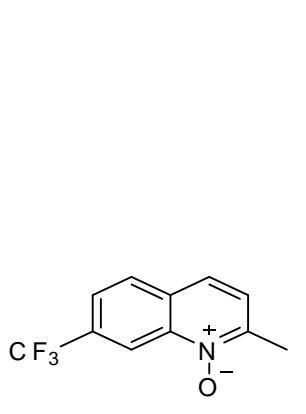

$2 \mathbf{h}$

${ }^{19}$ F NMR $\left(376 \mathrm{MHz}, \mathrm{CDCl}_{3}\right)$
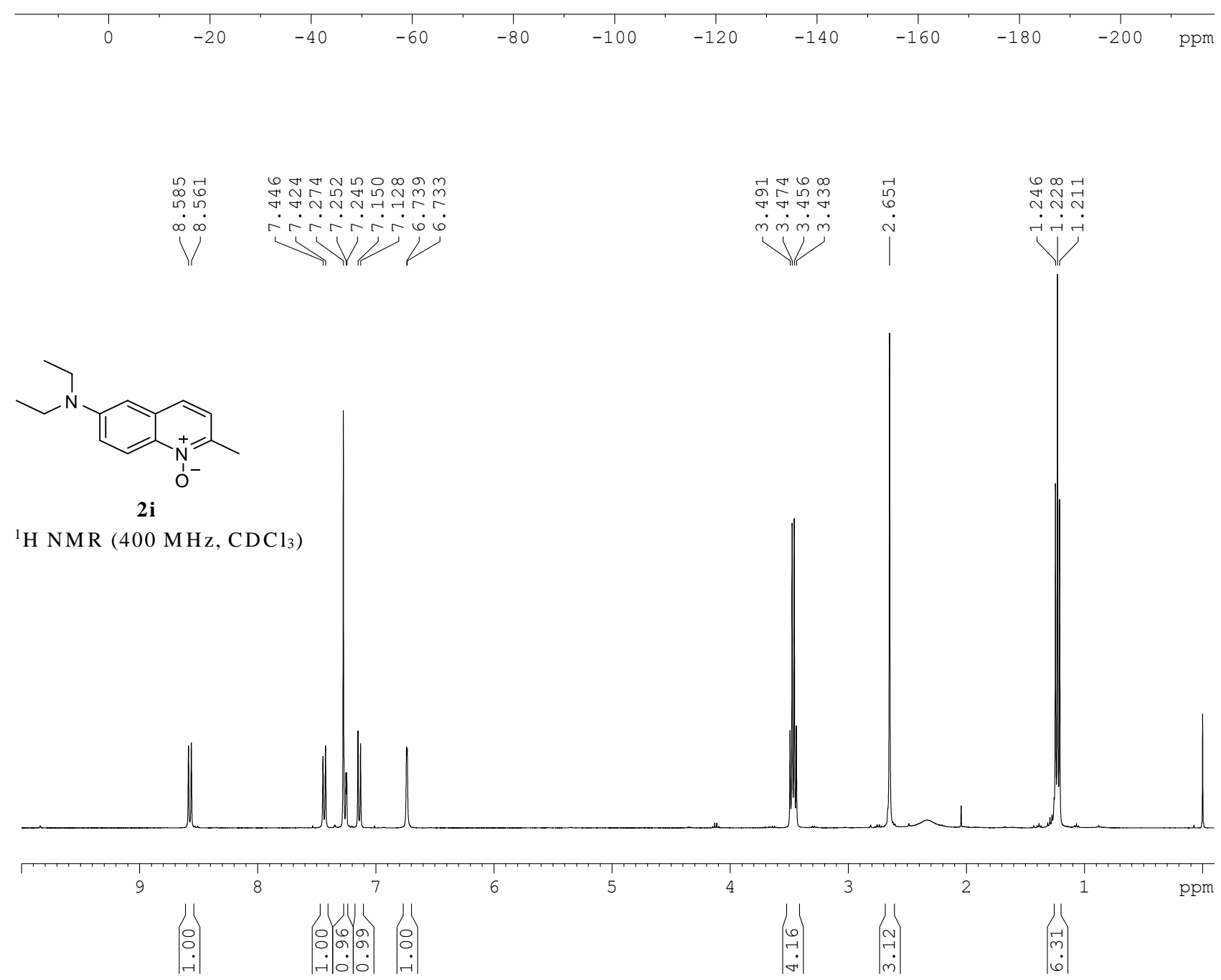

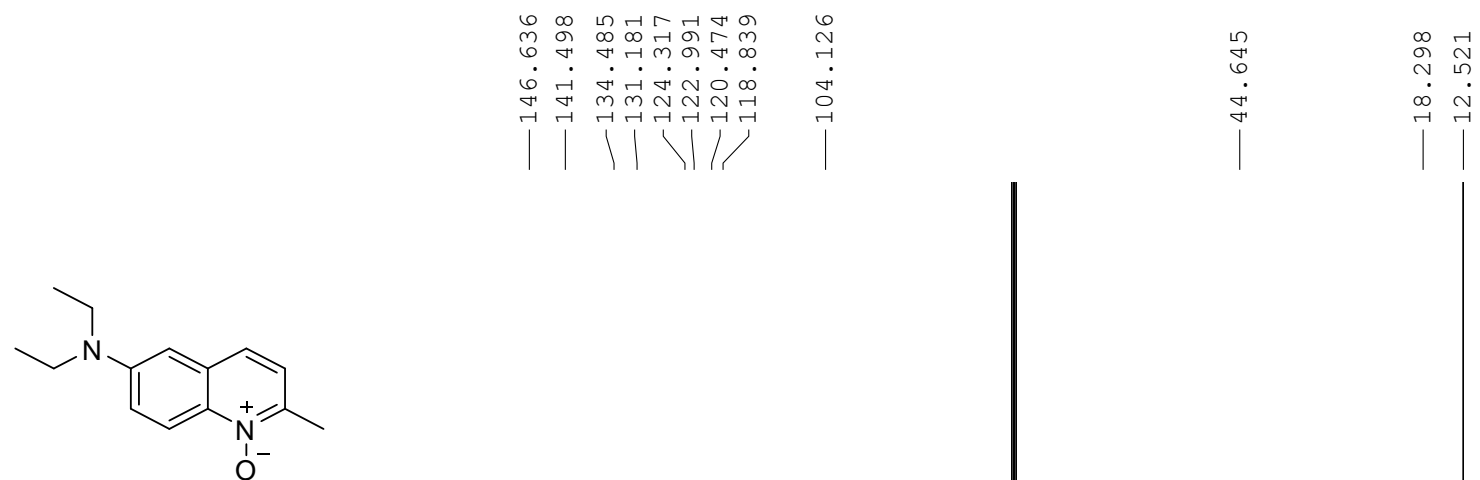

2i

${ }^{13} \mathrm{C}\left\{{ }^{1} \mathrm{H}\right\}$ NMR $\left(100 \mathrm{MHz}, \mathrm{CDCl}_{3}\right)$
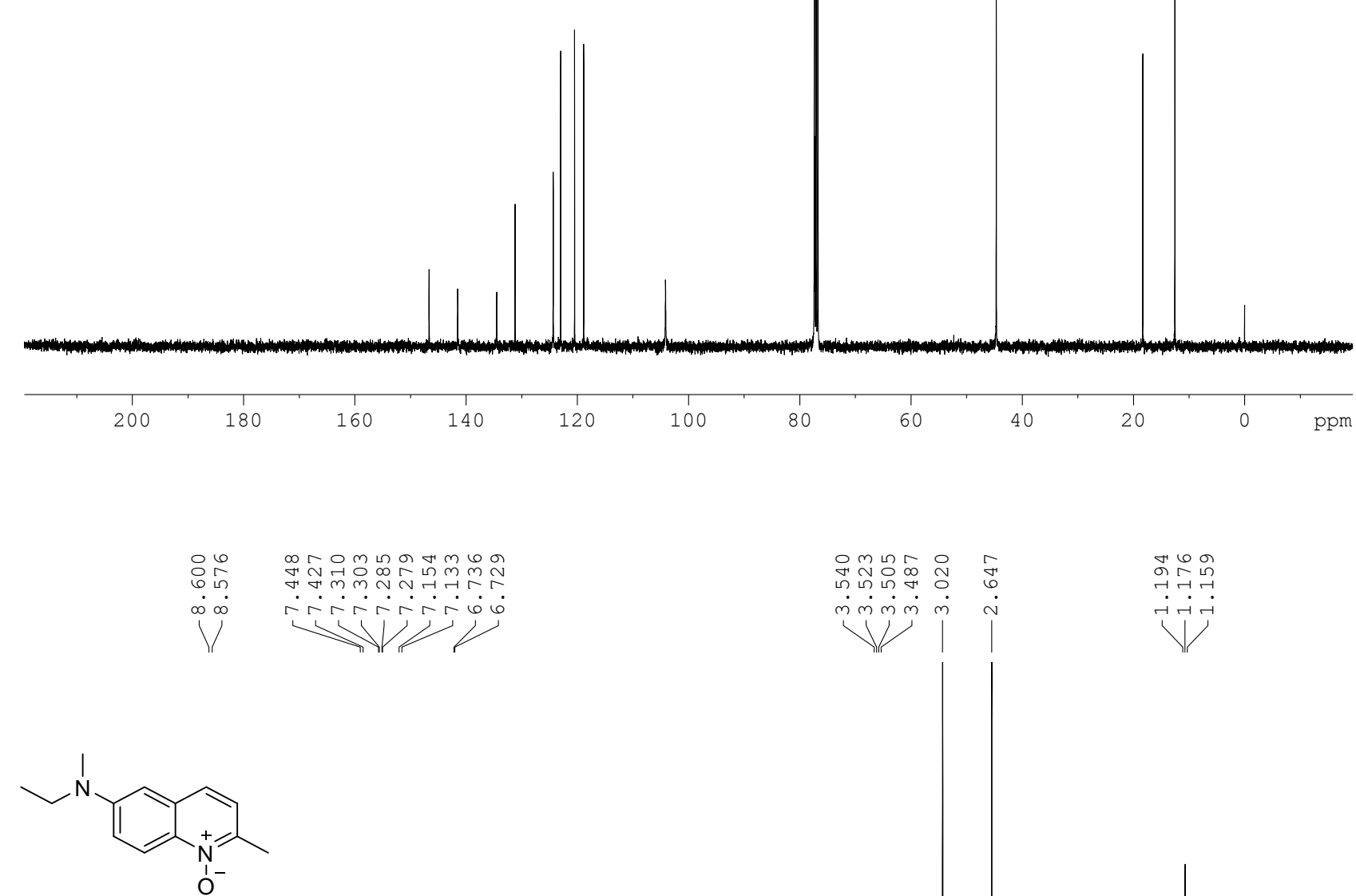

$2 \mathbf{j}$

${ }^{1} \mathrm{H} \mathrm{NMR}\left(400 \mathrm{MHz}, \mathrm{CDCl}_{3}\right)$

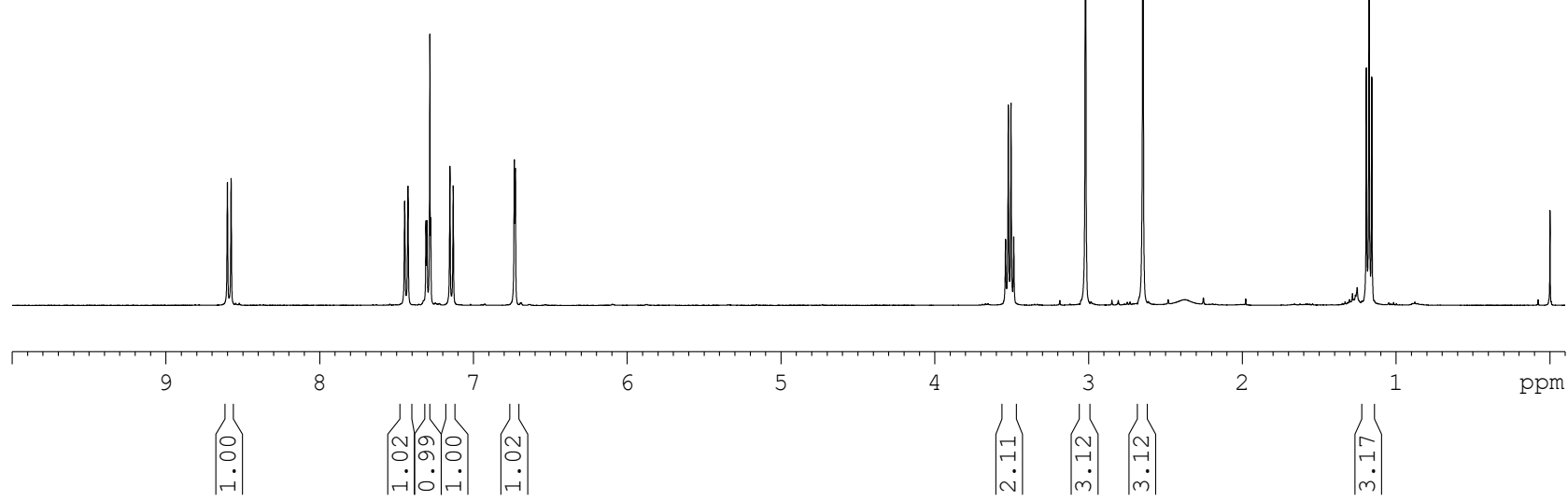


<smiles>CCN(C)c1ccc2c(ccc(C)[n+]2[O-])c1</smiles>

$2 \mathbf{j}$

${ }^{13} \mathrm{C}\left\{{ }^{1} \mathrm{H}\right\}$ NMR $\left(100 \mathrm{MHz}, \mathrm{CDCl}_{3}\right)$
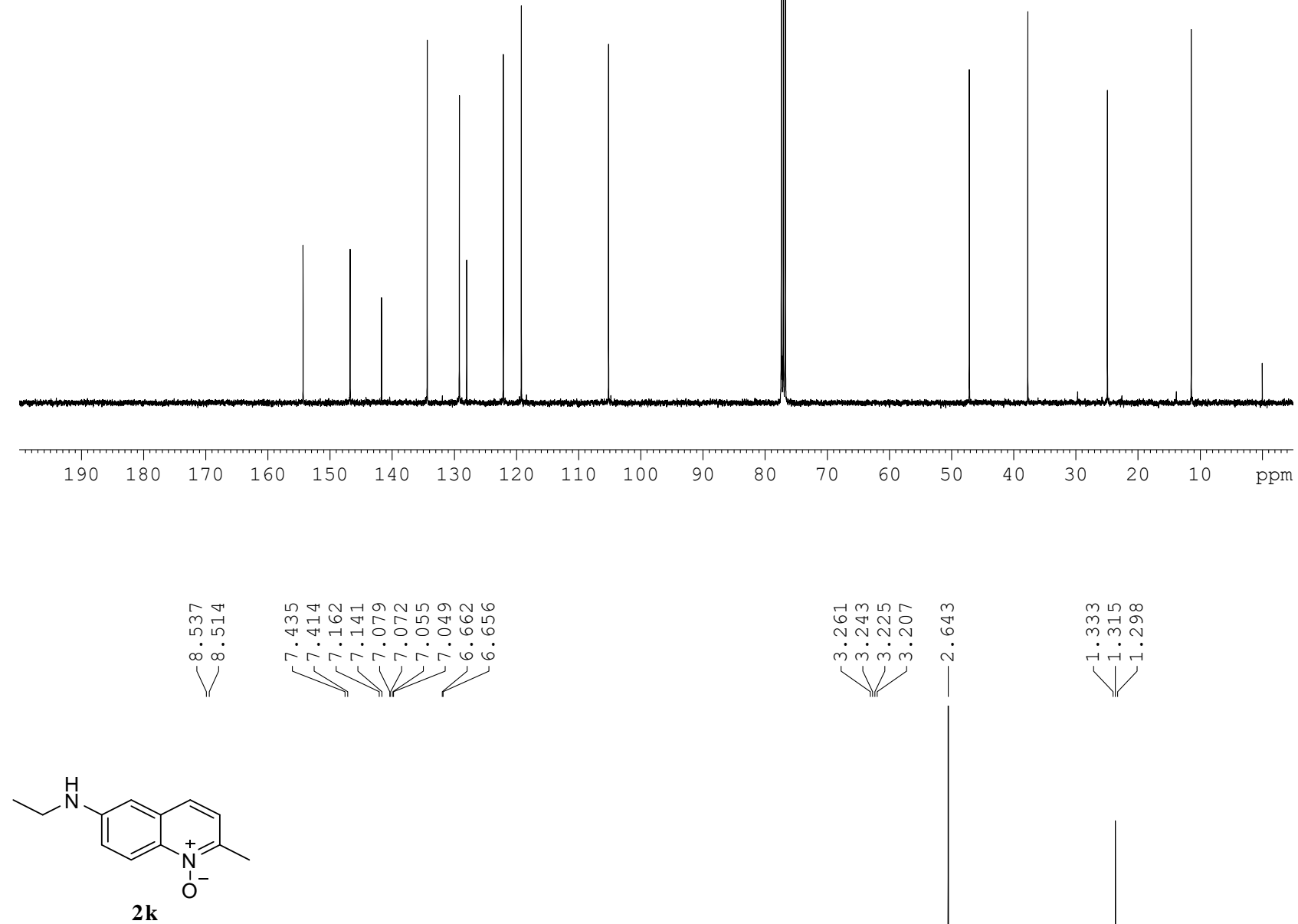

${ }^{1} \mathrm{H} \mathrm{NMR}\left(400 \mathrm{MHz}, \mathrm{CDCl}_{3}\right)$

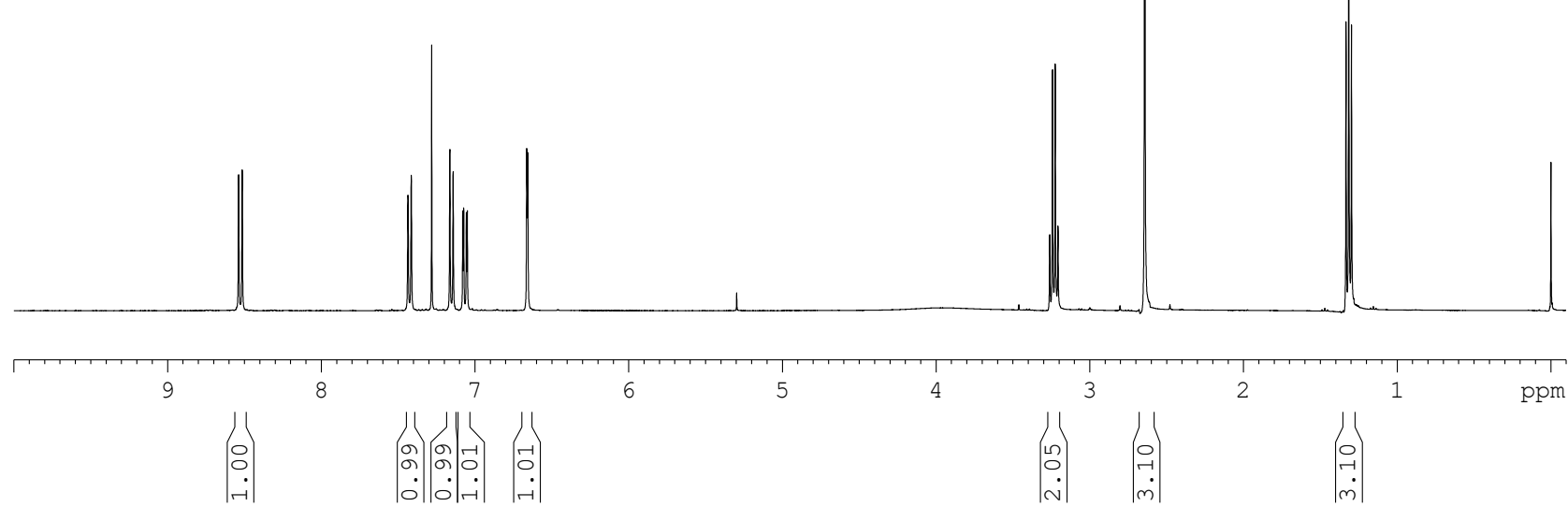



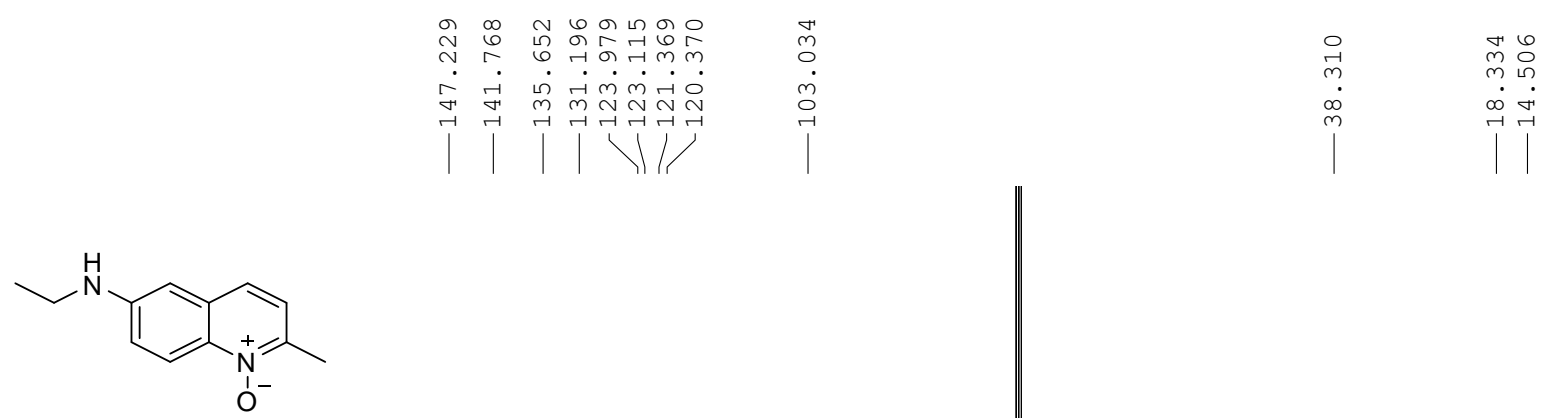

$2 \mathbf{k}$

${ }^{13} \mathrm{C}\left\{{ }^{1} \mathrm{H}\right\}$ NMR $\left(100 \mathrm{MHz}, \mathrm{CDCl}_{3}\right)$

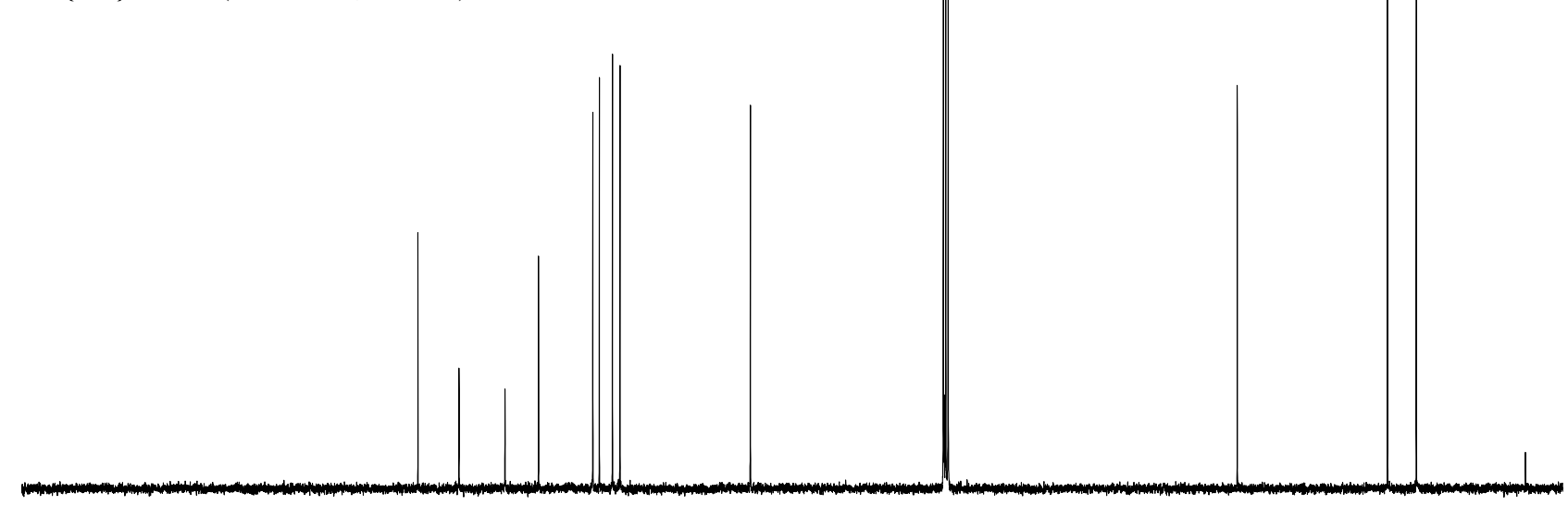

$\begin{array}{llllllllllllllllllll}190 & 180 & 170 & 160 & 150 & 140 & 130 & 120 & 110 & 100 & 90 & 80 & 70 & 60 & 50 & 40 & 30 & 20 & 10 & \mathrm{ppm}\end{array}$
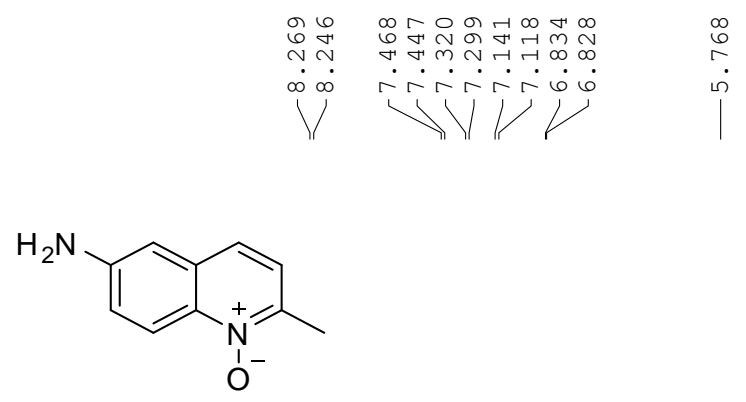

21

${ }^{1} \mathrm{H}$ NMR $\left(400 \mathrm{MHz}, \mathrm{DMSO}-d_{6}\right)$

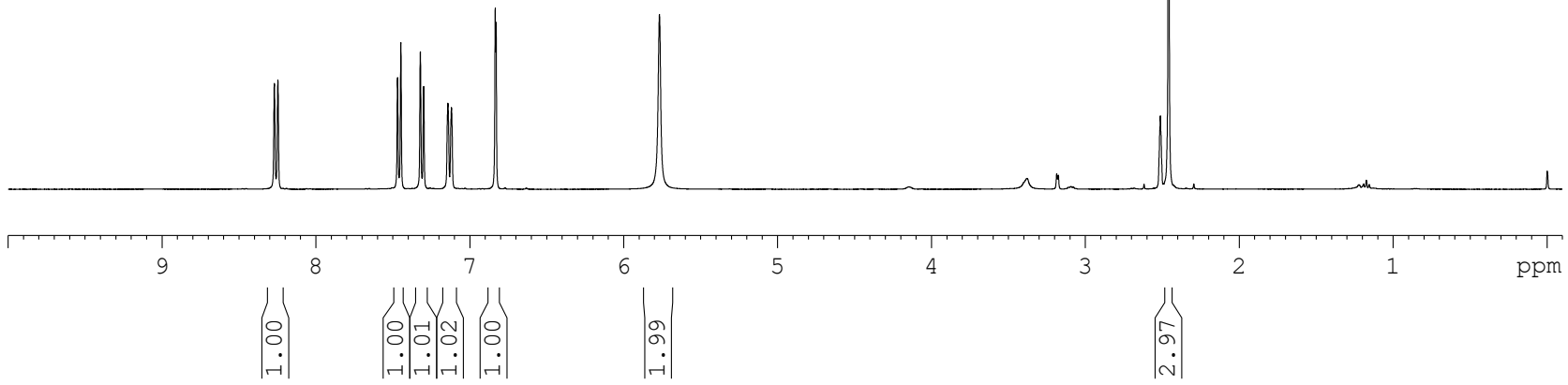




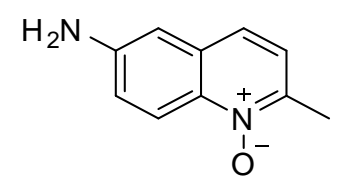

21

${ }^{13} \mathrm{C}\left\{{ }^{1} \mathrm{H}\right\}$ NMR $\left(100 \mathrm{MHz}, \mathrm{DMSO}-d_{6}\right)$
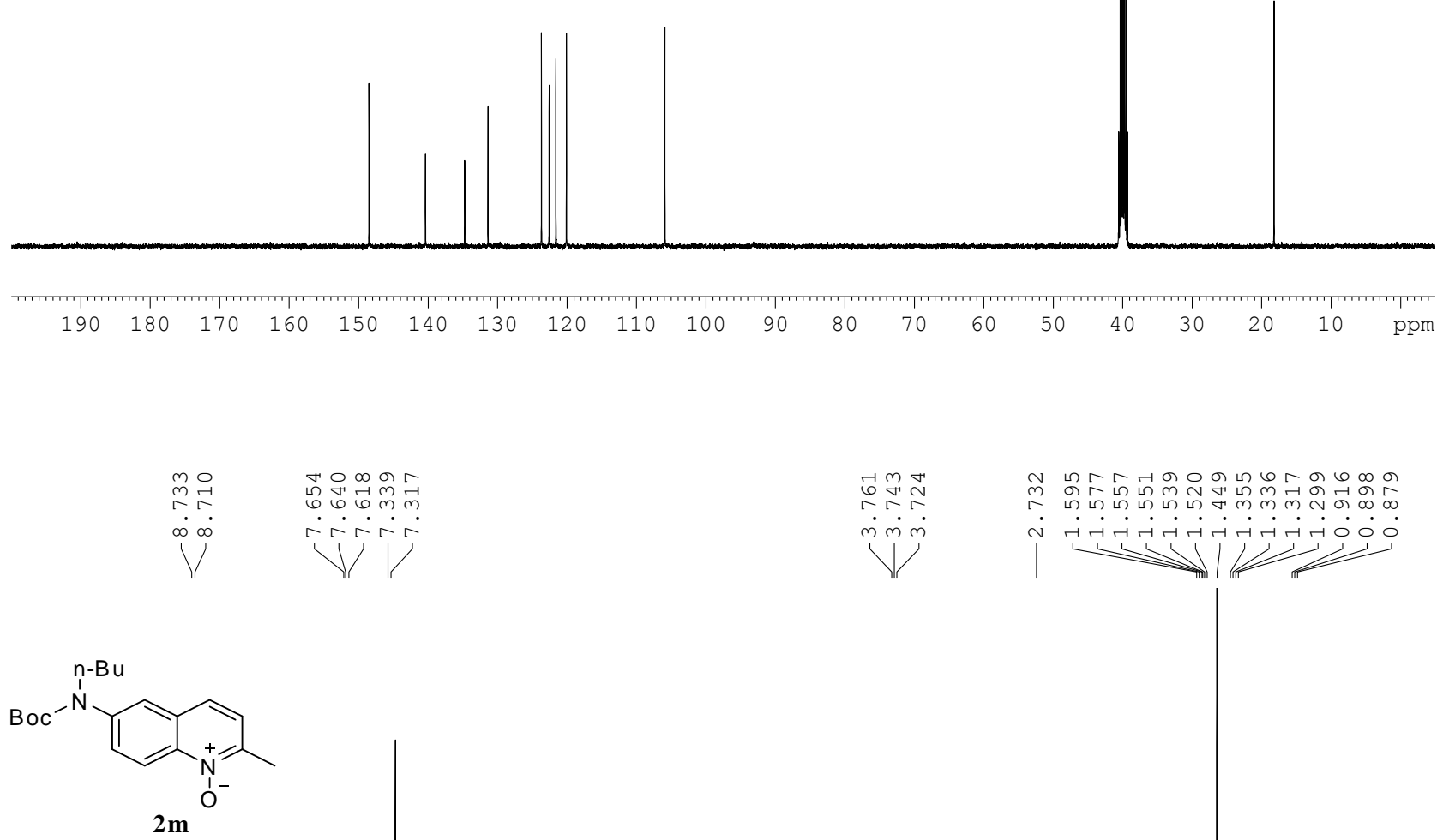

${ }^{1} \mathrm{H} \mathrm{NMR}\left(400 \mathrm{MHz}, \mathrm{CDCl}_{3}\right)$

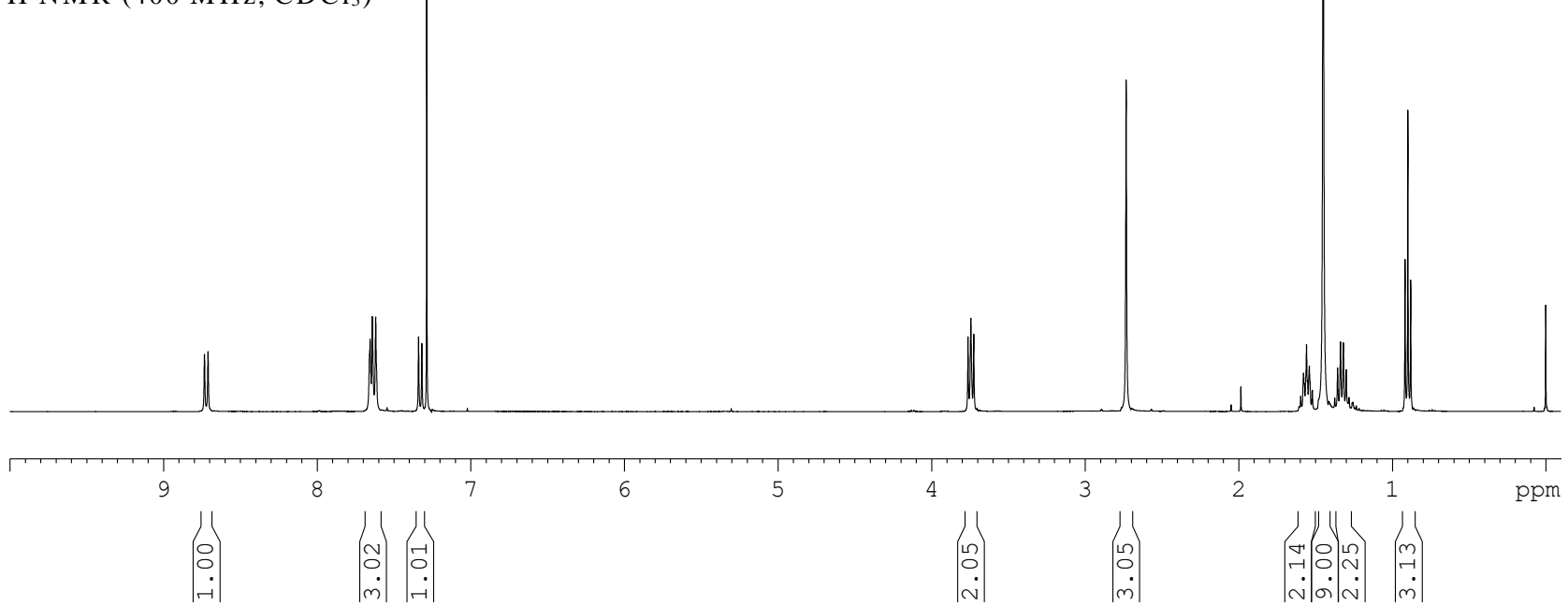



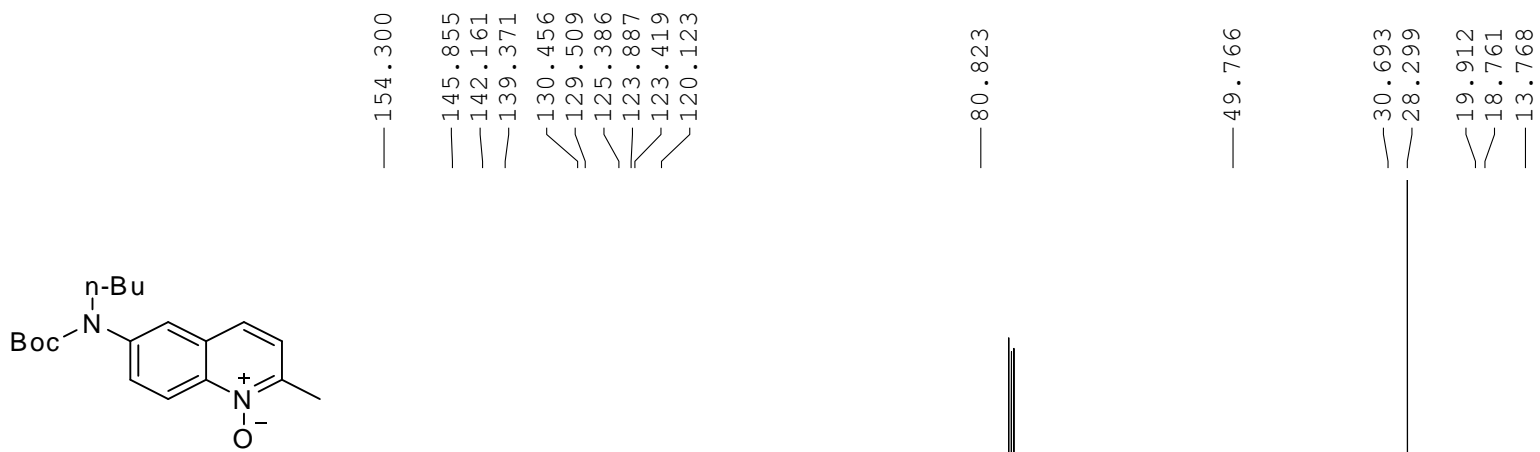

$2 \mathrm{~m}$

${ }^{13} \mathrm{C}\left\{{ }^{1} \mathrm{H}\right\}$ NMR $\left(100 \mathrm{MHz}, \mathrm{CDCl}_{3}\right)$
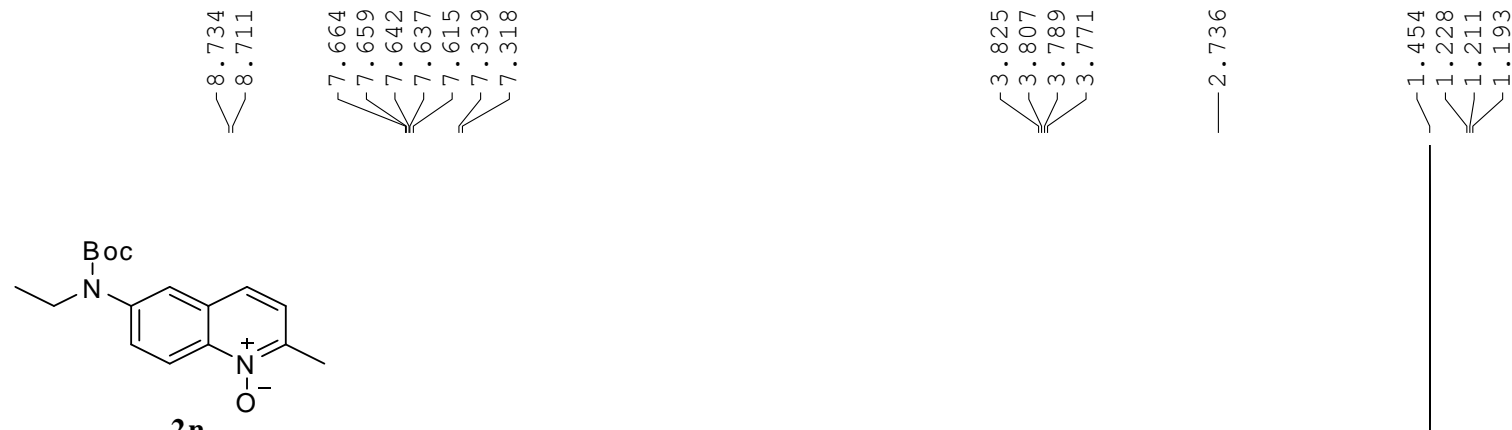

${ }^{1} \mathrm{H} \mathrm{NMR}\left(400 \mathrm{MHz}, \mathrm{CDCl}_{3}\right)$

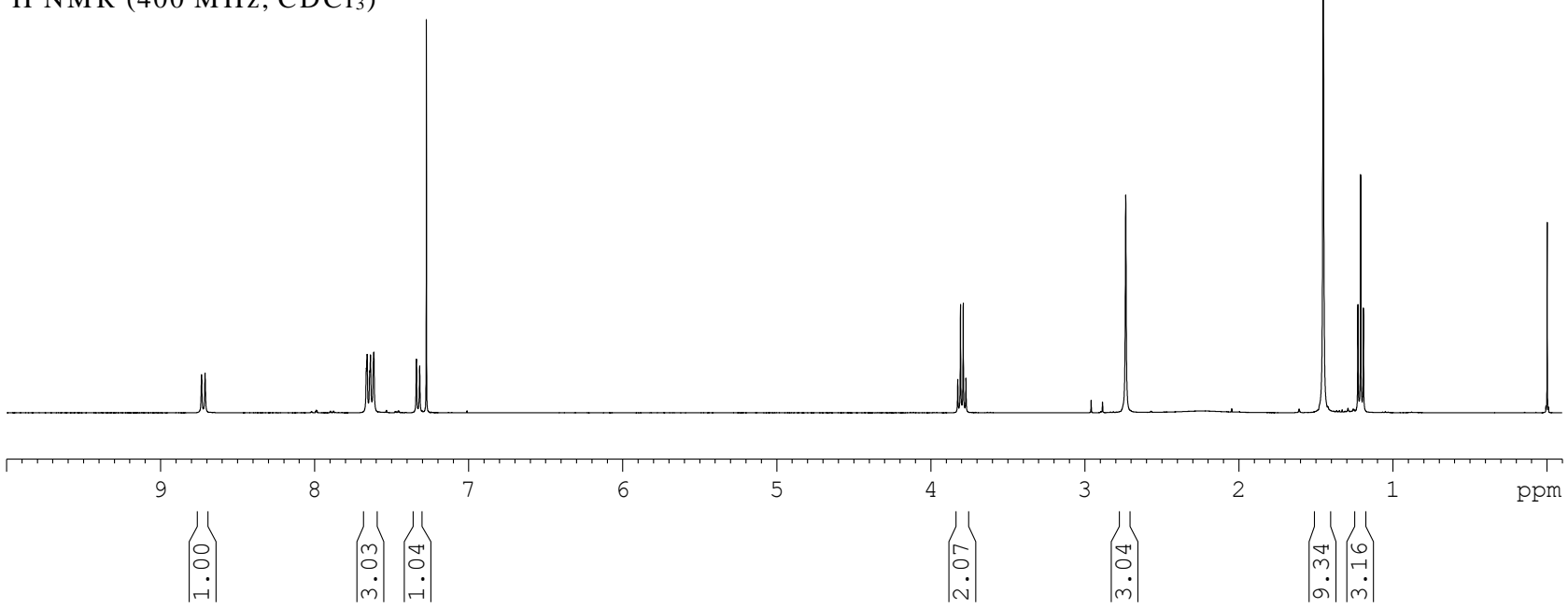



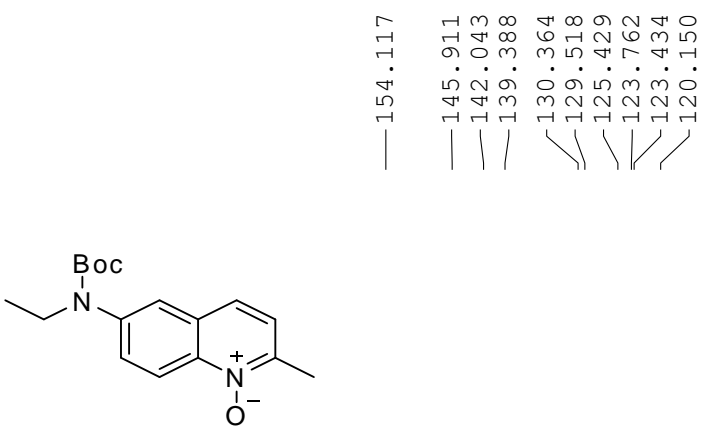

$2 n$

${ }^{13} \mathrm{C}\left\{{ }^{1} \mathrm{H}\right\} \mathrm{NMR}\left(100 \mathrm{MHz}, \mathrm{CDCl}_{3}\right)$
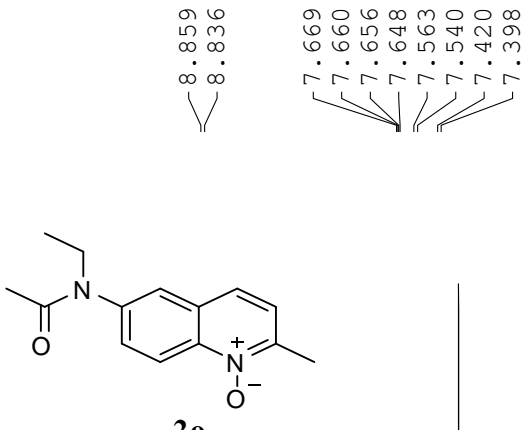

${ }^{1} \mathrm{H} \mathrm{NMR}\left(400 \mathrm{MHz}^{\mathrm{N}} \mathrm{CDCl}_{3}\right)$

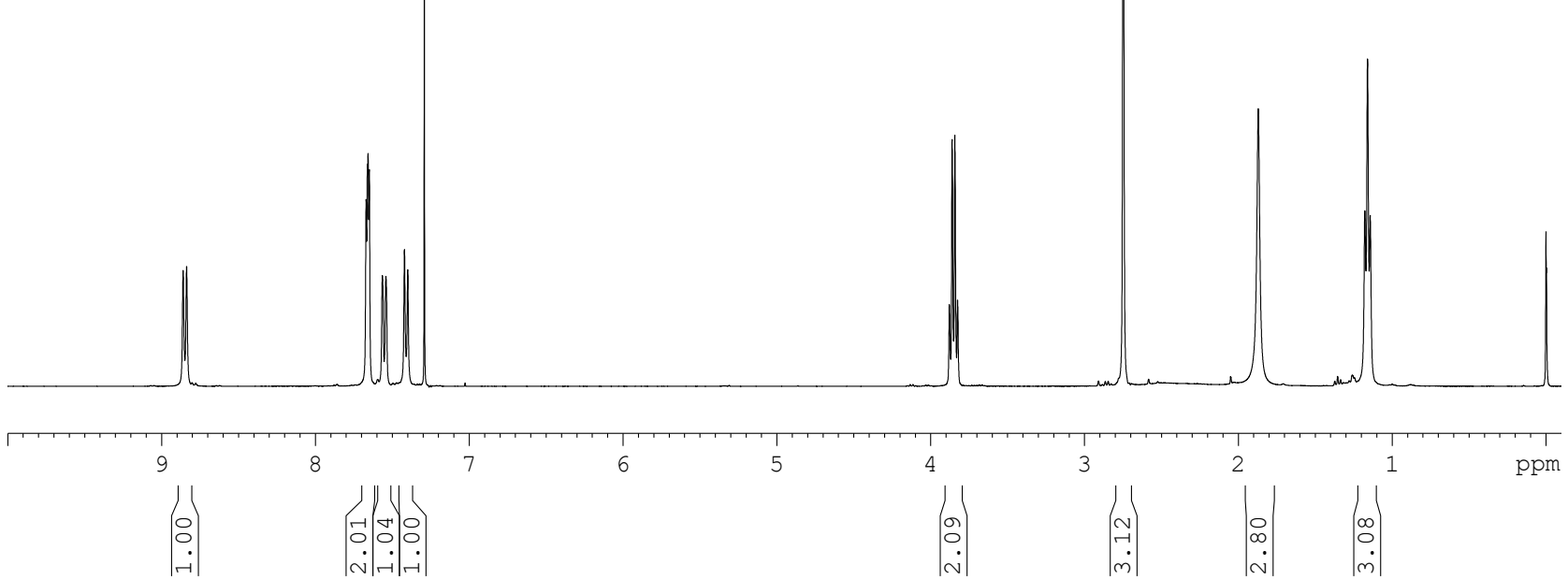



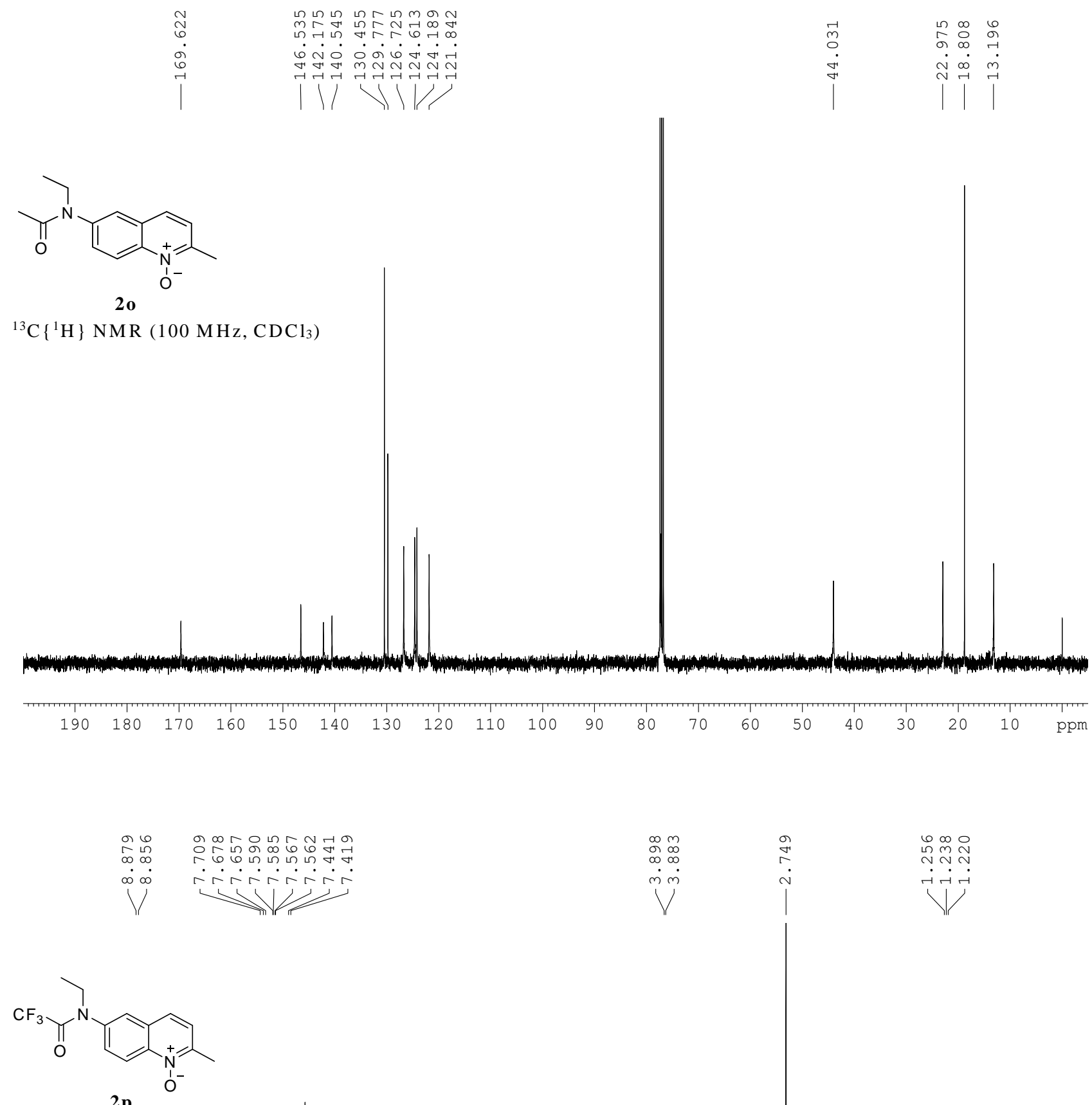

2p

${ }^{1} \mathrm{H} \mathrm{NMR}\left(400 \mathrm{MHz}, \mathrm{CDCl}_{3}\right)$

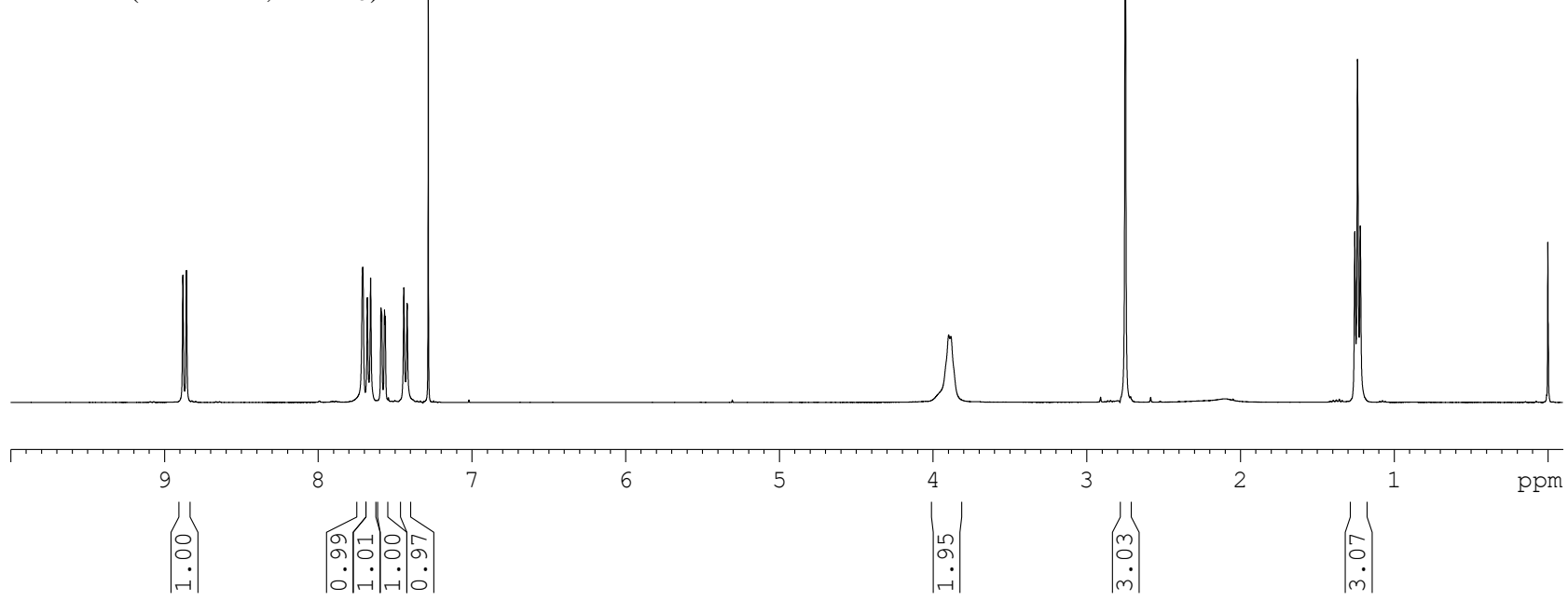



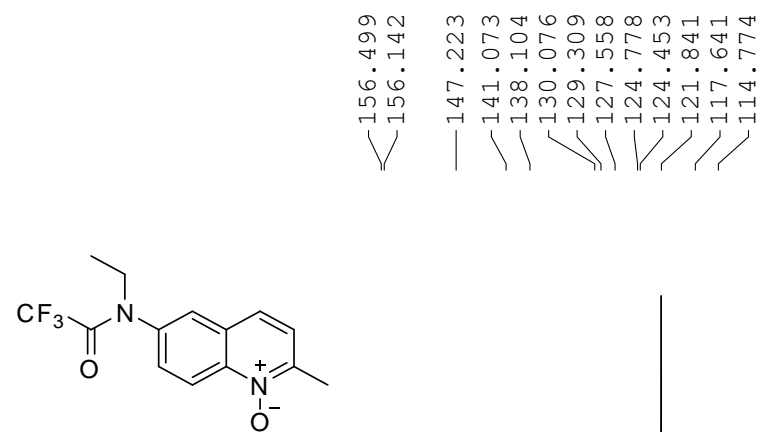

2p

${ }^{13} \mathrm{C}\left\{{ }^{1} \mathrm{H}\right\}$ NMR $\left(100 \mathrm{MHz}, \mathrm{CDCl}_{3}\right)$
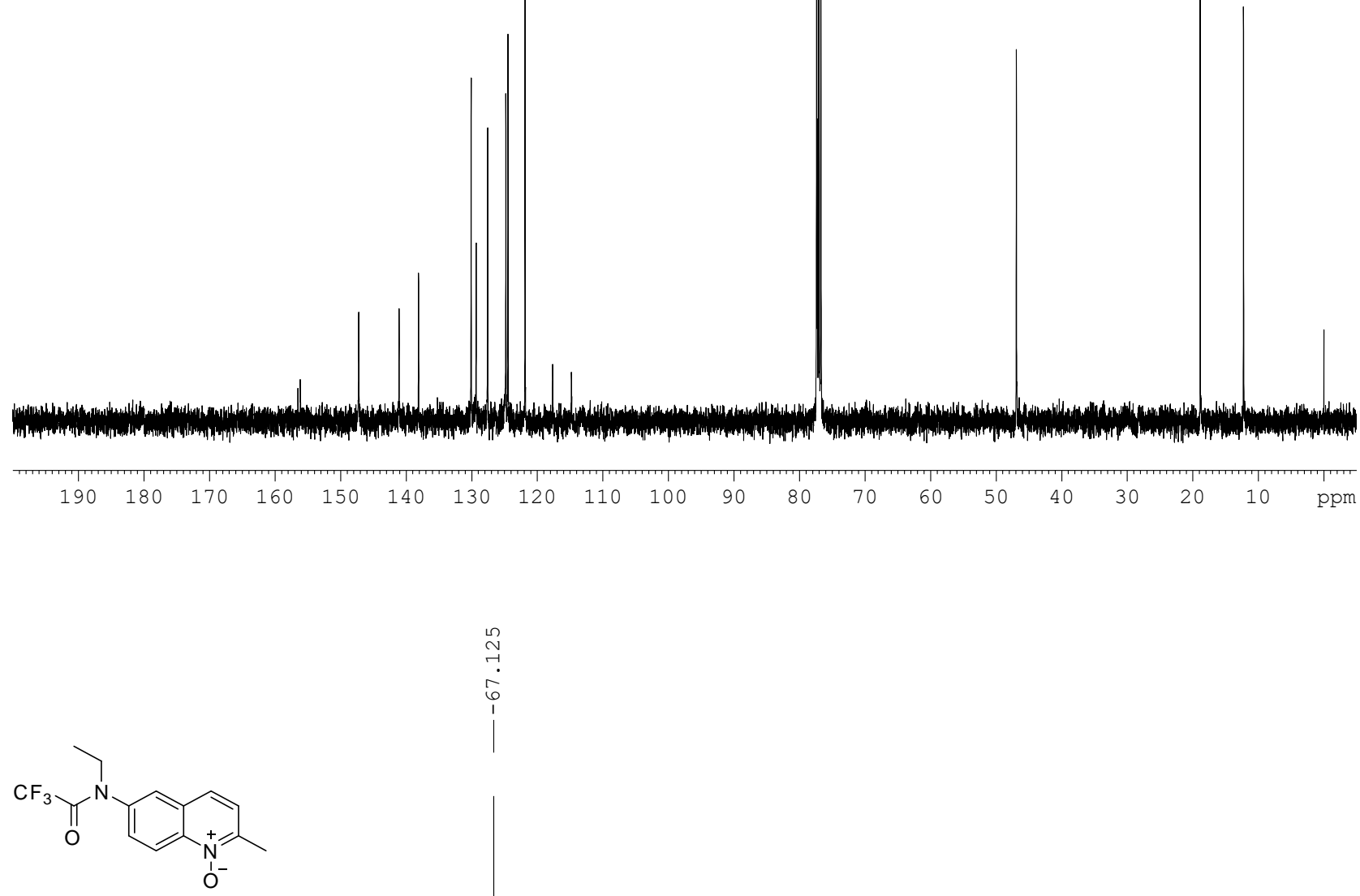

2p

${ }^{19}$ F NMR $\left(376 \mathrm{MHz}, \mathrm{CDCl}_{3}\right)$

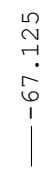




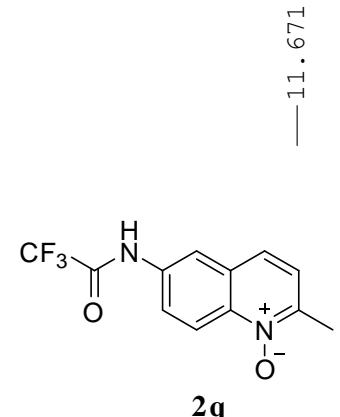

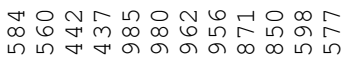

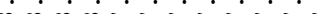

Non

${ }^{1} \mathrm{H}$ NMR (400 MHz, DMSO-d6)
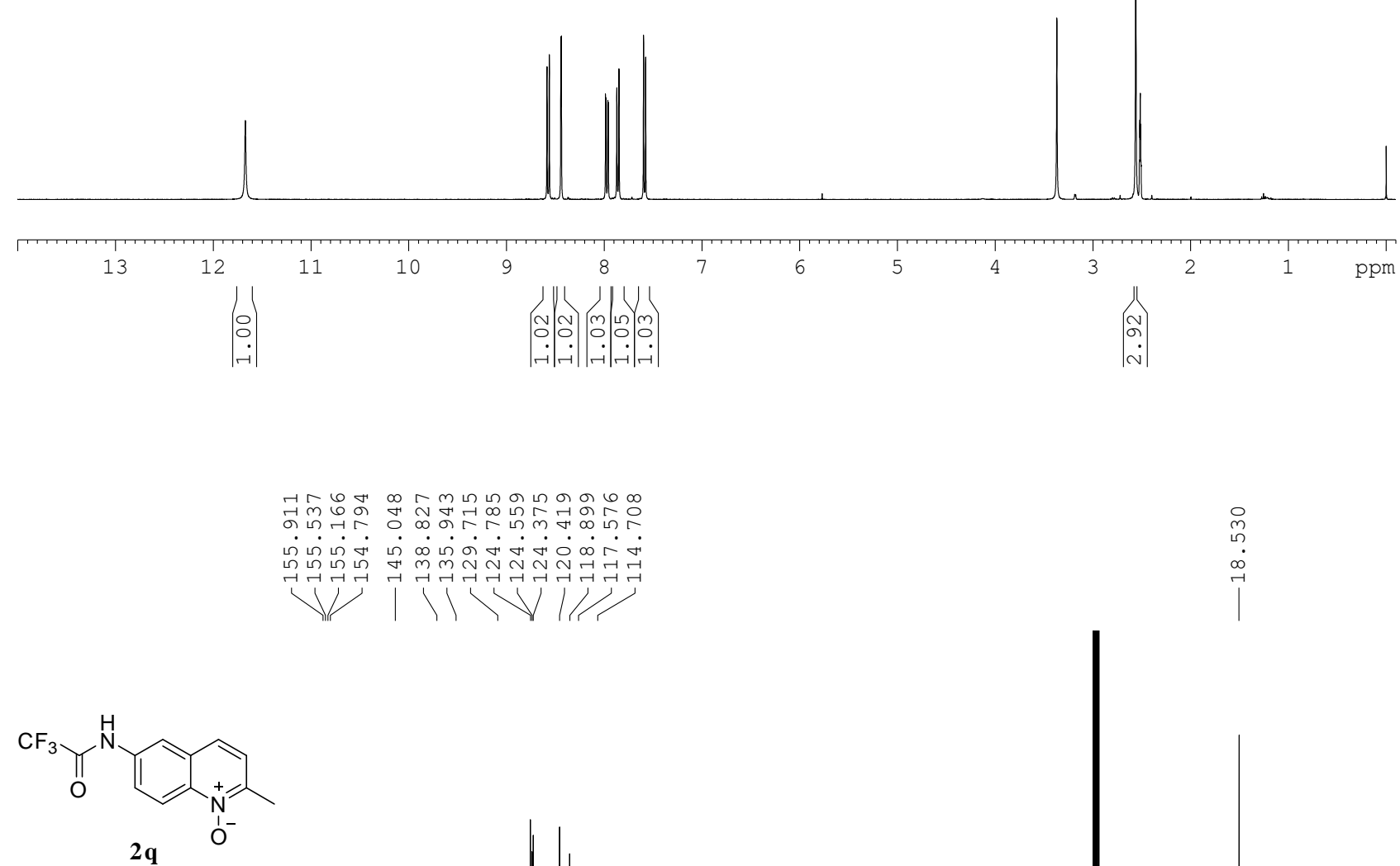

${ }^{13} \mathrm{C}\left\{{ }^{1} \mathrm{H}\right\}$ NMR $\left(100 \mathrm{MHz}\right.$, DMSO- $\left.d_{6}\right)$

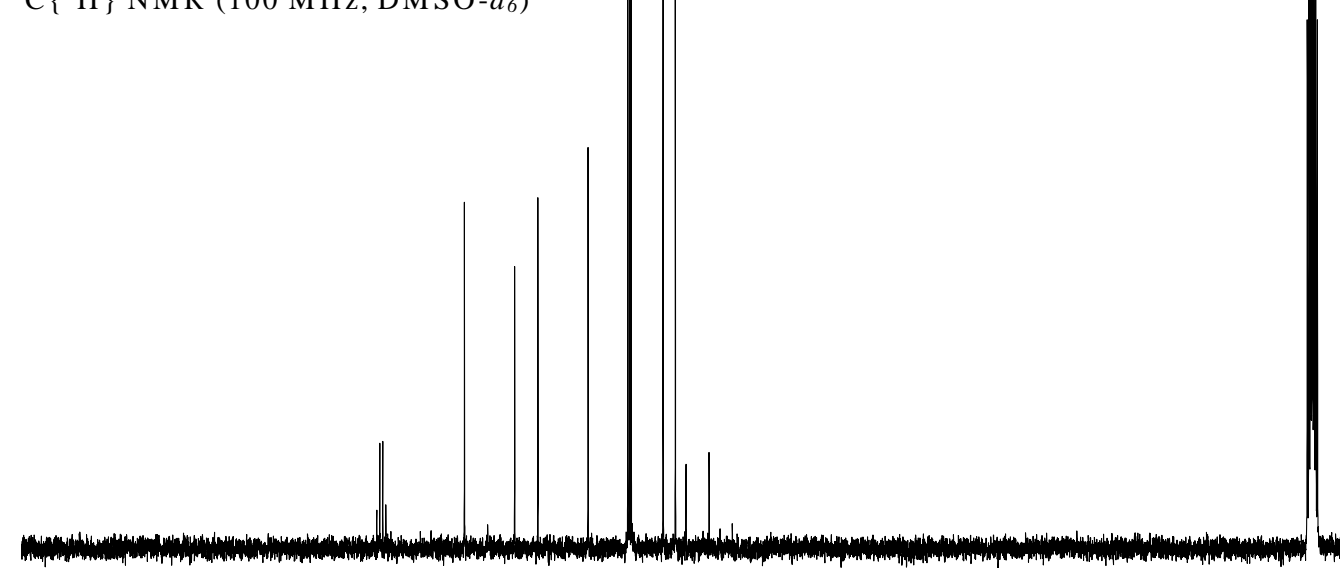

$\begin{array}{llllllllll}190 & 180 & 170 & 160 & 150 & 140 & 130 & 120 & 110 & 100\end{array}$

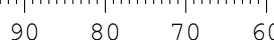

50

40

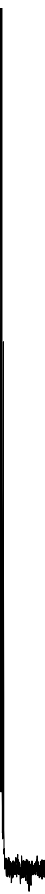


<smiles>Cc1ccc2cc(NC(=O)C(F)(F)F)ccc2[n+]1[O-]</smiles>

$\mathbf{2 q}$

${ }^{19} \mathrm{~F}$ NMR $\left(376 \mathrm{MHz}, \mathrm{DMSO}-d_{6}\right)$

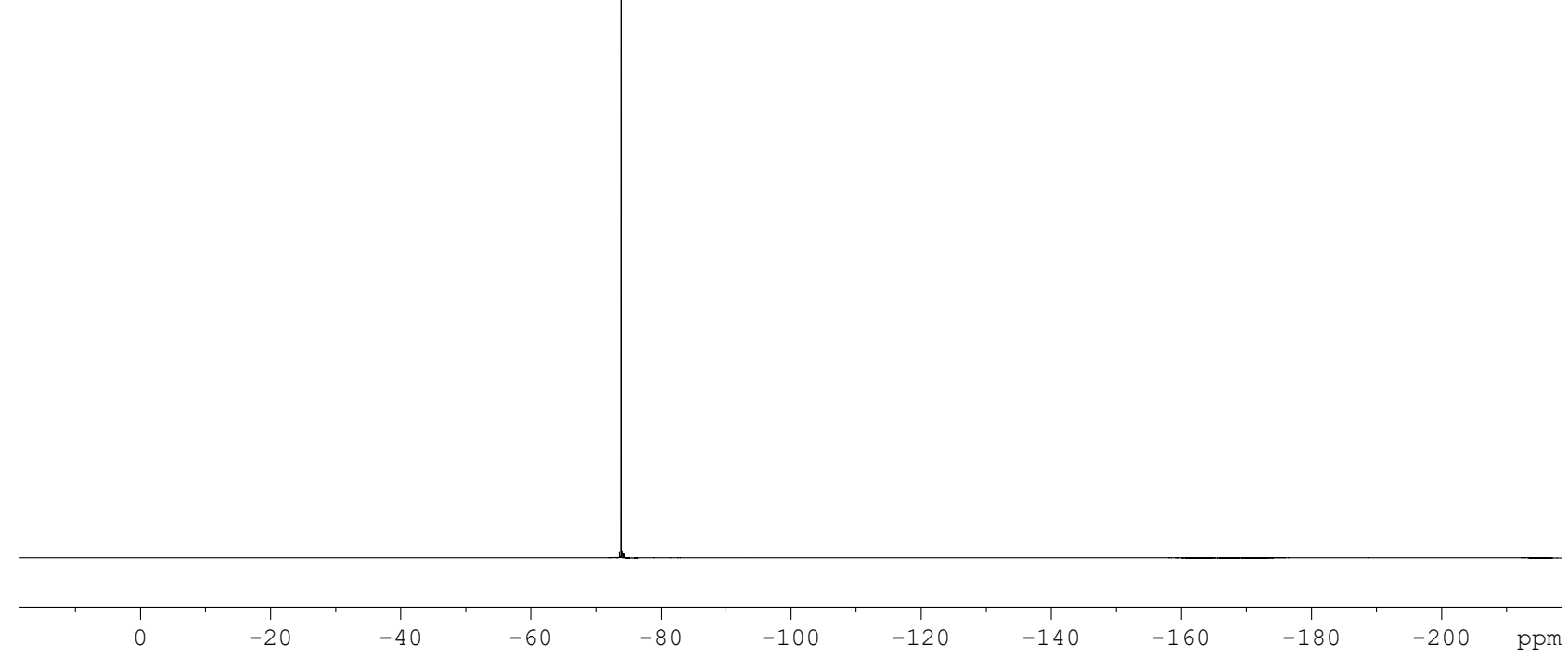

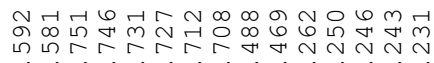

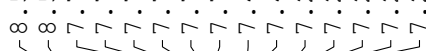

1<smiles>ClCc1ccccn1</smiles>

$3 \mathbf{a}$

${ }^{1} \mathrm{H} \mathrm{NMR}\left(400 \mathrm{MHz}, \mathrm{CDCl}_{3}\right)$

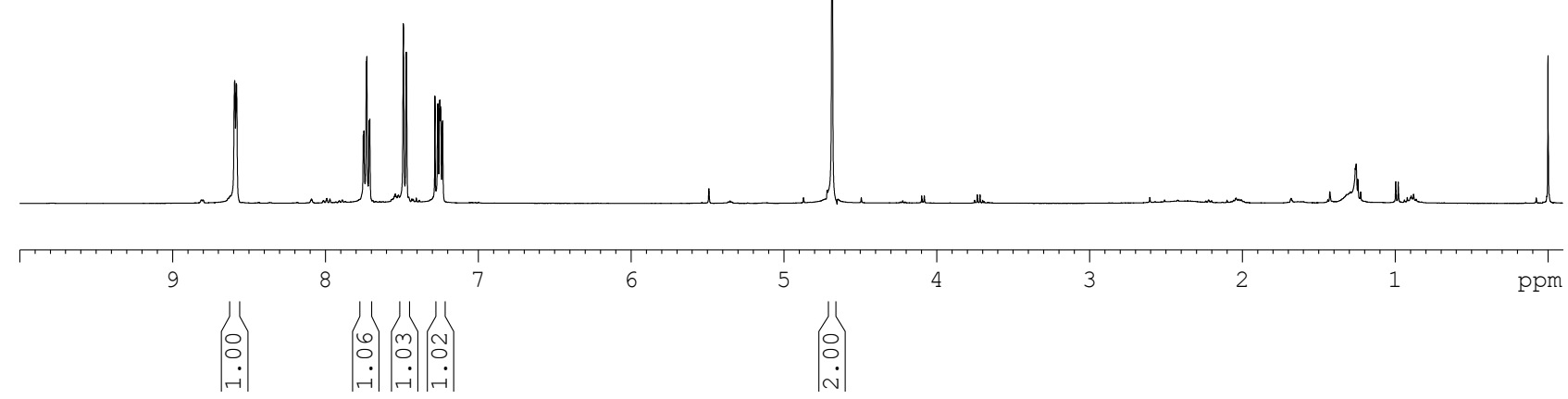




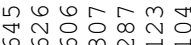

irivici.

VV<smiles>Cc1cccc(CCl)n1</smiles>

${ }^{1} \mathrm{H}$ NMR $\left(400 \mathrm{MHz}, \mathrm{CDCl}_{3}\right)$

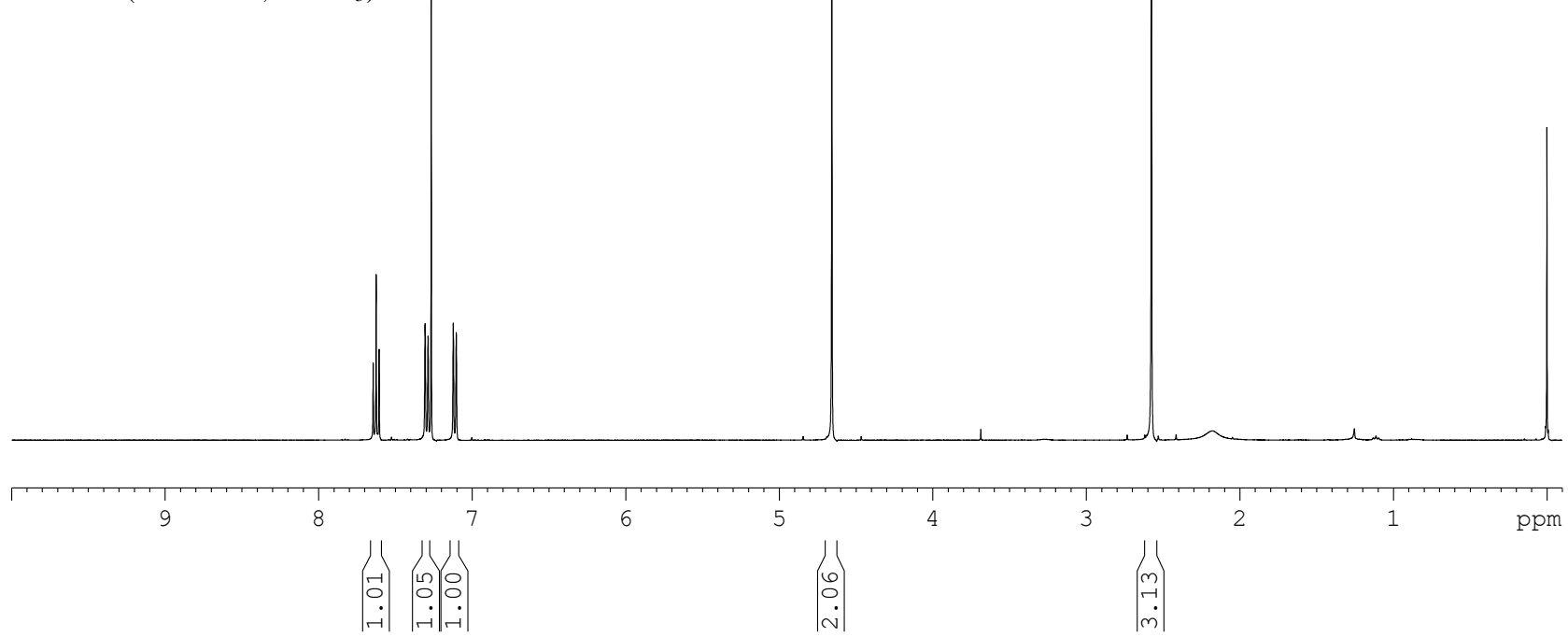

|
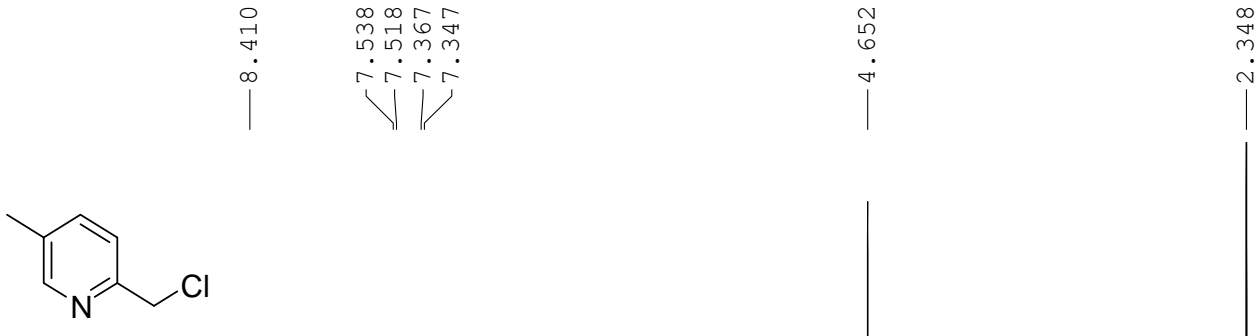

$3 c$

${ }^{1} \mathrm{H} \mathrm{NMR}\left(400 \mathrm{MHz}, \mathrm{CDCl}_{3}\right)$

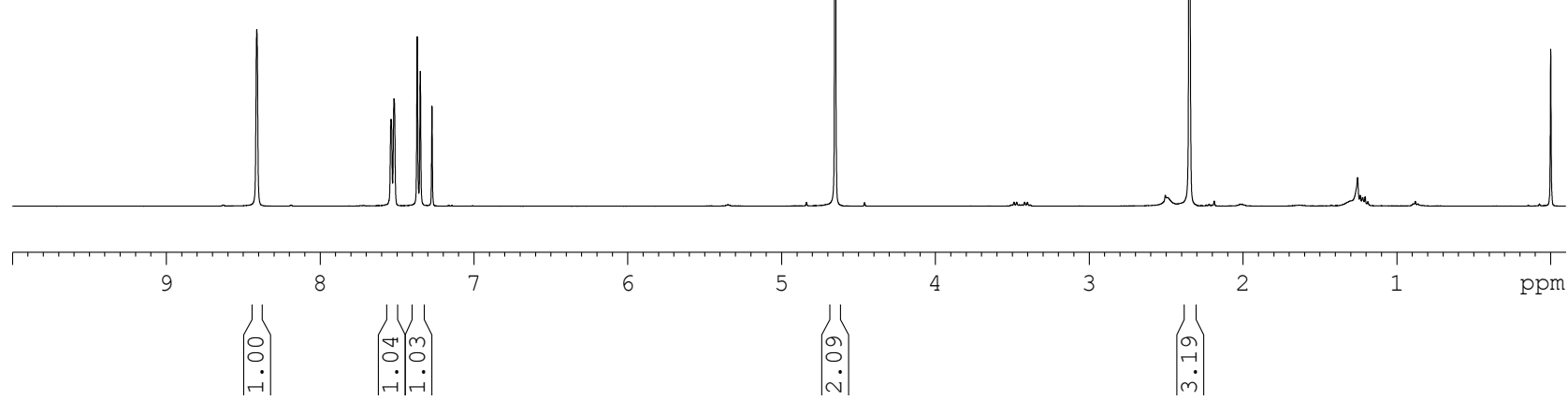




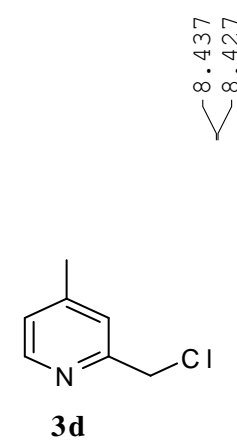

${ }^{1} \mathrm{H} \mathrm{NMR} \mathrm{(400} \mathrm{MHz,} \mathrm{CDCl} 3$ )
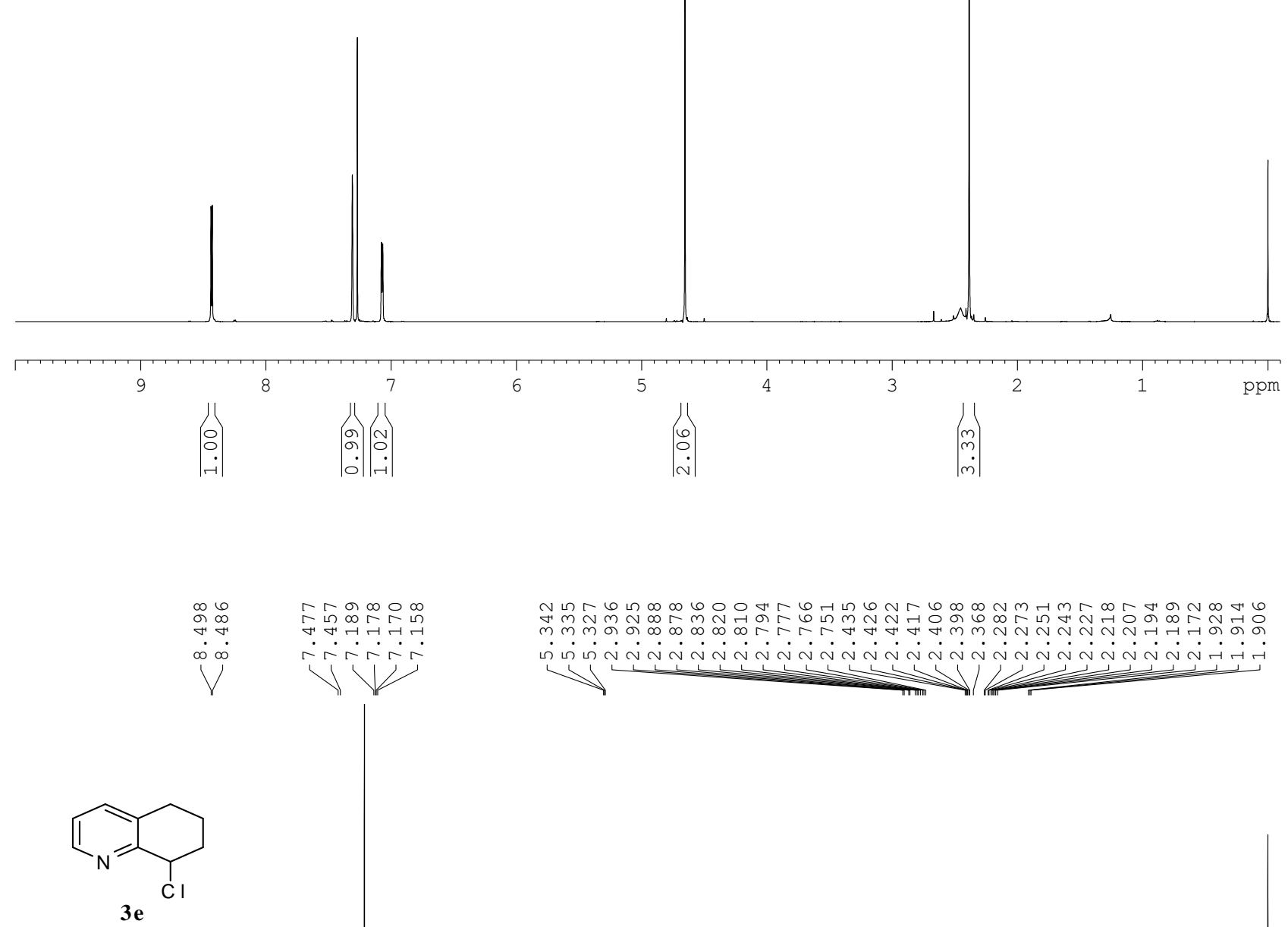

${ }^{1} \mathrm{H} \mathrm{NMR}\left(400 \mathrm{MHz}, \mathrm{CDCl}_{3}\right)$

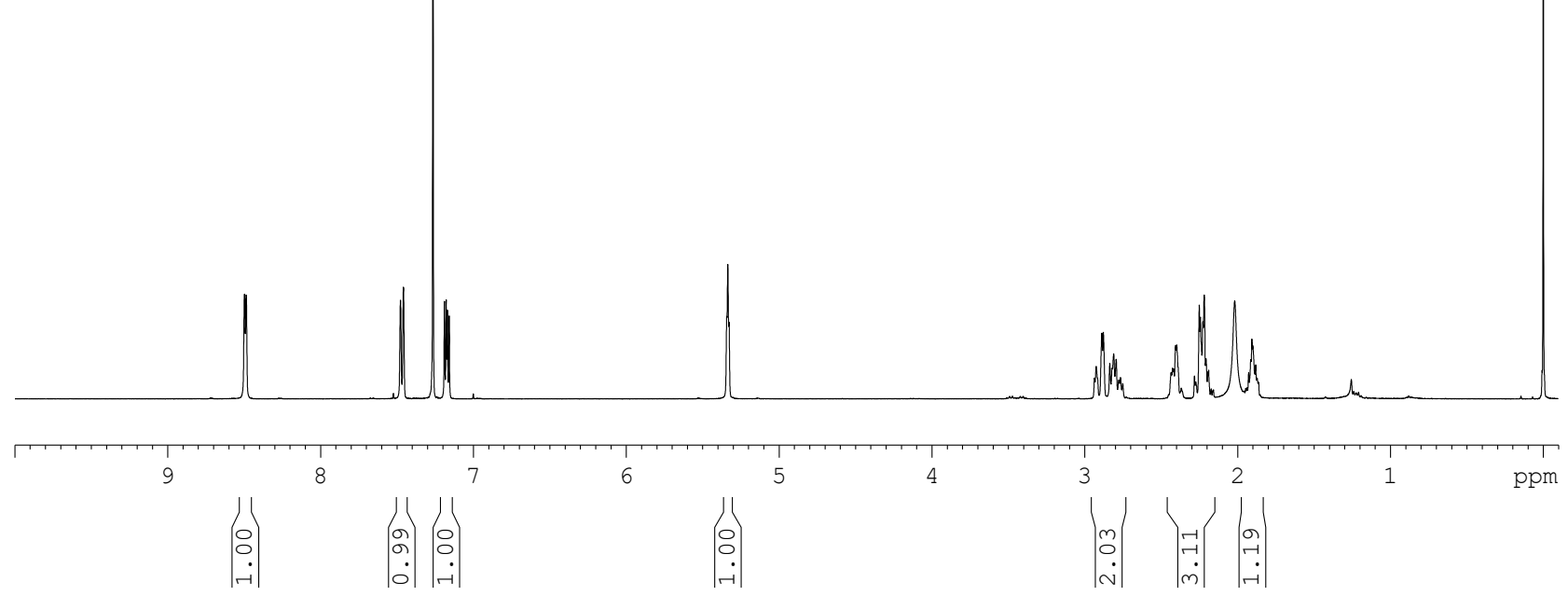



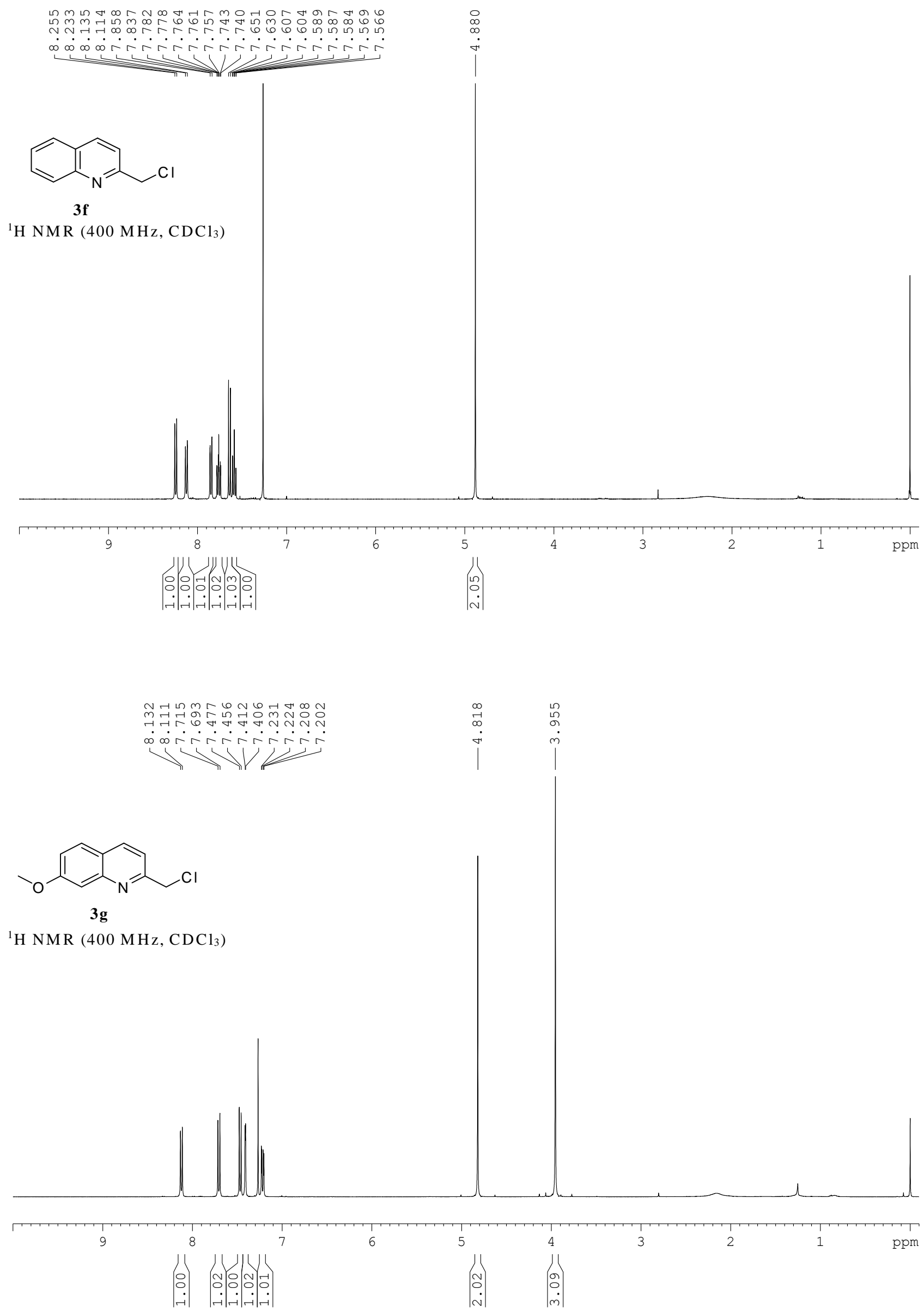


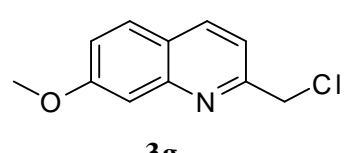

$3 \mathrm{~g}$

${ }^{13} \mathrm{C}\left\{{ }^{1} \mathrm{H}\right\} \mathrm{NMR}\left(100 \mathrm{MHz}, \mathrm{CDCl}_{3}\right)$
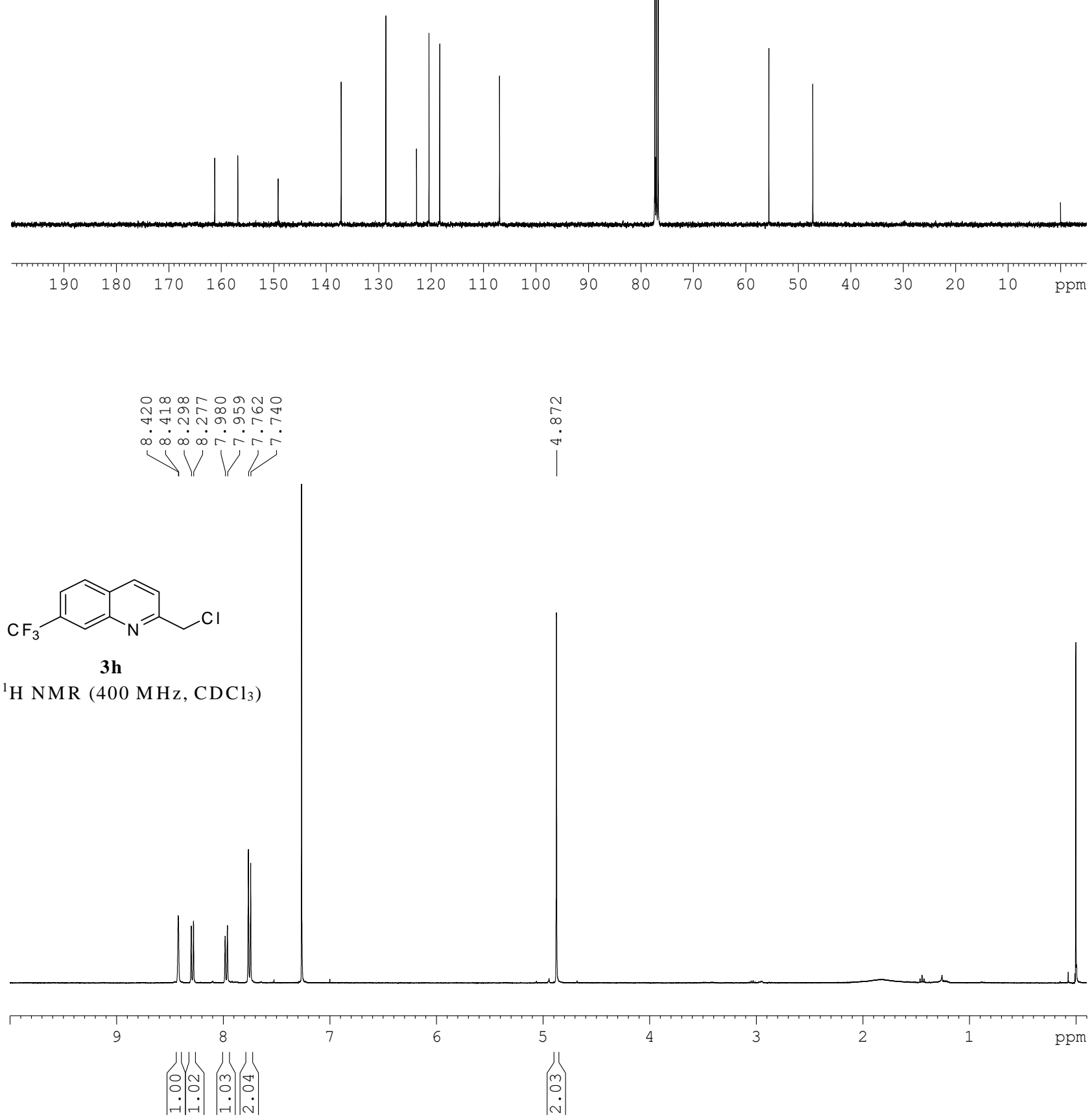

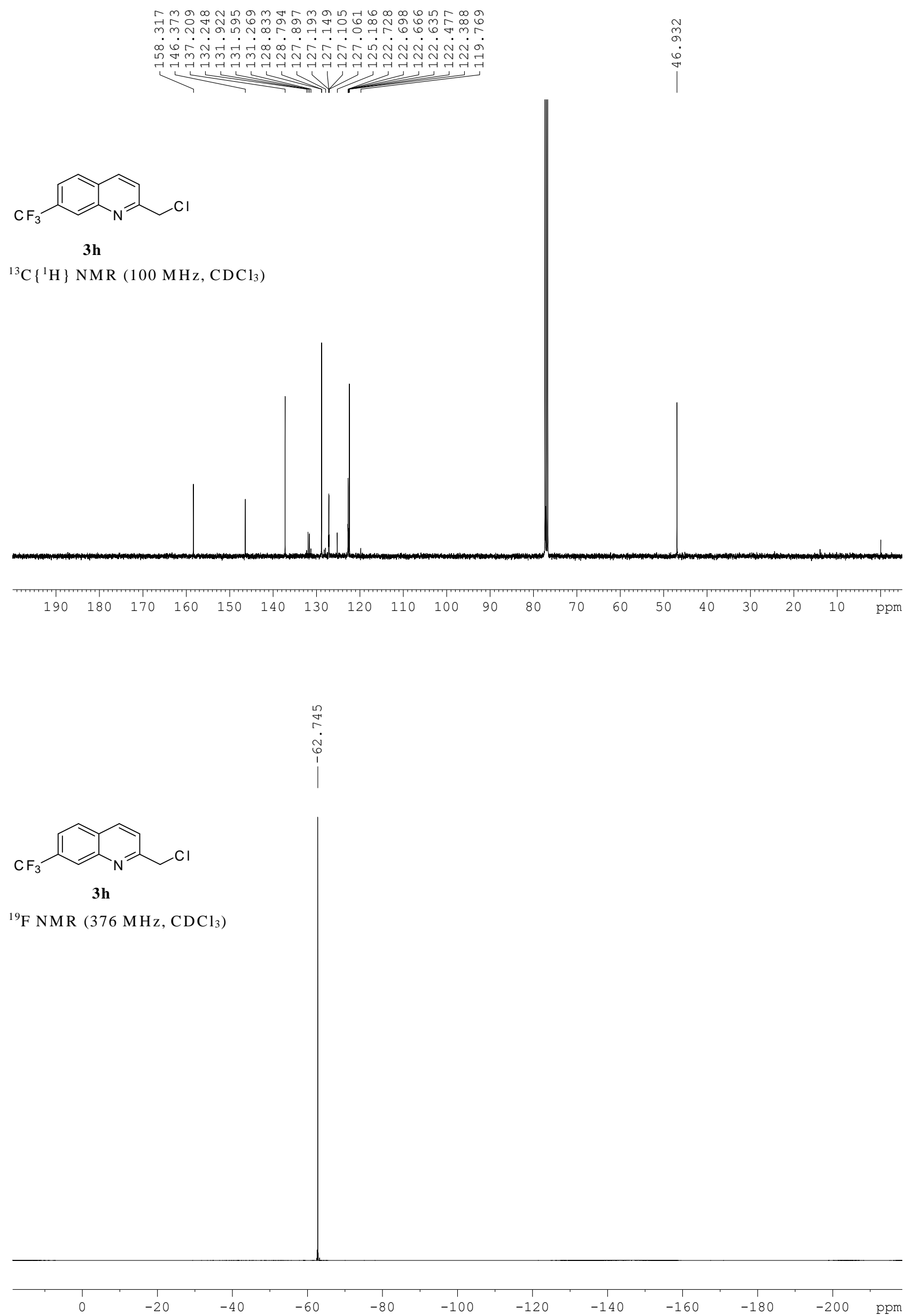

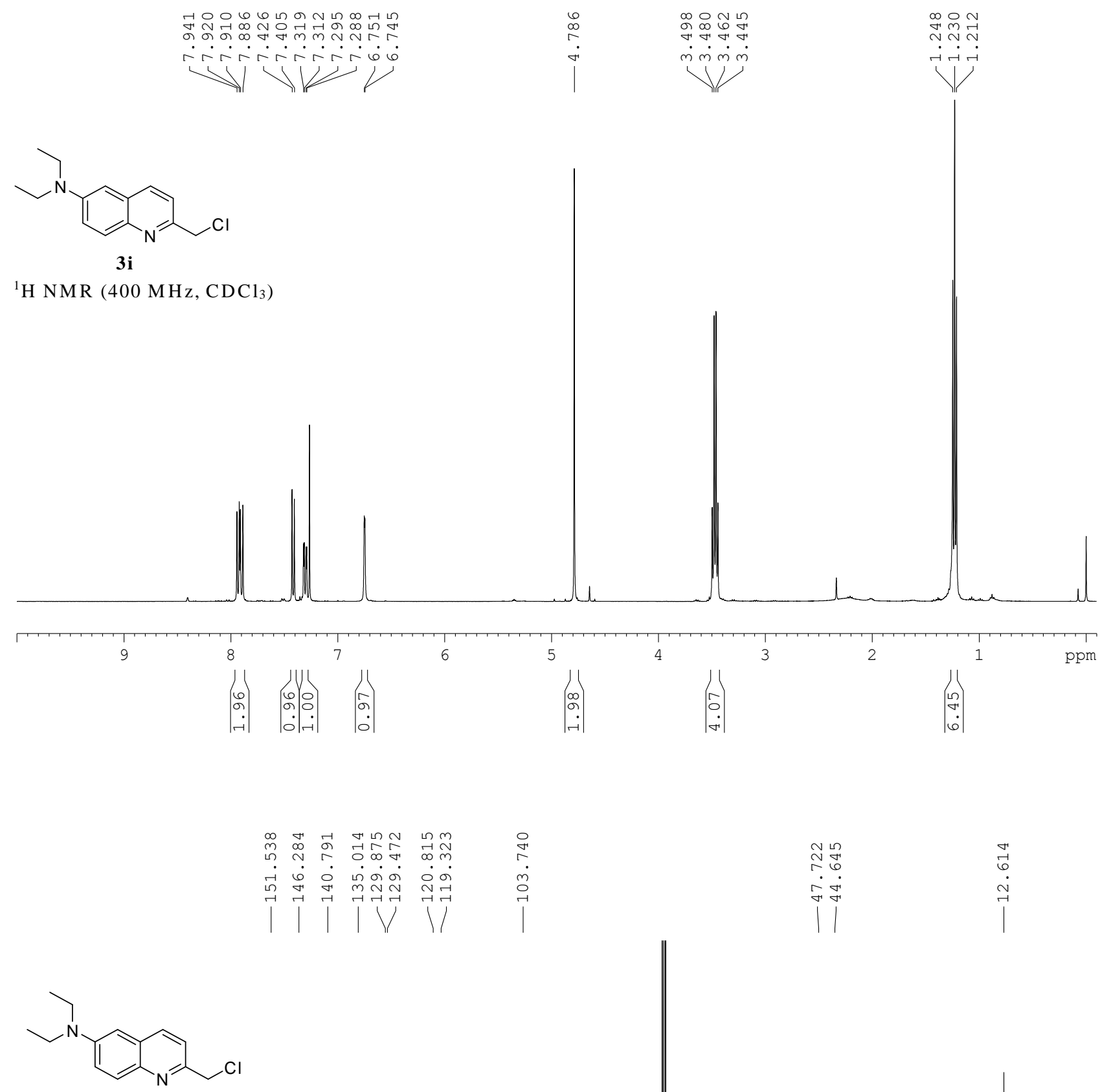

$3 i$

${ }^{13} \mathrm{C}\left\{{ }^{1} \mathrm{H}\right\}$ NMR $\left(100 \mathrm{MHz}, \mathrm{CDCl}_{3}\right)$ 


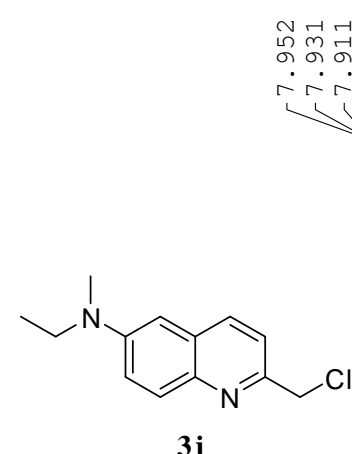

$3 \mathbf{j}$

${ }^{1} \mathrm{H} \mathrm{NMR}\left(400 \mathrm{MHz}^{\mathrm{N}} \mathrm{CDCl}_{3}\right)$

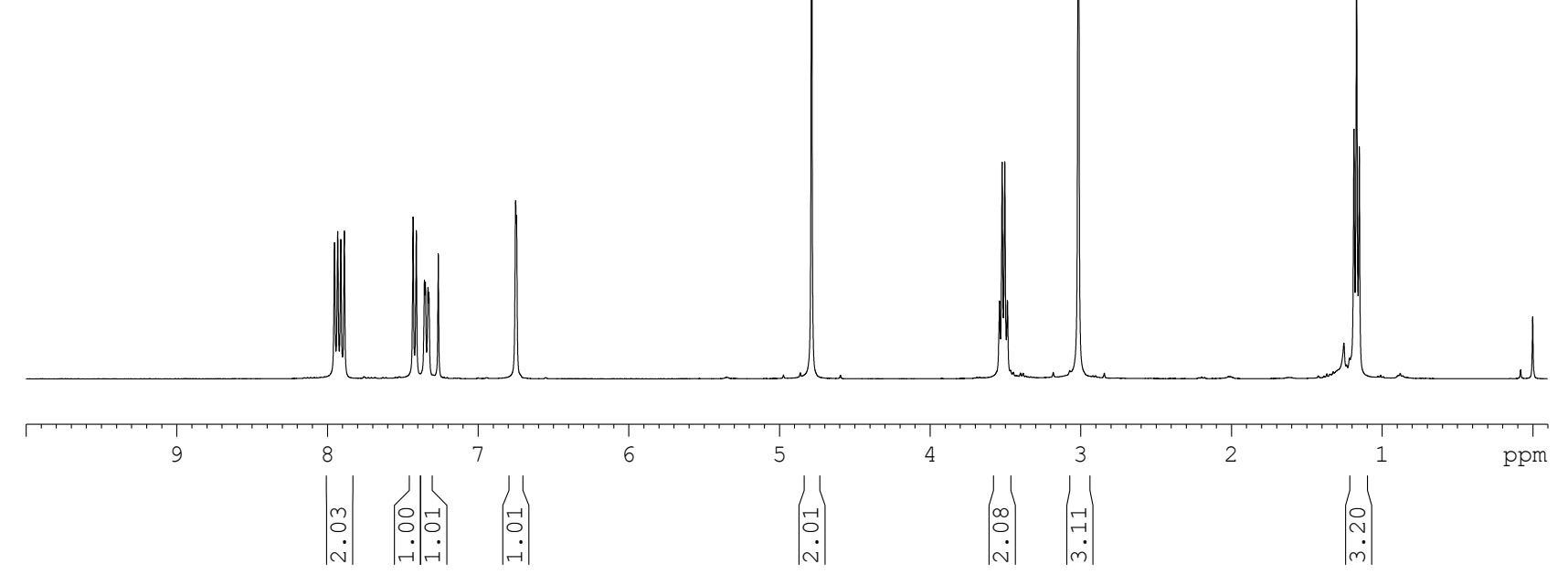

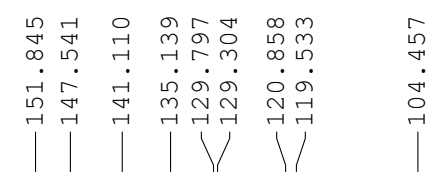
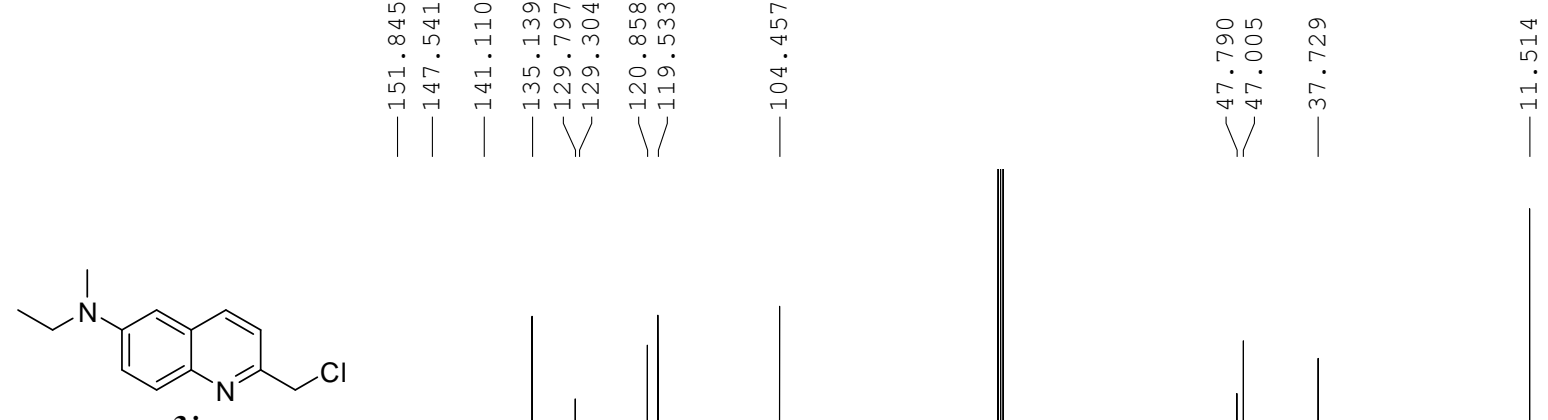

$3 \mathbf{j}$

${ }^{13} \mathrm{C}\left\{{ }^{1} \mathrm{H}\right\}$ NMR $\left(100 \mathrm{MHz}, \mathrm{CDCl}_{3}\right)$

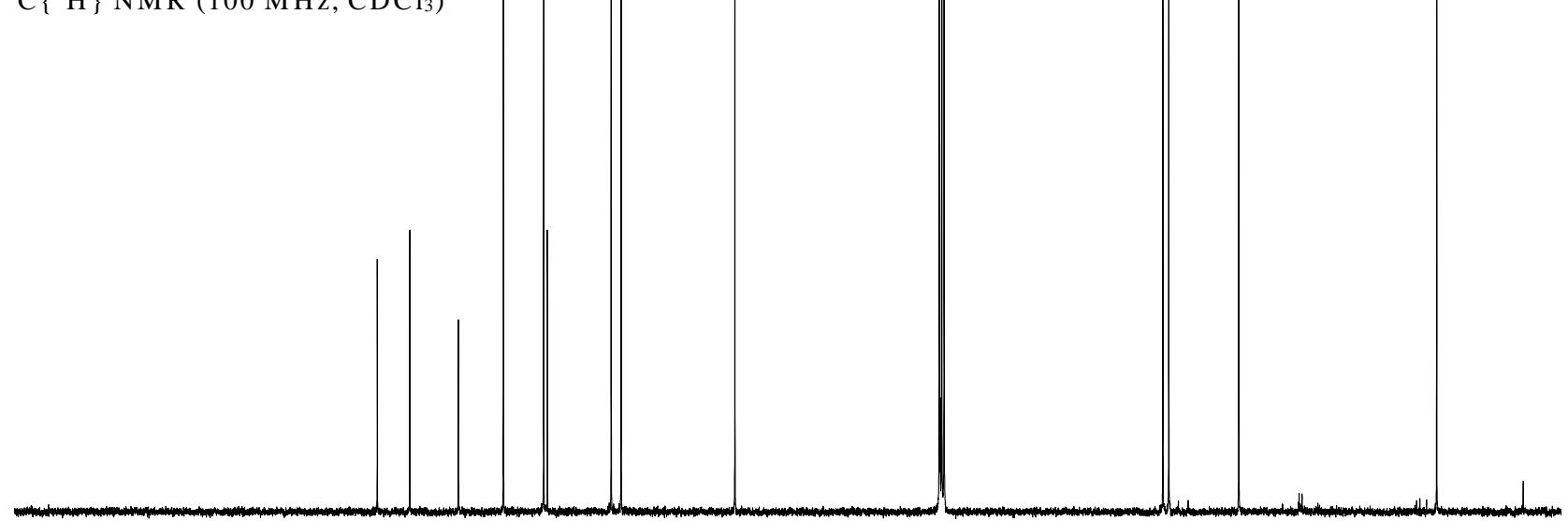




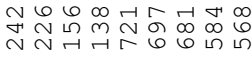

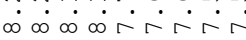

NV V/<smiles>CCNc1ccc2nc(CCl)ccc2c1</smiles>

$3 \mathbf{k}$

${ }^{1} \mathrm{H}$ NMR $\left(500 \mathrm{MHz}, \mathrm{CDCl}_{3}\right)$
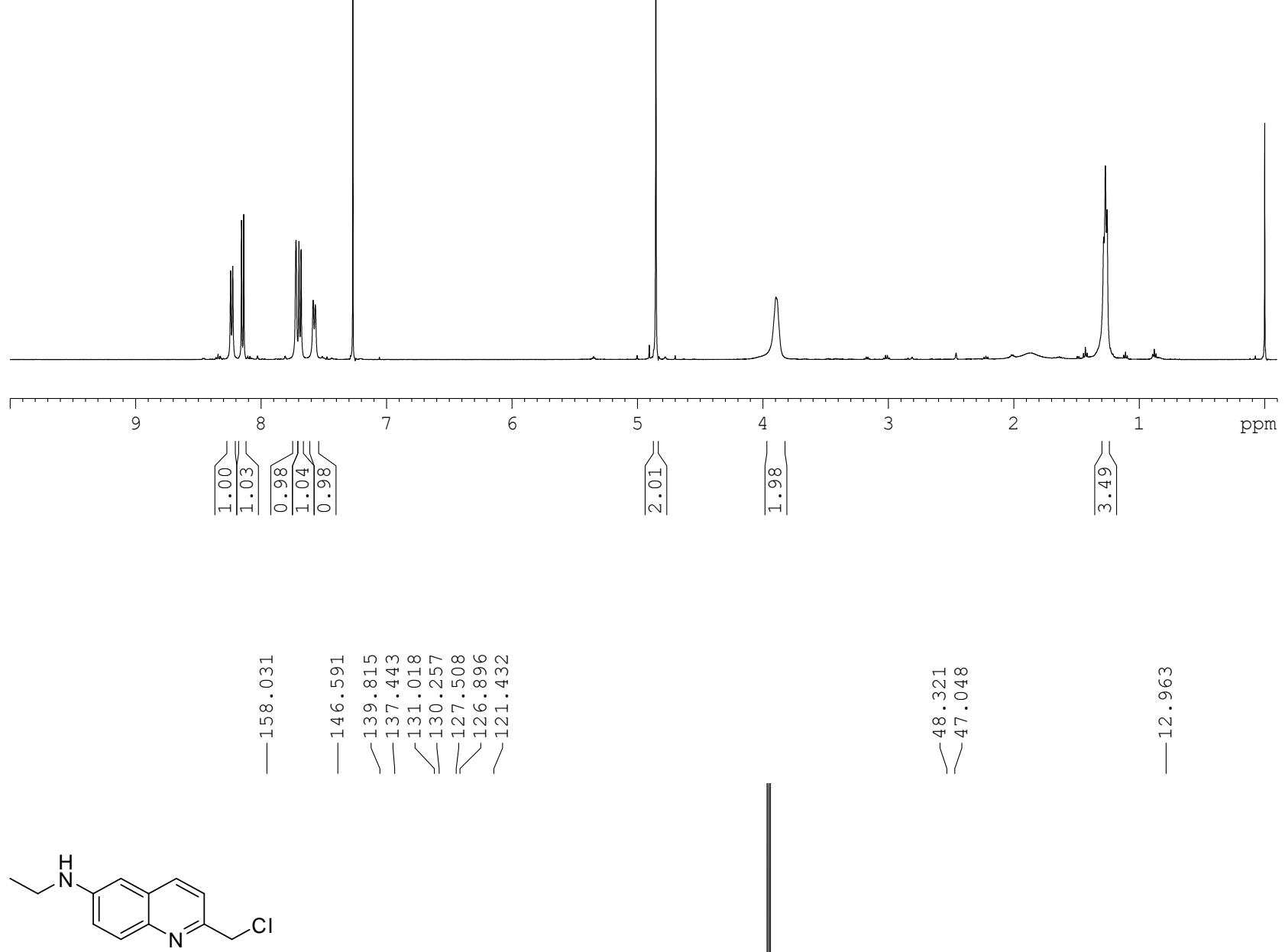

3k

${ }^{13} \mathrm{C}\left\{{ }^{1} \mathrm{H}\right\}$ NMR $\left(100 \mathrm{MHz}, \mathrm{CDCl}_{3}\right)$

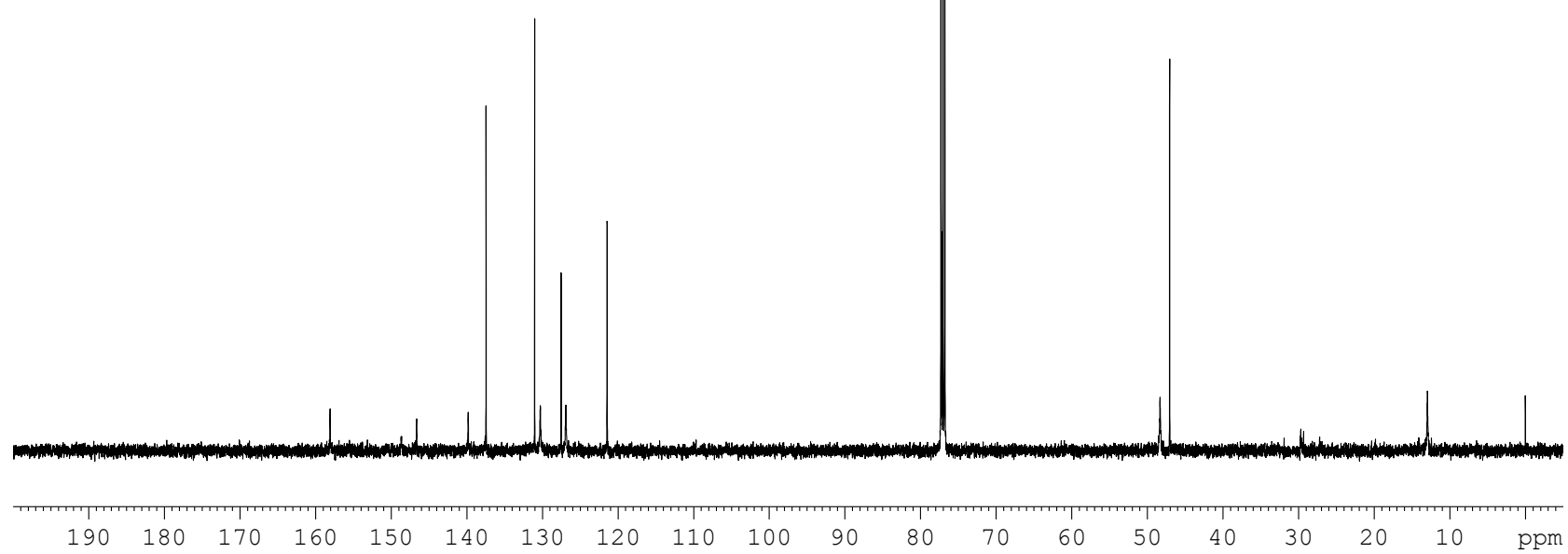




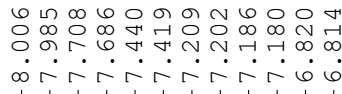

Mll

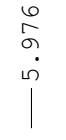

Cl

31

${ }^{1} \mathrm{H}$ NMR $\left(400 \mathrm{MHz}, \mathrm{DMSO}-d_{6}\right)$
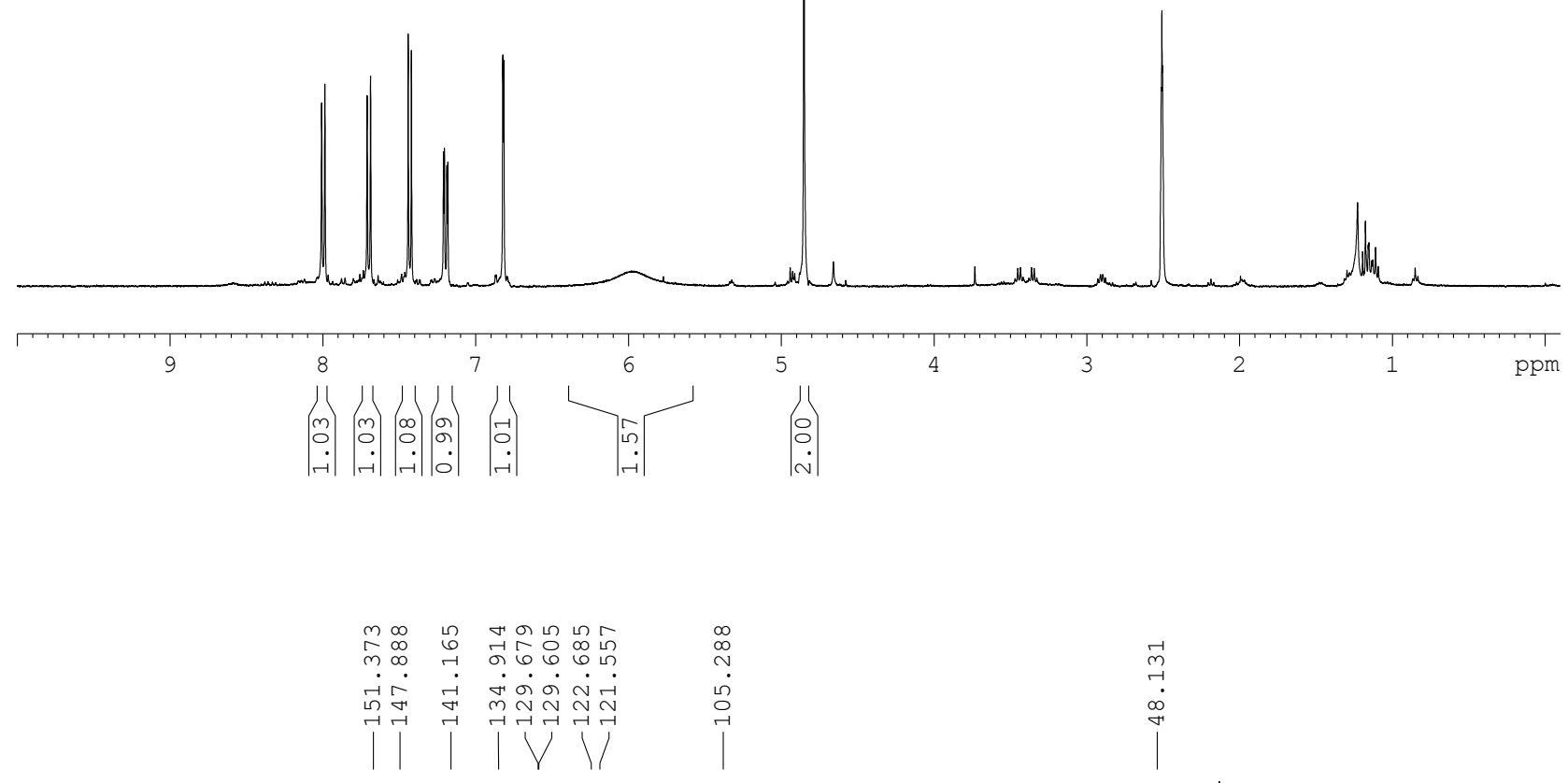

$\stackrel{-}{m}$
$\stackrel{+}{0}$
$\infty$
+

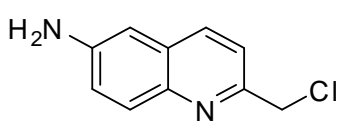

31

${ }^{13} \mathrm{C}\left\{{ }^{1} \mathrm{H}\right\}$ NMR $\left(100 \mathrm{MHz}, \mathrm{DMSO}-d_{6}\right)$

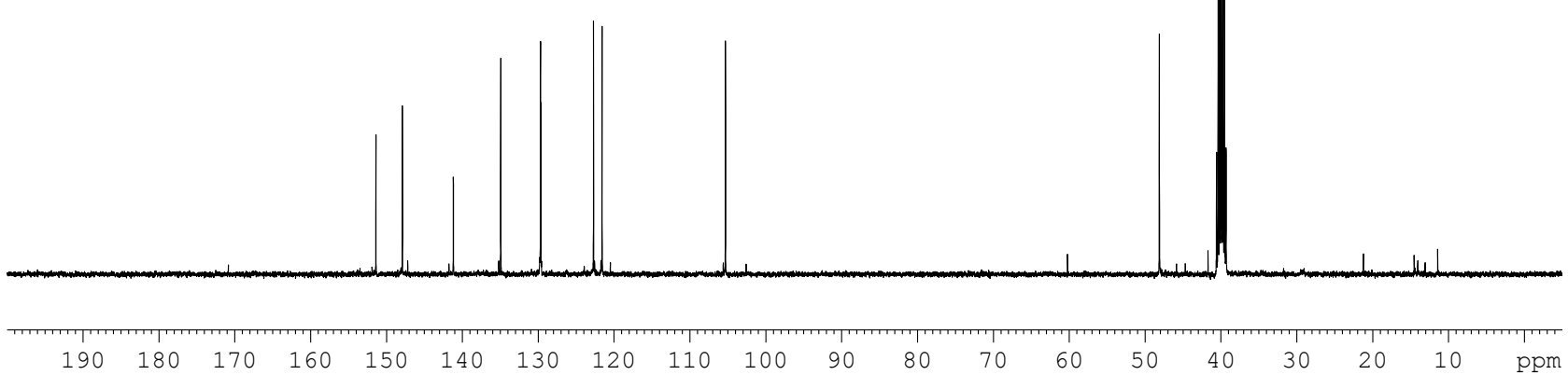




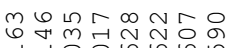

- $\cdot . \cdot 0$.

UVV

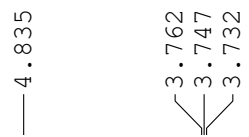

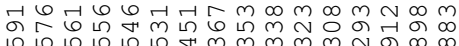

. . . . .

$\dot{m} \dot{m} \dot{m}$

다다

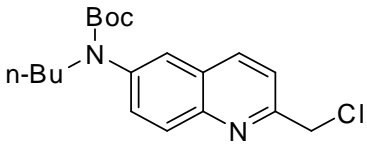

$3 \mathbf{m}$

${ }^{1} \mathrm{H}$ NMR $\left(500 \mathrm{MHz}_{2} \mathrm{CDCl}_{3}\right)$
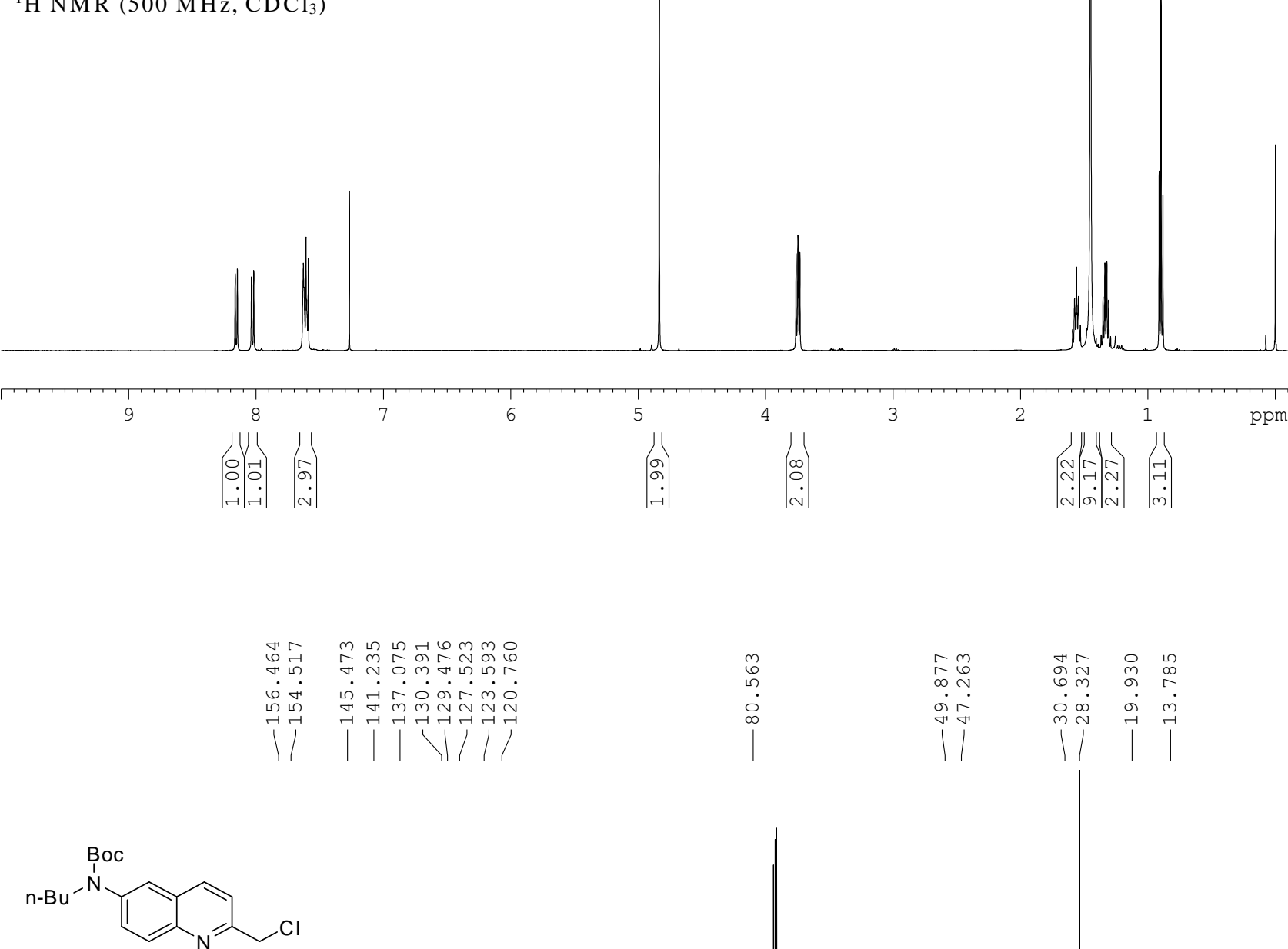

$3 \mathbf{m}$

${ }^{13} \mathrm{C}\left\{{ }^{1} \mathrm{H}\right\}$ NMR $\left(125 \mathrm{MHz}, \mathrm{CDCl}_{3}\right)$

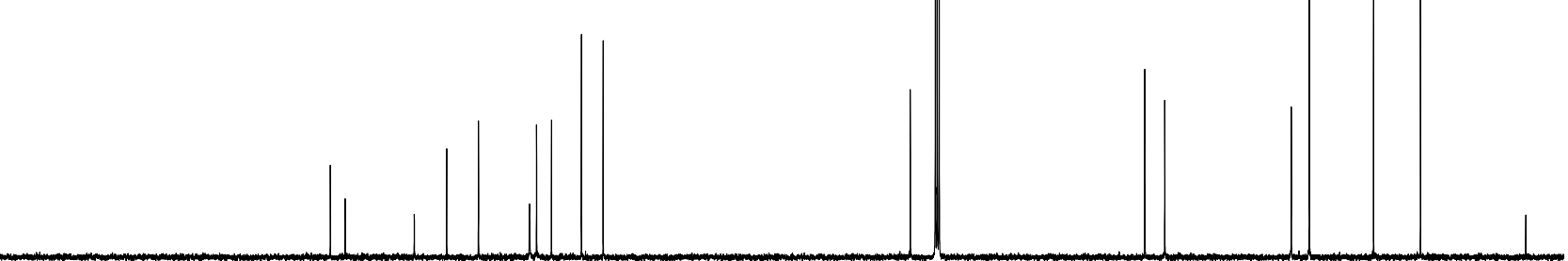

$\begin{array}{lllllllllllllllllll}190 & 180 & 170 & 160 & 150 & 140 & 130 & 120 & 110 & 100 & 90 & 80 & 70 & 60 & 50 & 40 & 30 & 20 & 10\end{array}$ 

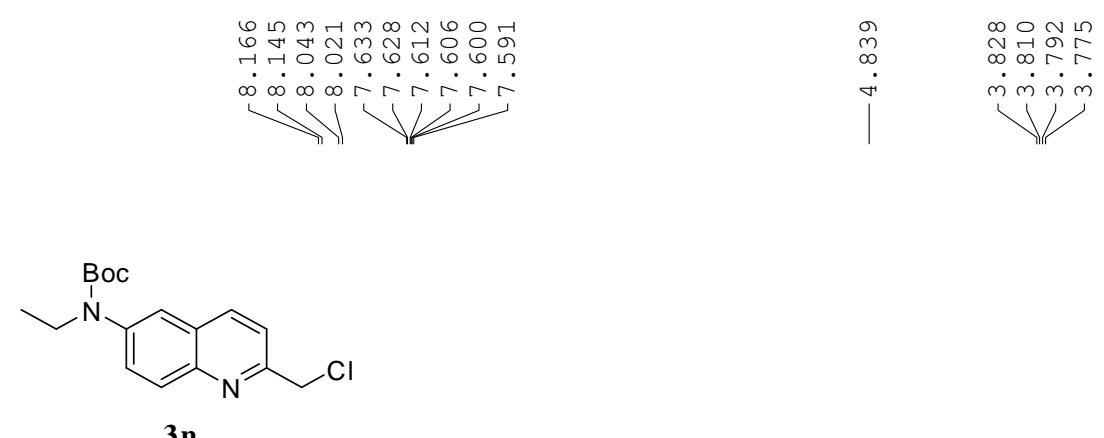

3n

${ }^{1} \mathrm{H} \mathrm{NMR}\left(400 \mathrm{MHz}, \mathrm{CDCl}_{3}\right)$
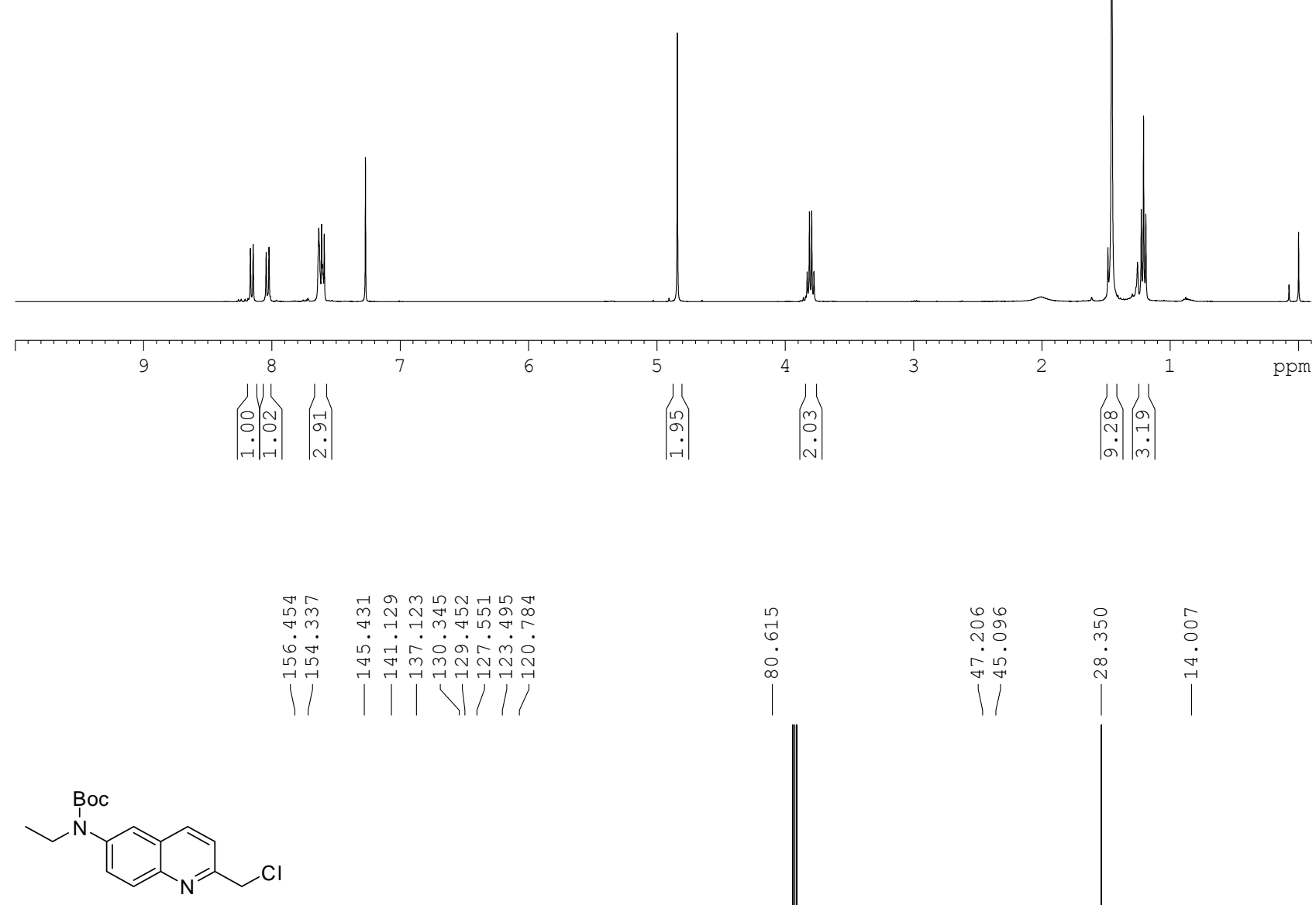

3n

${ }^{13} \mathrm{C}\left\{{ }^{1} \mathrm{H}\right\} \mathrm{NMR}\left(100 \mathrm{MHz}, \mathrm{CDCl}_{3}\right)$
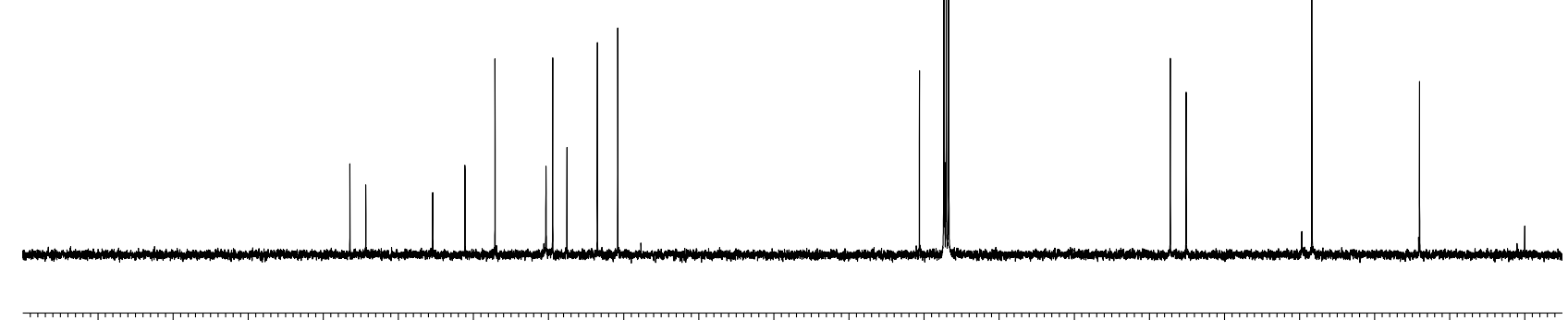

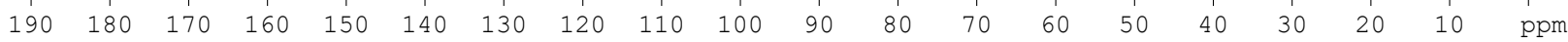



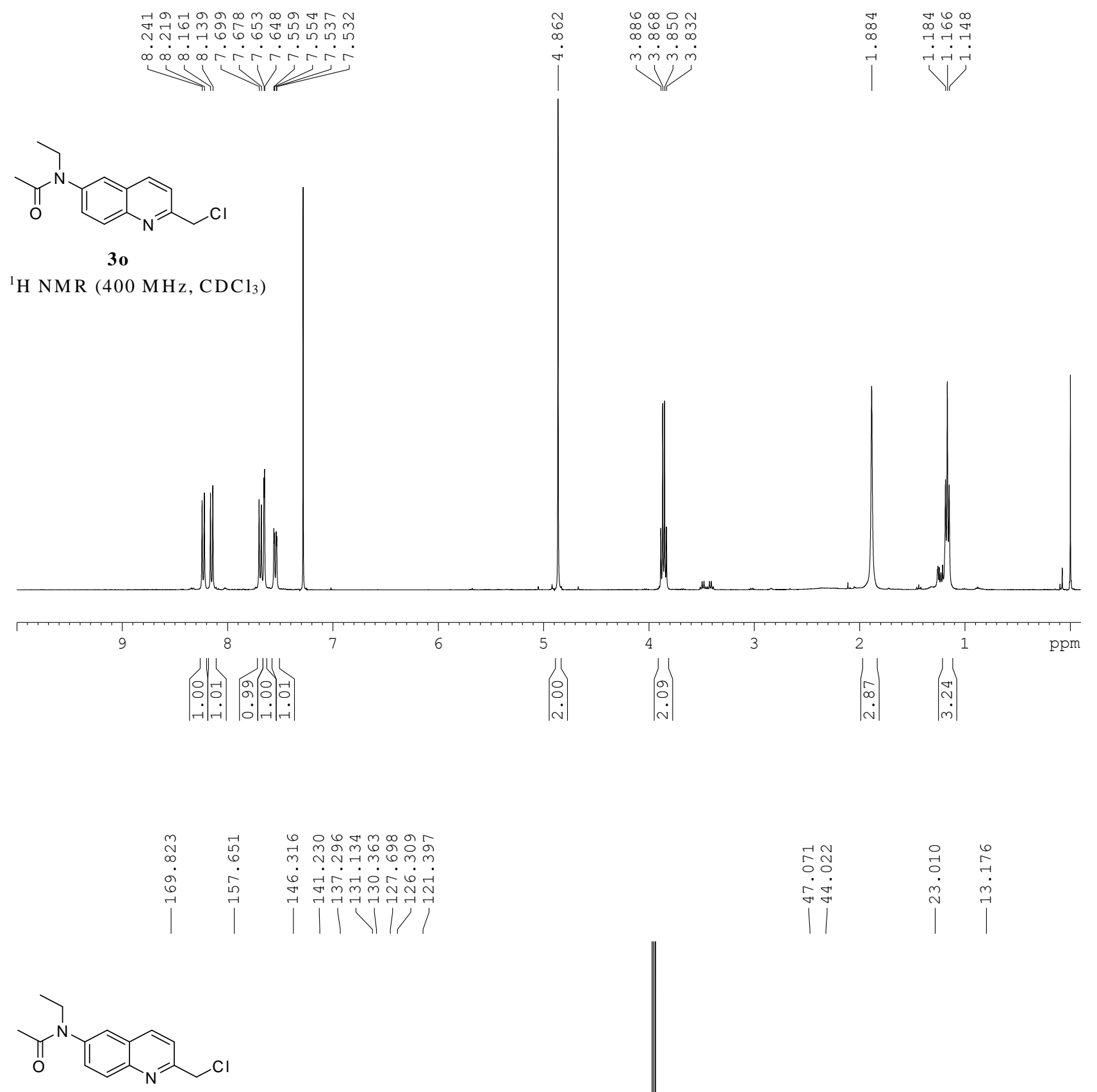

30

${ }^{13} \mathrm{C}\left\{{ }^{1} \mathrm{H}\right\}$ NMR $\left(100 \mathrm{MHz}, \mathrm{CDCl}_{3}\right)$

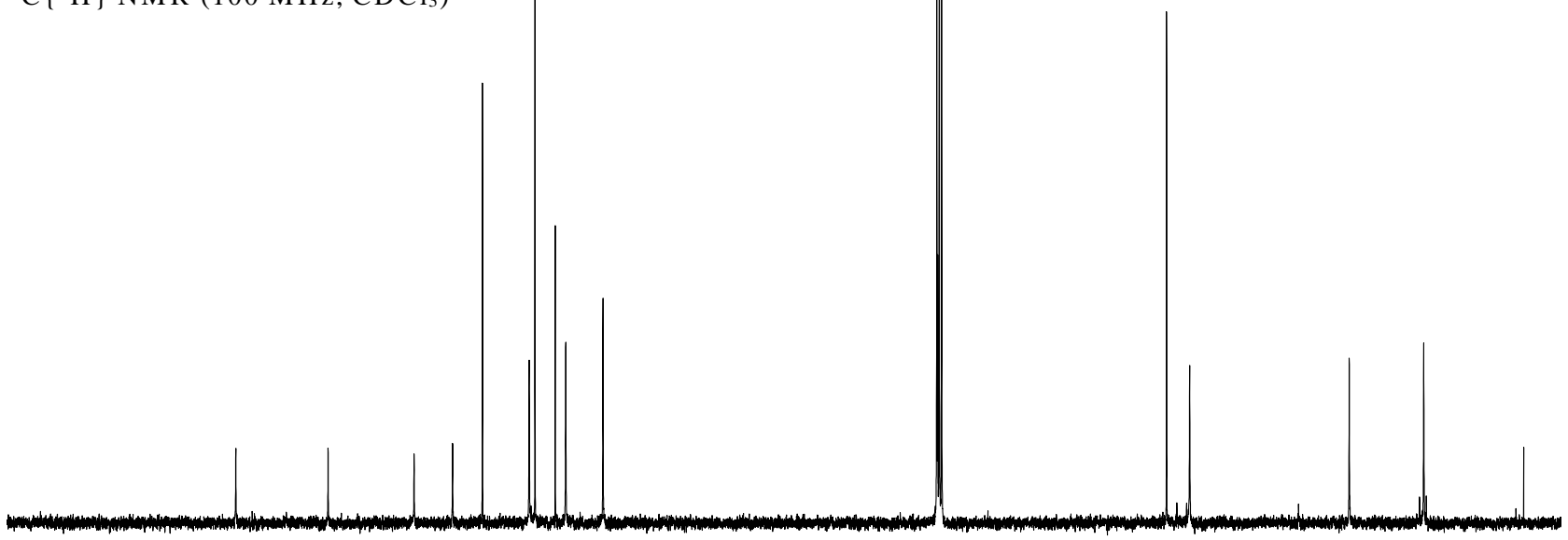

$\begin{array}{llllllllllllllllll}190 & 180 & 170 & 160 & 150 & 140 & 130 & 120 & 110 & 100 & 90 & 80 & 70 & 60 & 50 & 40 & 30 & 20\end{array}$ 


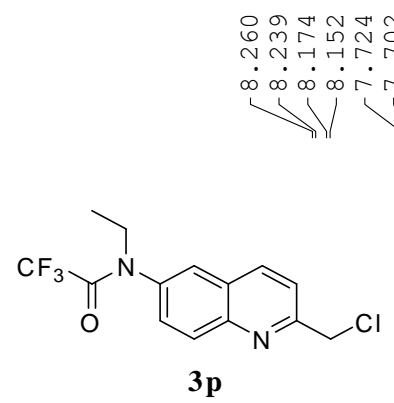

${ }^{1} \mathrm{H}$ NMR $\left(400 \mathrm{MHz}, \mathrm{CDCl}_{3}\right)$

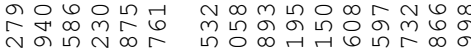

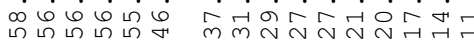

作

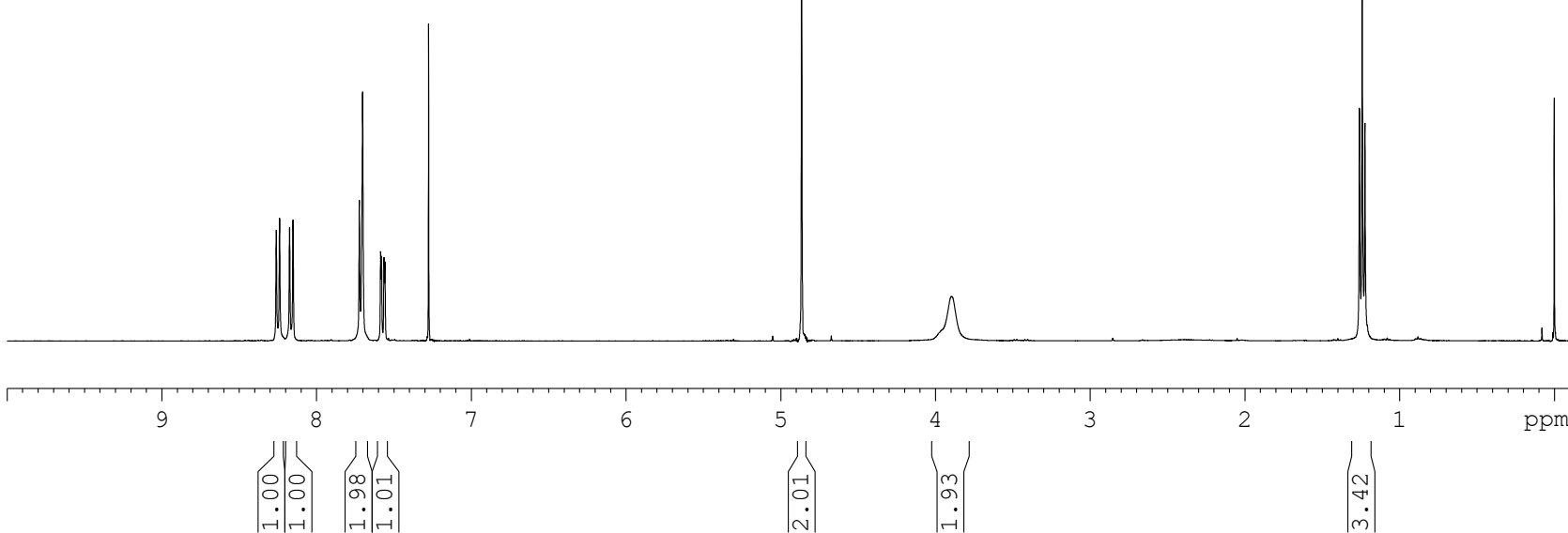

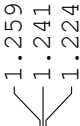

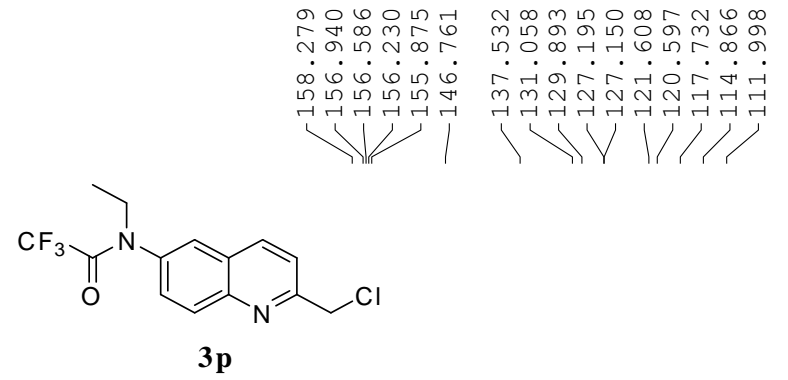

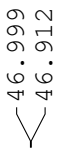

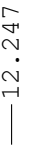

${ }^{13} \mathrm{C}\left\{{ }^{1} \mathrm{H}\right\}$ NMR $\left(100 \mathrm{MHz}, \mathrm{CDCl}_{3}\right)$

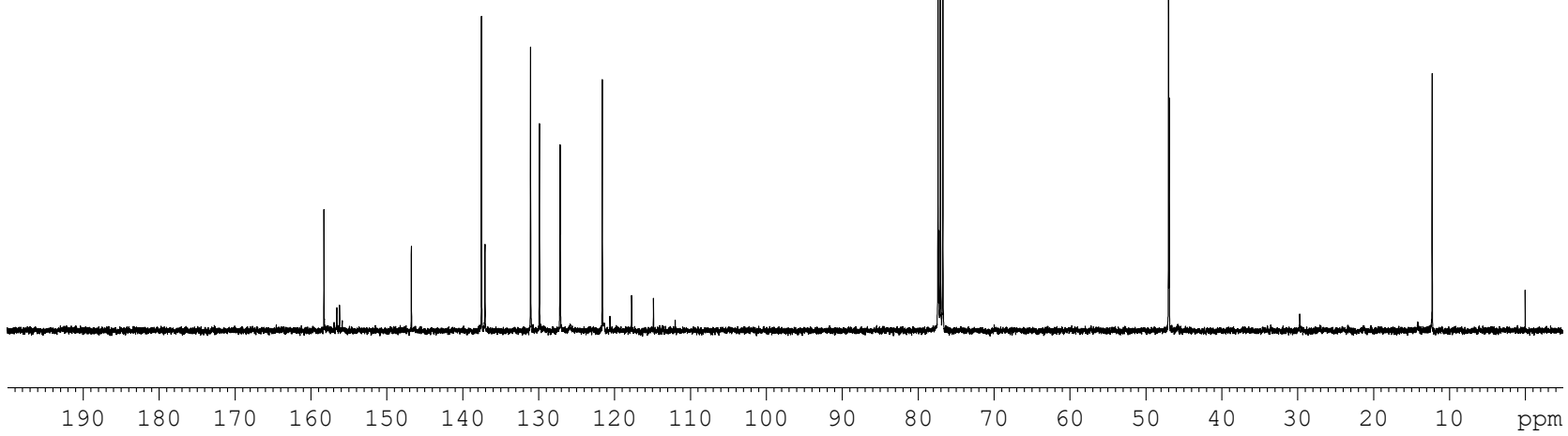




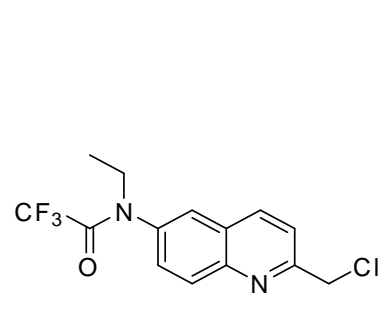

3 p

${ }^{19} \mathrm{~F} \mathrm{NMR}\left(376 \mathrm{MHz}, \mathrm{CDCl}_{3}\right)$

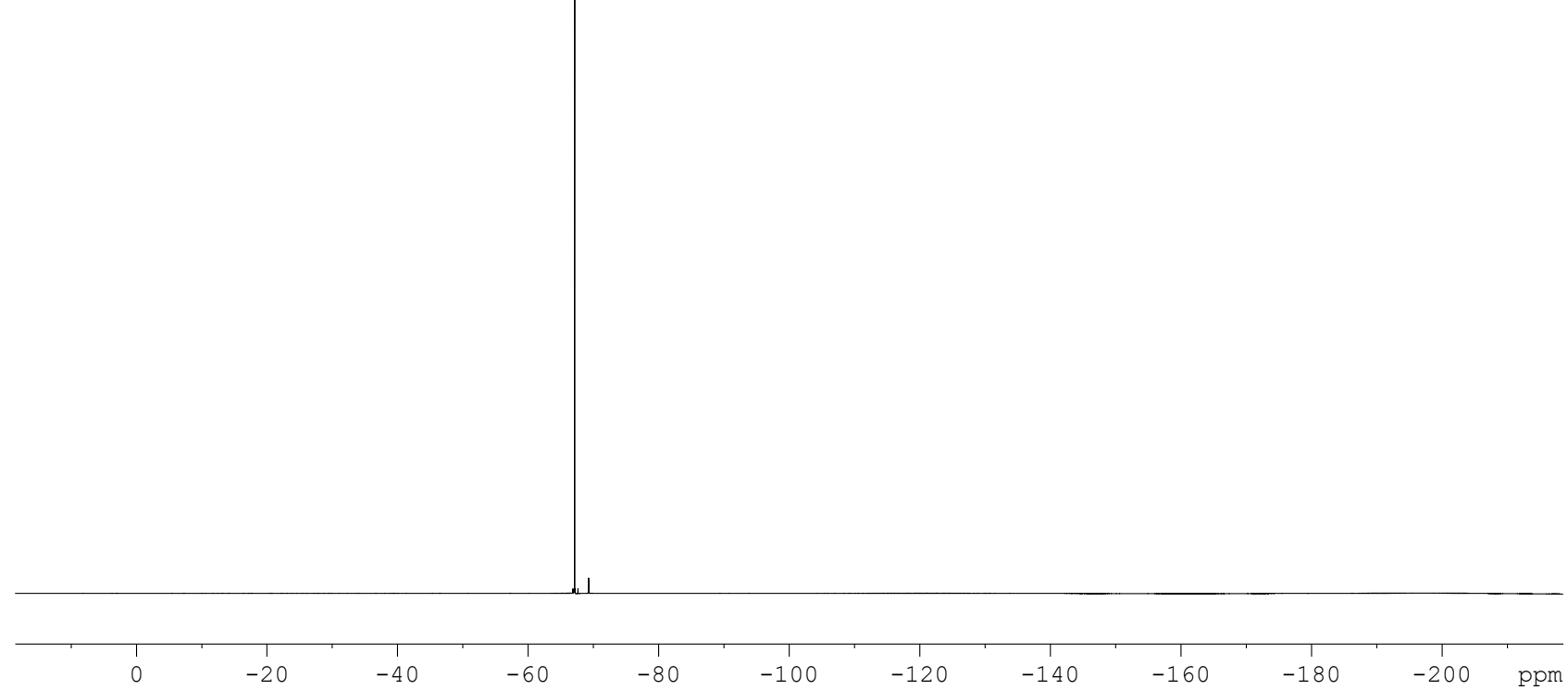

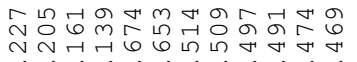

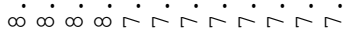

(2)

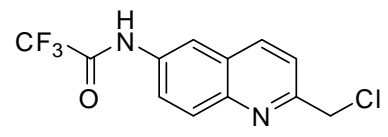

$3 q$

${ }^{1} \mathrm{H} \mathrm{NMR}\left(400 \mathrm{MHz}, \mathrm{CDCl}_{3}\right)$

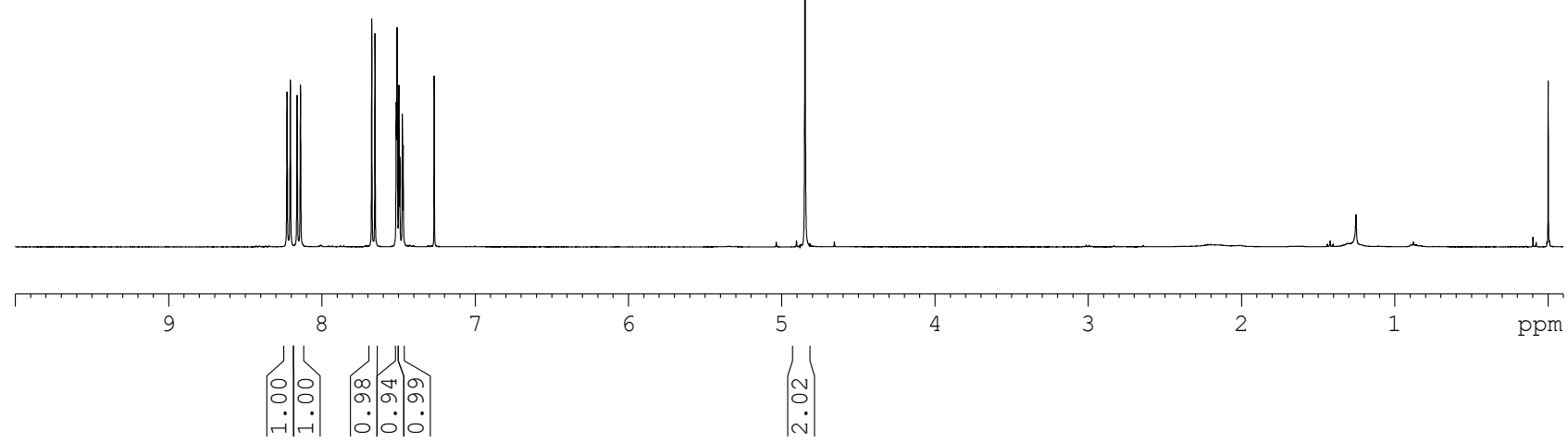




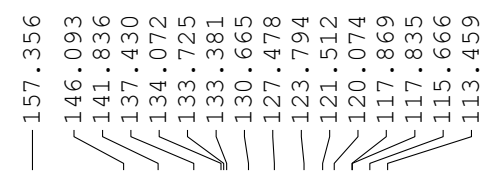

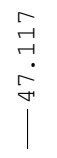

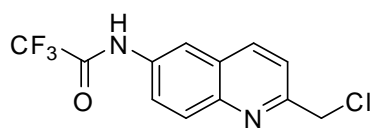

$3 \mathbf{q}$

${ }^{13} \mathrm{C}\left\{{ }^{1} \mathrm{H}\right\}$ NMR $\left(125 \mathrm{MHz}, \mathrm{CDCl}_{3}\right)$

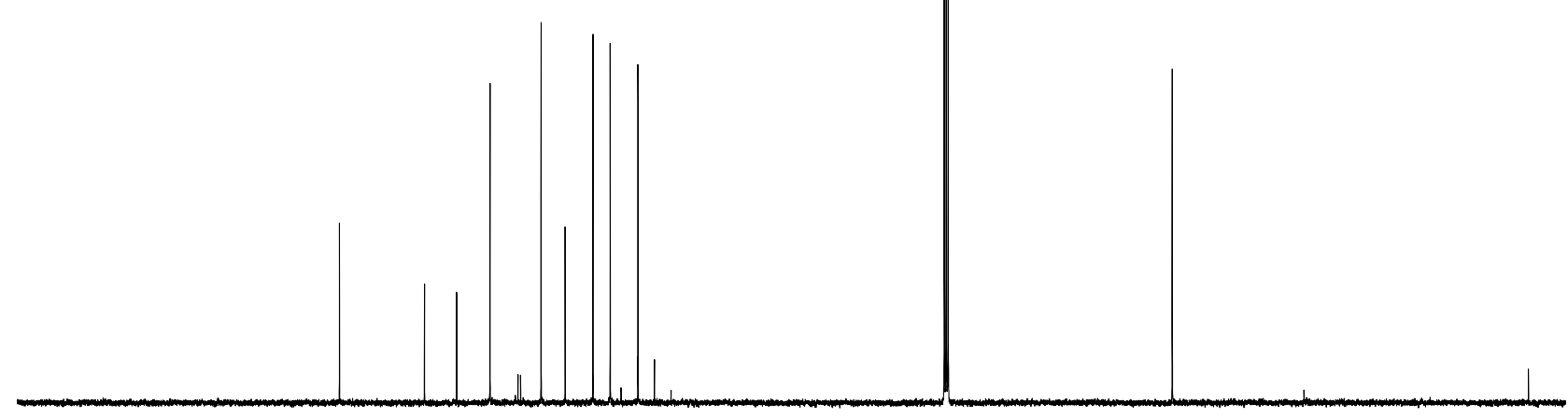

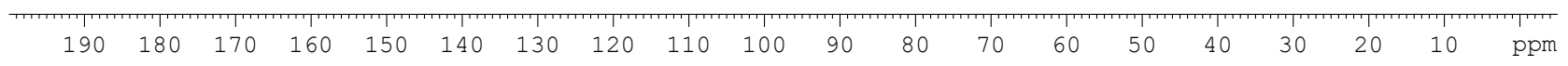

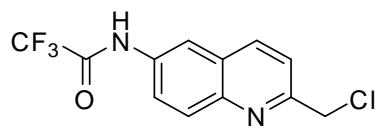

$3 \mathbf{q}$

$\left.{ }^{19} \mathrm{~F} \mathrm{NMR} \mathrm{(376} \mathrm{MHz,} \mathrm{CDCl}_{3}\right)$

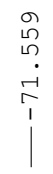

19 ${ }^{2} \mathrm{MR}\left(376 \mathrm{MH}_{2}, \mathrm{CDCl}\right)$

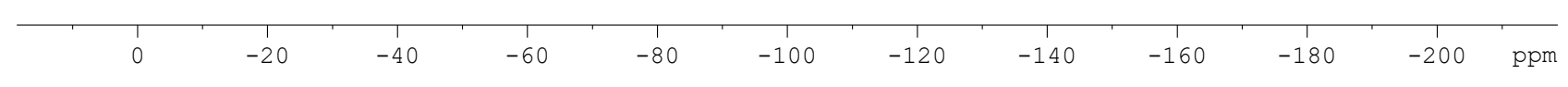

S40 

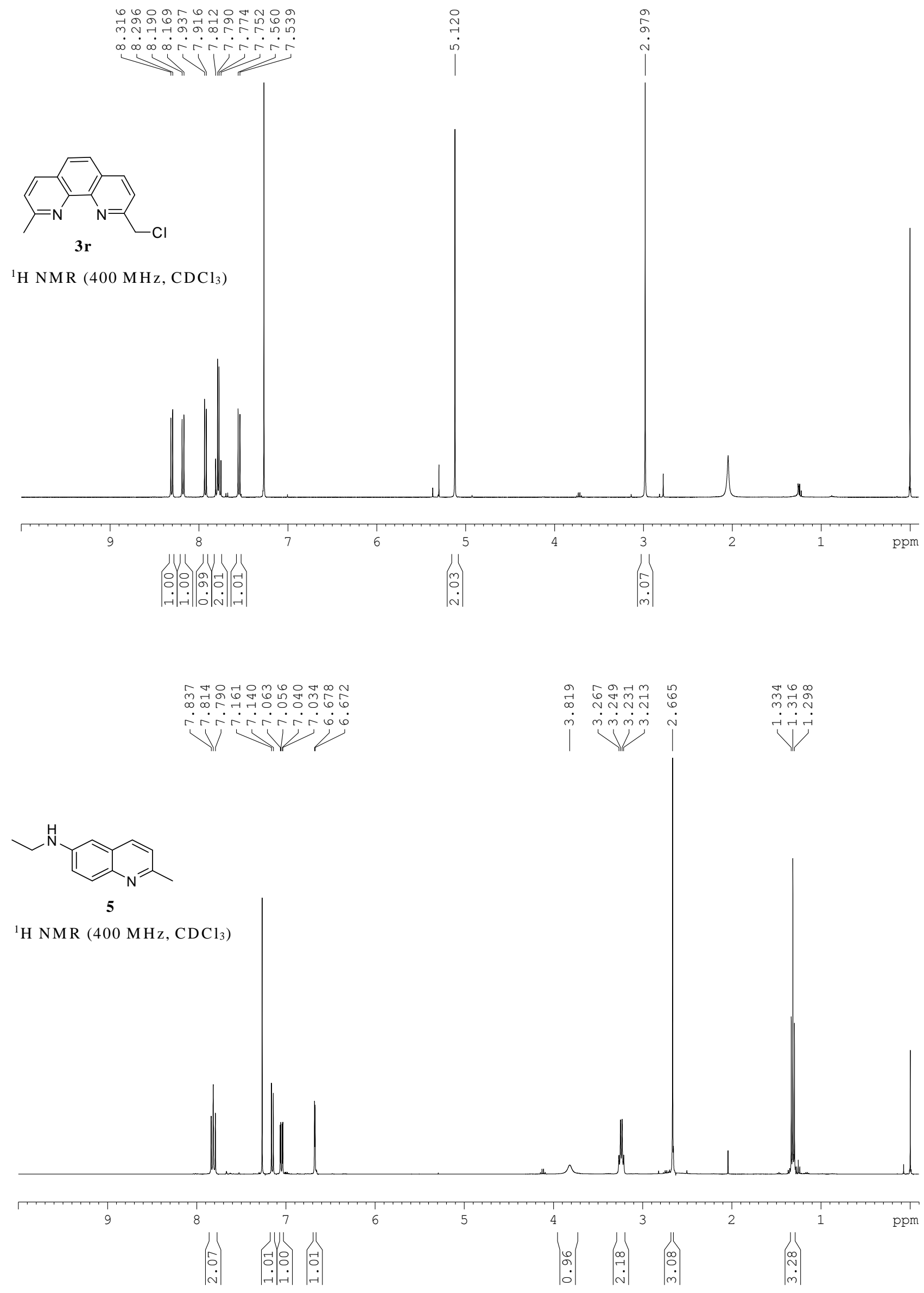